\title{
Scalable and Cost-effective Barrier Layer Coating to Improve Stability and Performance of SOFC Cathode
}

\author{
Shanshan $\mathrm{Hu}$ \\ Mechanical Engineering, shhu@mix.wvu.edu
}

Follow this and additional works at: https://researchrepository.wvu.edu/etd

\section{Recommended Citation}

$\mathrm{Hu}$, Shanshan, "Scalable and Cost-effective Barrier Layer Coating to Improve Stability and Performance of SOFC Cathode" (2019). Graduate Theses, Dissertations, and Problem Reports. 7465.

https://researchrepository.wvu.edu/etd/7465

This Dissertation is protected by copyright and/or related rights. It has been brought to you by the The Research Repository @ WVU with permission from the rights-holder(s). You are free to use this Dissertation in any way that is permitted by the copyright and related rights legislation that applies to your use. For other uses you must obtain permission from the rights-holder(s) directly, unless additional rights are indicated by a Creative Commons license in the record and/ or on the work itself. This Dissertation has been accepted for inclusion in WVU Graduate Theses, Dissertations, and Problem Reports collection by an authorized administrator of The Research Repository @ WVU.

For more information, please contact researchrepository@mail.wvu.edu. 


\title{
Scalable and Cost-effective Barrier Layer Coating to Improve Stability and Performance of SOFC Cathode
}

\author{
Shanshan Hu \\ Dissertation submitted to \\ Benjamin M. Statler College of Engineering and Mineral Resources \\ at West Virginia University \\ in partial fulfillment of the requirements for the degree of
}

Doctor of Philosophy

In

Mechanical Engineering

\author{
Xingbo Liu, Ph.D., Chair \\ Harry Finklea, Ph.D. \\ Edward Sabolsky, Ph.D. \\ David Mebane, Ph.D. \\ Konstantinos Sierros, Ph.D. \\ Wenyuan Li, Ph.D.
}

Department of Mechanical and Aerospace Engineering

Morgantown, West Virginia

2019

Keywords: solid oxide fuel cells, electrophoretic deposition, gadolinium doped ceria, yttrium stabilized zirconia, bubble-free and homogeneous

Copyright 2019 Shanshan Hu 


\begin{abstract}
Scalable and Cost-effective Barrier Layer Coating to Improve Stability and Performance of SOFC Cathode
\end{abstract}

Shanshan $\mathrm{Hu}$

Replacing the electronically conductive $(\mathrm{LaSr}) \mathrm{MnO}_{3 \pm \delta}(\mathrm{LSM})$ cathode in the $\mathrm{LSM} / \mathrm{yttrium}-$ stabilized zirconia (YSZ) system with the mixed ion-electron conductive (MIEC) $(\mathrm{LaSr})(\mathrm{CoFe}) \mathrm{O}_{3-\delta}$ (LSCF) will promote cathode performance in SOFCs significantly. However, it might be hindered by the reaction between YSZ and LSCF, producing some insulating phases, which lowers the cell performance. To address this issue, a dense barrier layer of doped ceria is always adopted between these two components to eliminate the reaction as well as to boost the cell performance. In this study, a scalable and cost-effective method, electrophoretic deposition (EPD), is used to realize the deposition of gadolinium doped ceria (GDC) on non-conductive YSZ substrate. The fundamental characteristics of EPD of GDC on YSZ and the mechanism are also systematically investigated.

Highly compact GDC green layers are obtained by the EPD process in an ethanol-based suspension. GDC thin layers in a thickness range of 5-8 $\mu \mathrm{m}$ have been successfully densified at temperatures as low as $1300^{\circ} \mathrm{C}$ and the adhesion between GDC and YSZ is excellent. Compared to a GDC barrier layer made by a conventional spin-coating method, the ohmic resistance of GDC made by EPD is lower. The deposition rate of GDC on PPy coated YSZ is slower than that on graphite at the same voltage. However, at constant current, the mass of GDC deposited per coulomb of charge is larger on the PPy-coated YSZ cathode. An $\mathrm{H}^{+}$ion accumulation zone is formed near the PPy coated YSZ after applying the voltage. The thickness of this $\mathrm{H}^{+}$ion accumulation zone increases at the beginning and then decreases. Finally, the ion accumulation zone is replaced by an ion depletion zone; the main reason contributing to the increasing resistance is the formation of an ion depletion zone. The absorbed $\mathrm{H}^{+}$ions desorb from particles after deposition and then move through the porous deposit to the cathode to be reduced. The reduction of free $\mathrm{H}^{+}$ions and absorbed $\mathrm{H}^{+}$ions corresponds to the unavoidable side reaction and the deposition of GDC particles, respectively. Deposition efficiency, $f$, the percentage of electric charge associated with the reduction of $\mathrm{H}^{+}$ions in the total charge, is introduced to reflect the competitive relationship between deposition and the side reactions. $f$ decreases with the increase of current density.

A dense GDC layer is successfully obtained by AC-EPD at $500 \mathrm{~Hz}$ after sintering at a relatively low temperature, e.g., $1250^{\circ} \mathrm{C}$, which is anticipated to eliminate the reaction between $\mathrm{LSCF}$ and YSZ. An optimum frequency of $500 \mathrm{~Hz}$ leads to the maximum deposition rate by balancing the suppression of bubble evolution and the acceleration of the particle migration. The deposit yield in a given time grows with the increase of voltage ratio and forward width percentage. In ACEPD with negligible faradic current, the deposition rate of GDC particles is determined by both the transport process and the desorption process, wherein the latter process is irreversible. The 
deposit yield is monotonically controlled by the deposition time, suggesting the possibility of fabrication of GDC layer with tunable thickness.

Dense and homogeneous GDC films have also been successfully prepared by AC-EPD in an aqueous suspension. The parameters influencing the quality of deposition films are thoroughly investigated and the optimal deposition conditions includes the frequency of $1 \mathrm{kHz}$, forward width percentage of $50 \%$ and a voltage ratio of 10/4. This work provides a facile approach to fabricating smooth GDC barrier layers with tunable thickness in an environmentally benign, rapid, versatile and low-cost manner, indicating its promise for SOFC and other applications. 


\section{Acknowledgement}

First of all, I would like to thank my advisor Dr. Xingbo Liu. He innovatively trained me how to do the research from a starter. I feel so grateful to him for his patience, support and guidance throughout the course of my Ph.D. study.

Secondly, I am grateful to Dr. Harry Finklea, Dr. Wenyuan Li and Dr. Wei Li for their help in journal paper discussion and modification.

Next, I would like to thank my committee members, Dr. Harry Finklea, Dr. Edward Sabolsky, Dr. David Mebane, Dr. Konstantinos Sierros, Dr. Wenyuan Li, for their constructive suggestions on my work.

My warmest thank to my wife, with her company in thus journey full of highs and lows, I am not alone. Life is complete with her.

At last, I would like to thank all my group members, Dr. Wenyuan Li, Dr, Wei Li, Dr. Meng Yao, Dr. Xinxin Zhang, Dr. Greg Collins, Dr. Liang Ma, Bo Guan, Nan Zhang, He Qi and et al. Because of them, the memory is sweet. 


\section{Table of Contents}

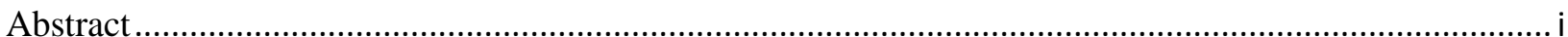

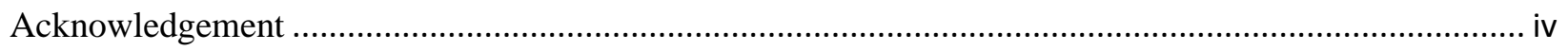

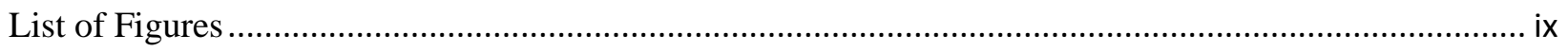

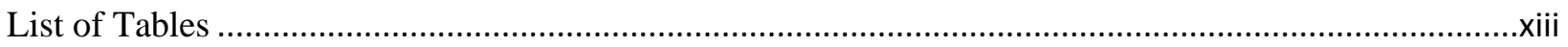

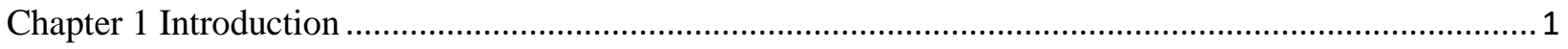

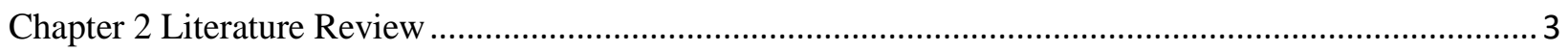

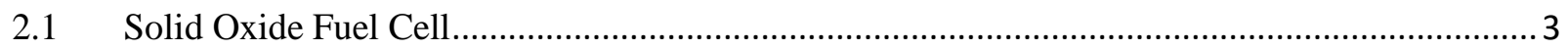

2.1.1 Oxygen reduction reaction of SOFC cathode …........................................................... 3

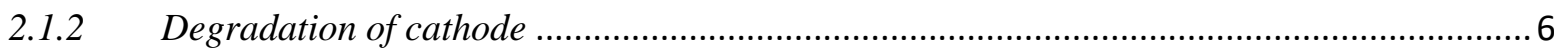

2.1.3 Barrier Layers Function and Deposition Methods .................................................... 7

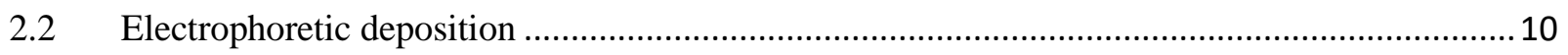

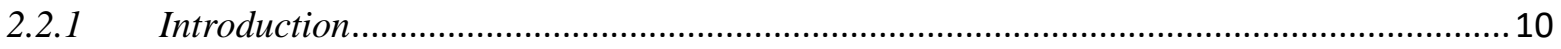

2.2.2 Factors influencing the film formation ................................................................... 11

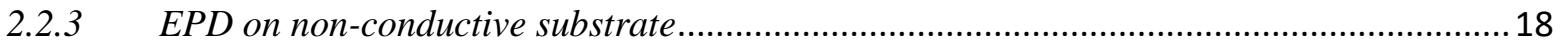

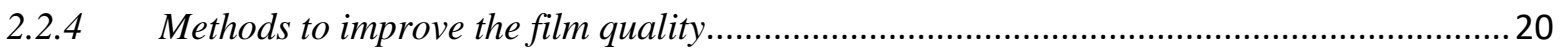

2.2.5 Applications of EPD in solid oxide fuel cells (SOFCs) .................................................26

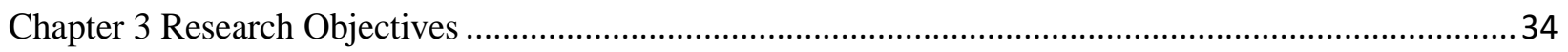

Chapter 4 Direct Current Electrophoretic Deposition (DC-EPD) of Gadolinium-doped Ceria as a Barrier

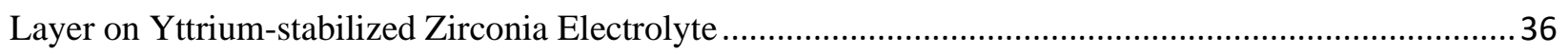




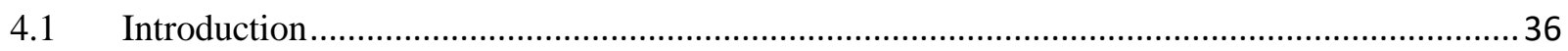

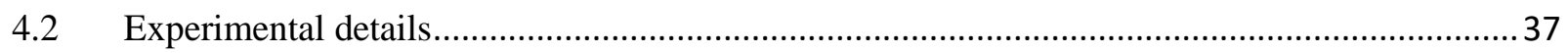

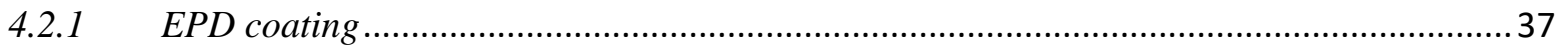

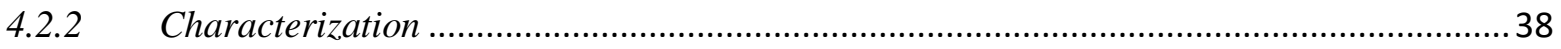

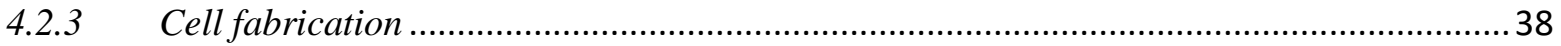

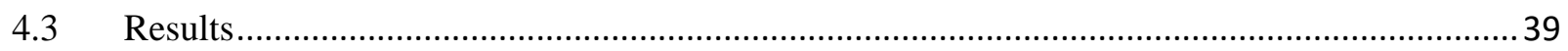

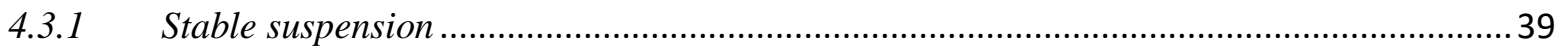

4.3.2 Characterization of conductive polypyrrole …............................................................. 40

4.3.3 Deposition of GDC on PPy coated YSZ ................................................................ 45

4.3.4 Dynamic process during deposition ......................................................................... 47

4.3.5 Morphology of GDC on YSZ by EPD …................................................................... 48

4.3.6 Performance and long-term stability .................................................................... 52

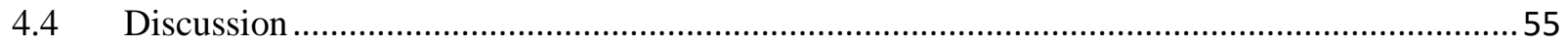

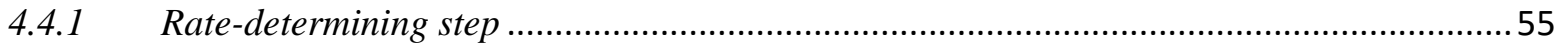

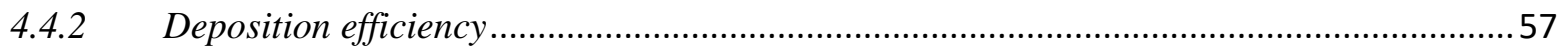

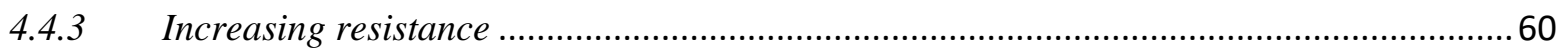

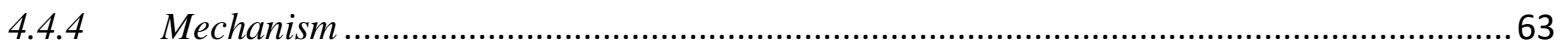

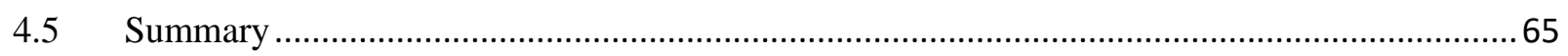

Chapter 5 Alternating Current Electrophoretic Deposition (AC-EPD) of Gadolinium Doped Ceria on Yttrium Stabilized Zirconia as a Barrier Layer in Solid Oxide Fuel Cells (SOFCs) ..............................67

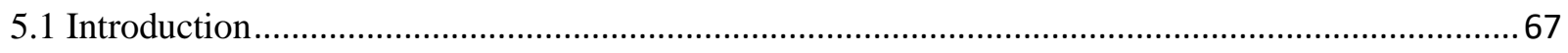


5.2 Experimental details.

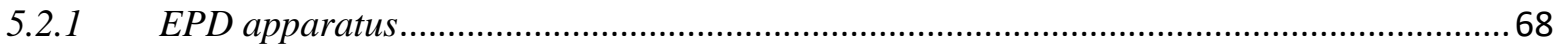

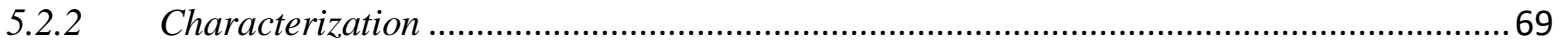

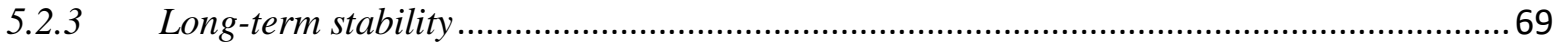

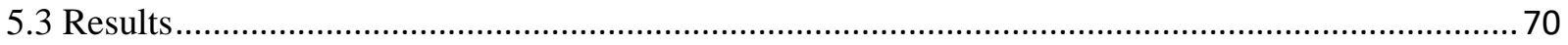

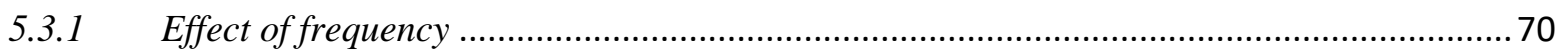

5.3.2 Effect of voltage ratio and forward width percentage .................................................... 72

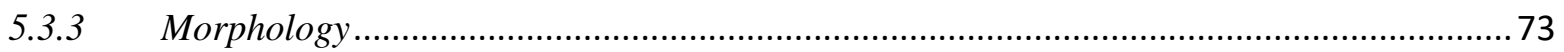

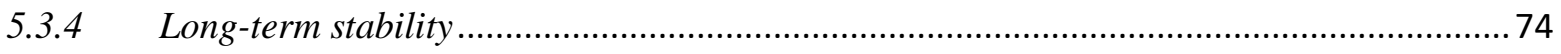

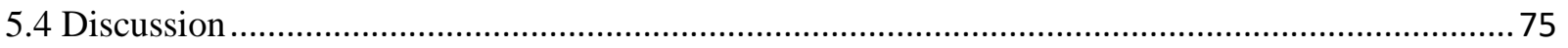

5.4.1 Effect of parameters of AC electric field ........................................................................ 75

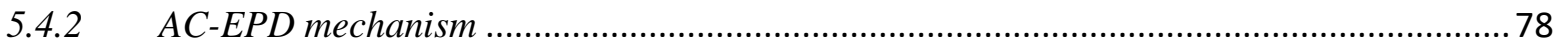

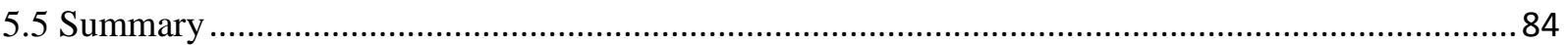

Chapter 6 Alternating Current Electrophoretic Deposition of Gadolinium Doped Ceria in the Aqueous

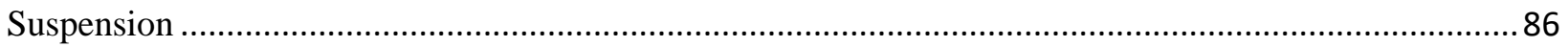

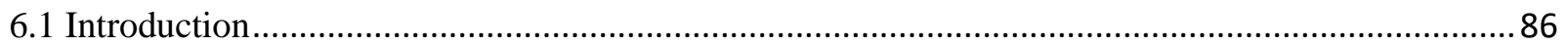

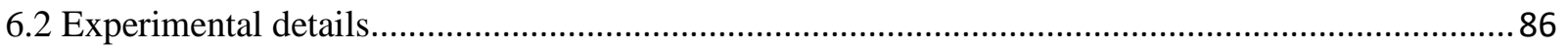

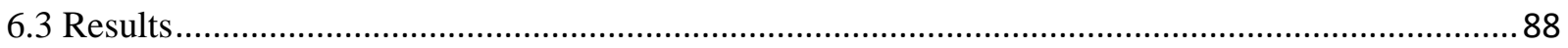

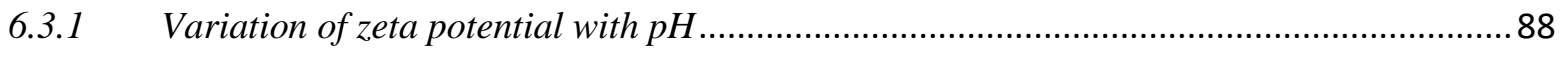

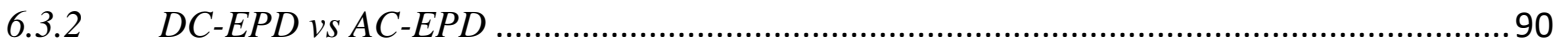

6.3.3 Effect of voltage ratio and forward width percentage ..................................................94 


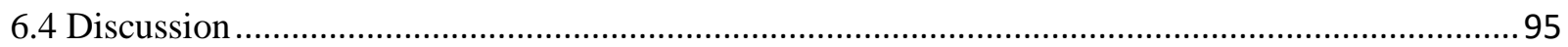

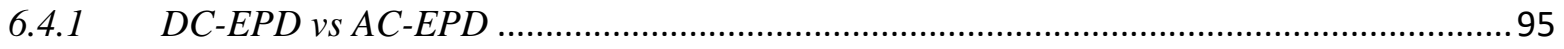

6.4.2 Effect of parameters related to AC electric field ............................................................98

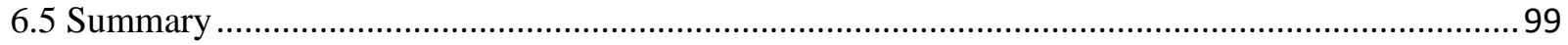

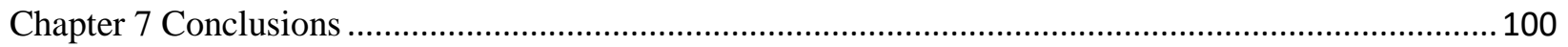

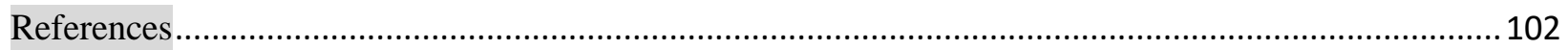




\section{List of Figures}

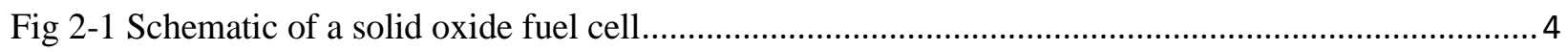

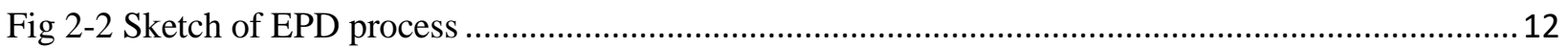

Fig 2-3 SEM images of coatings deposited at 20V/cm and 60s from (a) methanolic (b) ethanolic (c)

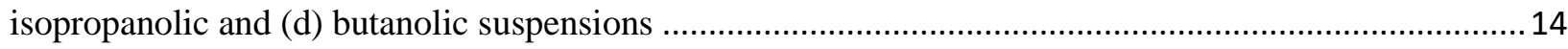

Fig 2-4 EPD as a function of voltage for fixed $30 \mathrm{~s}$ depositions from propylene carbonate (PC) based suspensions showing (a) deposited mass and (b) film thickness after vacuum annealing at $160{ }^{\circ} \mathrm{C} \ldots \ldots \ldots . . .17$

Fig 2-5 Relationship between deposit thickness and time of deposition for $\mathrm{ZnO}$ coatings on copper electrode at different applied potential.......................................................................................... 18

Fig 2-6 Schematic illustration of (a) experimental setup and (b) EPD of YSZ powders onto porous NiOYSZ composite substrate coated with a thin graphite layer ...........................................................2 20

Fig 2-7 Surface morphologies of alumina green bodies as a function of HQ concentration .....................21

Fig 2-8 Experimental set-up for the electrophoretic deposition/ impregnation process from aqueous suspensions .22

Fig 2-9 Surface morphology of deposits obtained by pulsed DC EPD in constant current mode (a) applied current: 0.004 A, (b) applied current: $0.006 \mathrm{~A}$ (suspension: 5 vol\%, $\mathrm{pH} 4.5$, substrate: stainless steel (316 L), pulse ON time: 3 min, pulse duty cycle: $50 \%$, inter-electrode distance: $20 \mathrm{~mm}$ ) .24

Fig 2-10 Photograph of the top surface of as - deposited alumina obtained by pulse electrophoretic deposition from a 5 vol\% suspension at $\mathrm{pH} 4.5$ on (a) stainless steel (316 L) substrate (applied potential=40 V), (b) stainless steel (316 L) substrate (applied potential=20 V); (c) nickel substrate (applied potential $=20 \mathrm{~V}$ ).

Fig 2-11 (A) One period of the applied asymmetric $\mathrm{AC}$ signal and $\alpha-\mathrm{Al}_{2} \mathrm{O}_{3}$ deposits formed using. (B) $100 \mathrm{~V} \mathrm{DC}$ for 1200 s. (C) A $50 \mathrm{~Hz} 500 \mathrm{~V}_{\mathrm{p}-\mathrm{p}}$ asymmetric AC field with asymmetry factor of 4. 
Fig 4-1 Zeta potential and the deposit mass on PPy coated YSZ for 5 mins as a function of the

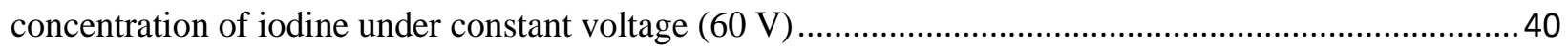

Fig 4-2 Macroscopy and XRD pattern of the deposited GDC layer .................................................... 40

Fig 4-3 Schematic of polypyrrole synthesis process .................................................................. 41

Fig 4-4 (a) Cross-section and (b) surface morphology of GDC layer on YSZ substrate ..........................42

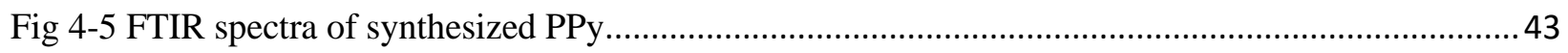

Fig 4-6 (a) Cross - section and (b) surface morphology of PPy coated on YSZ .................................... 43

Fig 4-7 EIS spectra of the suspension using graphite and PPy coated YSZ as the working electrode.......44

Fig 4-8 (a) The deposit yield and (b) the current density as a function of time under constant voltage (60

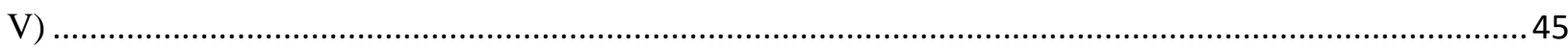

Fig 4-9 The average deposition rate and the current density as a function of time under constant voltage (60 V) when using (a) the graphite plate and (b) the PPy coated YSZ pellet as the cathode. 46

Fig 4-10 Deposit mass per area as a function of current density under constant current and same quantity of electric charge by using PPy coated YSZ and graphite as the cathode. .47

Fig 4-11 The voltage as a function of time under constant current (0.016 A) using PPy coated YSZ as the cathode. .47

Fig 4-12 The $\mathrm{pH}$ in the vicinity of cathode as a function of time under a constant current of $16 \mathrm{~mA} \ldots \ldots . . .48$ Fig 4-13 Cross - sectional morphology of GDC deposited on YSZ for 10 minutes as a function of applied voltage (a) $60 \mathrm{~V}$, (b) $80 \mathrm{~V}$, (c) $100 \mathrm{~V}$, (d) $120 \mathrm{~V}$, (e) $140 \mathrm{~V}$ and (f) $160 \mathrm{~V}$ after sintering at $1300{ }^{\circ} \mathrm{C} \ldots \ldots . . .50$ Fig 4-14 SEM view of (a) green, (c) sintered GDC surface and cross - sectional view of (b) green, (d) sintered GDC layer.

Fig 4-15 (a) SEM view of the surface and (b) cross - sectional view of the sintered GDC layer with 2 $\operatorname{mol} \% \mathrm{FeO}_{1.5}$ 
Fig 4-16 (a) EIS at $750{ }^{\circ} \mathrm{C}$ and (b) temperature dependence of ohmic resistance of symmetric cell with GDC layer formed by spin coating and EPD. .53

Fig 4-17 Equivalent circuit used to fit the EIS data. .54

Fig 4-18 Cross - section morphology of symmetric cell with GDC layer formed by (a) spin coating and (b) EPD. .54

Fig 4-19 Cross-section morphology and EDS line scan of YSZ/GDC/LSCF+GDC after sintering at 800

${ }^{\circ} \mathrm{C}$ for $500 \mathrm{~h}$ .55

Fig 4-20 The schematic of the EPD process on graphite at different deposition times 57

Fig 4-21 The schematic of an EPD cell with an existing deposit. 60

Fig 4-22 The equivalent circuit of the EPD bath .... 61

Fig 4-23 The schematic of the EPD process on a PPy coated YSZ at different deposition times. 63

Fig 4-24 The schematic model of the EPD mechanism of GDC on PPy coated YSZ. 65

Fig 5-1 the figure of the applied AC signal .69

Fig 5-2 The cross-sectional morphologies of GDC layers formed on PPy coated YSZ by DC-EPD at -100 V (a) and AC-EPD with a frequency of $10 \mathrm{~Hz}$ (b), $100 \mathrm{~Hz}$ (c), $200 \mathrm{~Hz}$ (d), $500 \mathrm{~Hz}$ and $1 \mathrm{KHz}$ (voltage ratio: $-100 /+80$, D: $50 \%$ ) after sintering at $1350{ }^{\circ} \mathrm{C}$ for $4 \mathrm{~h}$. .71

Fig 5-3 The deposit yield for $10 \mathrm{~min}$ as a function of frequency (voltage ratio: $-100 /+80$; forward width percentage: $50 \%$ ) 72

Fig 5-4 The deposit weight for $10 \mathrm{~min}$ as a function of (a) voltage ratio (frequency: $500 \mathrm{~Hz}$; forward width percentage: 50\%) and (b) forward width percentage (frequency: $500 \mathrm{~Hz}$; Voltage ratio: -100/+80)73 Fig 5-5 The surface and cross-sectional morphology of GDC with 2 at $\% \mathrm{FeO}_{1.5}$ after sintering at $1250{ }^{\circ} \mathrm{C}$

Fig 5-6 Cross-sectional morphology of the full cell and the EDX result after test .75

Fig 5-7 The equivalent circuit of the EPD cell 76 
Fig 5-8 Time dependence of current density in one period in AC-EPD with different frequencies (a) 0.1

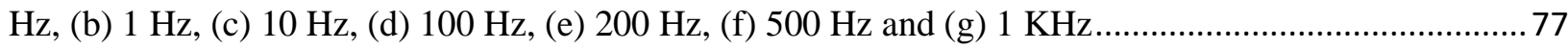
Fig 5-9 Current density as a function of time in one period in AC-EPD with different (a) voltage ratios and (b) forward width percentage .78

Fig 5-10. The schematic of EPD process .79

Fig 5-11 (a) current density in one period and (b) deposit mass as a function of time under AC-EPD at $500 \mathrm{~Hz}$ 82

Fig 5-12 The schematic model of the mechanism of AC-EPD of GDC particles .84

Fig 6-1 (a) The schematic of the applied AC signal and (b) setup for measuring the current..... .87

Fig 6-2 Zeta potential of GDC particles and deposit mass in $5 \mathrm{~min}$ at $10 \mathrm{~V}$ as a function of $\mathrm{pH}$ in the aqueous suspension. 89

Fig 6-3 Size distribution histogram by volume for GDC particles .90

Fig 6-4 Surface morphology of deposits obtained by (a) DC-EPD at $10 \mathrm{~V}$ and (b-f) AC-EPD with varied frequencies [D: $\left.50 \%, \mathrm{~V}_{1} / \mathrm{V}_{2}: 10 / 4\right]$

Fig 6-5 Surface (a-d) and cross-section (e and f) morphology of green films obtained by DC-EPD (a, b and e) and AC-EPD with a frequency of $1 \mathrm{KHz}(\mathrm{c}, \mathrm{d}$ and $\mathrm{f}$ )......

Fig 6-6 (a) Deposit weight for $10 \mathrm{~min}$ as a function of frequency [D: 50\%, V1/V2: 10/4] and (b) time dependence of deposit yield under AC-EPD [f: $1 \mathrm{kHz}, \mathrm{D}: 50 \%, \mathrm{~V}_{1} / \mathrm{V}_{2}: 10 / 4$ ] and DC-EPD at $10 \mathrm{~V} \ldots \ldots . . .93$ Fig 6-7 Surface morphology of deposits obtained by AC-EPD at (a) various forward width percentage [f:

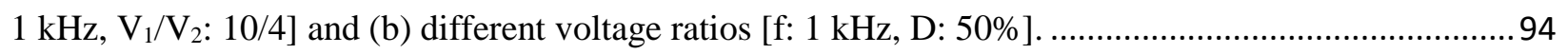

Fig 6-8 The current as a function of time in one period under AC-EPD with different frequencies. .98 Fig 6-9 The current as a function of time in one period under AC-EPD with (a) varied forward width percentage (f: $\left.1 \mathrm{kHz}, \mathrm{V}_{1} / \mathrm{V}_{2}: 10 / 4\right)$ and (b) different voltage ratios [f: $\left.1 \mathrm{kHz}, \mathrm{D}: 50 \%\right]$ .99 


\section{List of Tables}

Table 2-1 comparison for possible coating methods to deposit ceria barrier layer................................. 10

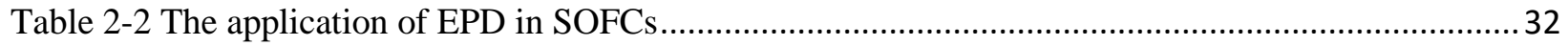

Table 5-1 the deposit mass before and after the reversed EPD under different conditions ......................81 


\section{Chapter 1 Introduction}

Due to severe environment problem and high fuel need, the exploitation and optimization of clean and regenerative energy is one of the major challenges for researchers. As a device which directly converts the electrochemical energy to electric energy, solid oxide fuel cell (SOFC) is a promising substitute energy source because of its advantages of excellent long-term stability, high energy conversion efficiency, low operation and maintenance cost, fuel flexibility, negligible pollution, high reliability and versatility.

It is well-known that MIEC cathode materials [1-5], such as LSCF, show superior electrode performance compared to a traditional LSM cathode. However, replacing LSM with LSCF is hindered by the reaction between LSCF and YSZ, which yields some insulating phases such as $\mathrm{La}_{2} \mathrm{Zr}_{2} \mathrm{O}_{7}, \mathrm{SrZrO}_{3}$, etc. in the interface, decreasing the cell performance. To address this issue, doped ceria has been extensively used as a barrier layer between YSZ and LSCF because of its good chemical and thermal compatibility with LSCF. Doped ceria has been confirmed for eliminating interactions between LSCF and YSZ as well as for boosting cell performance [6]. Screen-printing or spin-coating is usually used to deposit this barrier layer on the electrolyte, but it is difficult to obtain a sufficiently dense layer at a relatively low temperature, e.g. $1300{ }^{\circ} \mathrm{C}$. Sintering above $1400{ }^{\circ} \mathrm{C}$ may densify the barrier layer, but leads to the formation of resistive phases between YSZ and doped ceria [7]. For example, Zhou et al. [8] used screen printing to prepare a samaria-doped ceria (SDC) barrier layer containing certain porosity between LSCF and YSZ and found that Zr migrated into the SDC barrier layer causing a larger intercept resistance in the SOFC. Because the doped ceria layer is usually deposited on the non-shrinkable presintered electrolyte substrate, the resulting ceria layer has considerable porosity after sintering [9] 
which undermines the barrier layer's ability in mitigating the LSCF-YSZ reaction. Considerable effort has been devoted to new coating methods, such as physical vapor deposition (PVD) and chemical vapor deposition (CVD), in order to deposit a dense barrier layer without over-sintering $[10,11]$. However, PVD and CVD require sophisticated and expensive equipment, making them either undesirable or impracticable for implementation in SOFC manufacturing. A new process needs to emerge, one that allows dense, thin film to be deposited efficiently and economically, harmonizing mass production with optimal cell performance.

Electrophoretic deposition (EPD) is a colloidal process in which particles pack closely and densely directly from a suspension under the application of an electric field. It has the advantages of cost-effectiveness, fast deposition rate, simplicity and no requirement of the shape of substrate making it widely used in the fabrication of SOFC [12]. The process consists of two major steps: the migration of charged particles in a stable suspension to the oppositely charged electrode; the deposition of the charged particles onto the substrate under the effect of an electric field [13]. Layer thickness can be easily controlled by deposition time, voltage, and particle concentration.

In the present study, the technique feasibility of electrophoretic deposition of GDC on nonconductive YSZ substrate is demonstrated. Moreover, the fundamental characteristic of EPD including the deposition rate, increasing resistance, deposition efficiency and mechanism are investigated experimentally and analytically. 


\section{Chapter 2 Literature Review}

\subsection{Solid Oxide Fuel Cell}

\subsubsection{Oxygen reduction reaction of SOFC cathode}

Solid oxide fuel cells (SOFCs) converting chemical energy directly to electrical power offer advantages over other techniques in the intrinsically high conversion efficiency and minimal environmental impact [14]. The state-of-art SOFCs consist of NiO-YSZ anode, YSZ electrolyte and lanthanum strontium manganite (LSM) cathode. Fig. 2-1 shows the schematic of an anode supported SOFC. As shown in Fig. 2-1, oxygen, usually air, is fed to the cathode while a fuel, such as $\mathrm{H}_{2}, \mathrm{CH}_{4}$ is fed to the anode. When a load, such as a bulb, acted as the external circuit is put between cathode and anode, electrons flow from anode to cathode through the external circuit. Additionally, oxygen ions flow from cathode to anode through the internal circuit due to (1) overall electrical charge balance and (2) oxygen gradient between cathode and anode. By the combustion of fuel and oxygen, electricity is produced as shown in Fig. 2-1. The only byproduct of the whole process is water when using hydrogen as the fuel. Reforming nature gas or other hydrocarbon fuels to extract hydrogen can be finished within the fuel cells, eliminating the need of an external reformer [15]. 


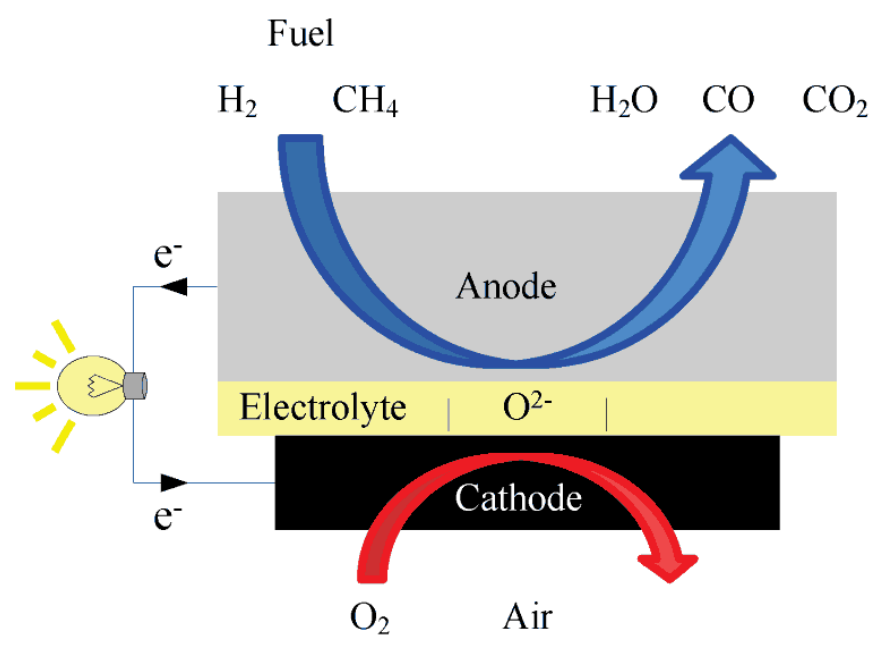

Fig 2-1 Schematic of a solid oxide fuel cell

The electrochemical reaction occurs at the cathode is the reduction of oxygen which is written as:

$$
\mathrm{O}_{2}+4 \mathrm{e}^{-}=2 \mathrm{O}^{2-}
$$

As illustrated by this simple equation, the following features desirable for cathode materials can be drawn:

High electronic conductivity (preferably more than $100 \mathrm{~S} \mathrm{~cm}^{-1}$ under oxidizing atmosphere).

Chemical stability under an oxidizing atmosphere during fabrication and operation.

High catalytic activity for the oxygen reduction reaction (ORR).

Considering the structure of fuel cell, the followings are also required:

Coefficient of thermal expansion matching with other components

Chemically compatible with the electrolyte and interconnect materials 
Conventional $\mathrm{La}_{\mathrm{x}} \mathrm{Sr}_{1-\mathrm{x}} \mathrm{MnO}_{3}$ (LSM) cathodes show relatively good stability under oxidizing atmospheres, high electronic conductivity, and a coefficient of thermal expansion (CTE) that matches the commonly used YSZ electrolyte. However, the oxygen ion conductivity of LSM and its oxygen trace diffusion coefficient are extremely low. Due to the low ionic conductivity in the bulk LSM, the active sites for ORR are largely confined to three-phase boundary (TPB). As a consequence, the performance of this type of cathode is highly dependent on the electrode morphology and is very sensitive to secondary phase formation at the electrode/electrolyte interface.

New mixed ion-electron conducting (MIEC) cathodes, such as doped $\mathrm{LaCoO}_{3}$ [16], RuddlesdenPopper phase $\mathrm{La}_{2} \mathrm{NiO}_{4+\delta}$ [17], or double-perovskite $\mathrm{GdBaCo}_{2} \mathrm{O}_{5+\delta}(\mathrm{GBCO})$ [18], have been extensively studied. Among these new cathodes, $\mathrm{La}_{\mathrm{x}} \mathrm{Sr}_{1-\mathrm{x}} \mathrm{Co}_{\mathrm{y}} \mathrm{Fe}_{1-\mathrm{y}} \mathrm{O}_{3}$ (LSCF) is the most popular one in industry, which has high ionic and electronic conductivities, $10^{-2}$ and $10^{2} \mathrm{~S} \mathrm{~cm}^{-1}$ at $800^{\circ} \mathrm{C}$ [19], respectively, and high catalytic activity for ORR. The electrochemically active region of the LSCF cathodes can extend over the width of the electrode/ electrolyte interface. In addition to a high electrical conductivity, cathode performance strongly depends on the oxygen bulk diffusion coefficient (D) and surface exchange rate (k). The ratio between D and k yields the characteristic length $\left(l_{c}=\mathrm{D} / \mathrm{k}\right)$ as a qualitative criterion for given material to determine whether the oxygen transport is controlled by surface oxygen exchange or bulk diffusion. For LSM-based cathodes, kinetic data for $\mathrm{D}$ and $\mathrm{k}$ obtained from isotopic exchange measurements indicate that the $\mathrm{l}_{\mathrm{c}}$ of LSM is in the range of $1 \sim 8 \mathrm{~nm}$ at $800^{\circ} \mathrm{C}$ [20]. Therefore, oxygen transport in LSM-based cathodes is typically controlled by bulk-diffusion since it is very difficult to fabricate samples thin enough to operate in the mixed regime. In contrast, electrical conductivity relaxation (ECR) experiments indicate that for LSCF, D is $5 \times 10^{-6} \mathrm{~cm}^{2} \mathrm{~S}^{-1}$ and $\mathrm{k}$ is $1 \times 10^{-4} \mathrm{~cm} \mathrm{~S}^{-1}$ at $800^{\circ} \mathrm{C}$ [21], 
the value of $l_{c}$ is six to seven orders of magnitude larger $\left(l_{c} \approx 50 \mathrm{~mm}\right)$ than that of LSM. Therefore, the oxygen transport for LSCF type cathodes is surface-limited.

\subsubsection{Degradation of cathode}

For LSM-based cathodes, principal reported concerns are particle growth, and the formation of insulator phases, such as $\mathrm{SrZrO}_{3}$ or $\mathrm{La}_{2} \mathrm{Zr}_{2} \mathrm{O}_{7}$, due to the interaction between LSM cathode and YSZ electrolyte [22]. The conductivity of these zirconates is two to three orders of magnitude lower than that of YSZ. In the meantime, the zirconate phases can induce undesirable polarization through (1) surface diffusion of electro-active oxygen along the LSM surface to the TPBs; and (2) electrochemical formation of $\mathrm{O}^{2-}$ at the TPB due to limited availability of electronic charge carriers [23]. Moreover, Mn diffusion from LSM into other components such as YSZ electrolyte and the chromium-containing metallic interconnect has been observed in the literature [22]. Mn diffusion leads to an increase in La activity at the interface and promotes interfacial reaction. Such instability and interaction can be reduced by minimizing the sintering temperature or avoiding certain operating conditions such as over-potentials and low oxygen partial pressures on the cathode side. For the SOFC technology to become commercially competitive, it is necessary to mitigate these limitations and restrictions in order to decrease both investment and production costs.

In the case of LSCF type cathodes, SIMS measurements reveal that strontium and lanthanum had been diffusing out of the cathode, leading to strontium depletion in the cathode and significantly lower performance $[24,25]$. Such cation segregation in an LSCF cathode can retard ORR kinetics by changing the composition stoichiometry and forming inactive surface species that block reaction sites. One possible mechanism for cation segregation is through cation interaction 
of Sr with a surface oxygen vacancy, thus blocking the oxygen which is crucial for catalyzing the ORR in perovskite [26], as shown by:

$$
2 S r_{L a}^{\prime}+2 O_{o}^{\times}+V_{o, L S C F}^{*}+2 s \leftrightarrow 2 \operatorname{SrO}(s)
$$

Formation of insulating surface species such as $\mathrm{SrO}$ can thus reduce the number of oxygen adsorption sites and oxygen vacancy availability for surface oxygen reduction [27]. Moreover, LSCF cathodes show low chemical stability (forming an insulating zirconate phase) and an unacceptably high CTE compared to the CTE for the YSZ electrolyte.

External factors can further augment the degradation of SOFC cathodes. For instance, most perovskite oxides containing alkaline-earth elements, such as LSM and LSCF, can react with gas species such as $\mathrm{CO}_{2}, \mathrm{SO}_{2}$, or water vapor, at a significant rate at temperatures less than $800{ }^{\circ} \mathrm{C}$ leading to additional insulator phase formation [28], as follows:

$$
\mathrm{SrO}+\mathrm{CO}_{2}(g) \rightarrow \mathrm{SrCO}_{3}(s)
$$

In particular, as a component of atmospheric air, the presence of $\mathrm{CO}_{2}$ inhibits the oxygen reduction process over the cathode surface and consequently decreases the cell performance [29].

\subsubsection{Barrier Layers Function and Deposition Methods}

Doped ceria is of interest as an electrolyte for SOFCs operated at intermediate and low temperatures because of its high-ionic conductivity compared to the state-of-the-art YSZ electrolyte. It is generally accepted that doped ceria materials form an acceptable barrier layer between the YSZ electrolyte and cathode to improve the cathode stability.

Although many researchers consider LSM a 'stable' cathode material and therefore do not apply 
a protective barrier layer between it and the YSZ electrolyte, recent studies have shown that a doped ceria interlayer in fact lowered the degradation of an LSM cathode and improved the electrochemical performance of the cell. For example, increased performance of SOFCs having protective SDC layers fabricated by screen printing at the LSM cathode/YSZ electrolyte interface were observed [8]. Those researchers ascribed this result to the SDC layer effectively blocking Ni diffusion from the Ni-YSZ anode, resulting in the coarsening and increased densification of the LSM microstructure.

For LSCF cathodes, gadolinium-doped and samarian-doped ceria (GDC, SDC) are chemically and thermally compatible with YSZ and therefore have been extensively investigated as the interlayer materials. GDC or SDC interlayers have been confirmed for eliminating interaction between LSCF and YSZ as well as for boosting whole cell performance [6, 30, 31]. Screen printing is typically used to deposit the barrier layer on the electrolyte but achieving a fully densified layer with a reasonable amount of sintering is difficult. Sintering above $1400{ }^{\circ} \mathrm{C}$ may densify the barrier layer, but often leads to the formation of a resistive phase between GDC and YSZ as well as over-sintering the anode functional layer. For example, Zhou et al. [8] used screen printing to prepare a SDC interlayer containing a certain porosity between LSCF and YSZ, and found that $\mathrm{Zr}$ migrated into the SDC interlayer causing a larger intercept resistance within the SOFC. Because the doped ceria layer is usually deposited on the non-shrinkable pre-sintered electrolyte substrate, the resulting ceria layer has considerable porosity after sintering $[9,32]$ which impairs the barrier layer's ability in mitigating the LSCF-YSZ reaction.

Considerable effort has been devoted to new coating methods, such as physical vapor deposition (PVD) and chemical vapor deposition (CVD), in order to deposit a dense barrier layer without over-sintering [11, 33]. However, PVD and CVD require sophisticated and expensive equipment, 
making them either undesirable or impracticable for implementation in SOFC manufacturing. A new process needs to emerge, one that allows dense, thin film to be deposited efficiently and economically, harmonizing mass production with optimal cell performance.

Table 2-1 summarizes the comparison of various coating methods for depositing a ceria barrier layer on YSZ substrate for SOFC applications. As shown in Table. 2-1, EPD offers significant advantages over other candidates in terms of cost, scalability and other parameters. 
Table 2-1 comparison for possible coating methods to deposit ceria barrier layer

\begin{tabular}{|c|c|c|c|c|c|c|c|}
\hline Method & $\begin{array}{c}\text { Green-body } \\
\text { porosity }\end{array}$ & Coating time & Cost & Scalable & $\begin{array}{c}\text { Composition } \\
\text { control }\end{array}$ & $\begin{array}{c}\text { Thickness } \\
\text { control }\end{array}$ & $\begin{array}{l}\text { Coat on non- } \\
\text { flat surface }\end{array}$ \\
\hline $\begin{array}{l}\text { Screen } \\
\text { printing }\end{array}$ & High & $\begin{array}{l}\text { Seconds/ } \\
\text { minutes }\end{array}$ & Low & Yes & Easy & Easy & Difficult \\
\hline Dip coating & High & $\begin{array}{l}\text { Seconds/ } \\
\text { minutes }\end{array}$ & Low & Yes & Easy & Easy/moderate & Easy \\
\hline Spin coating & High & $\begin{array}{l}\text { Seconds/ } \\
\text { minutes }\end{array}$ & Low & Difficult & Easy & Easy/moderate & Moderate \\
\hline Electroplating & Low & $\begin{array}{l}\text { Minutes/ } \\
\text { hours }\end{array}$ & Low & Yes & Moderate & Moderate & Easy/moderate \\
\hline Thermal Spray & Medium & Seconds & Medium & Yes & Easy & Difficult & Easy \\
\hline Tape Casting & High & $\begin{array}{l}\text { Seconds/ } \\
\text { minutes }\end{array}$ & Low & Yes & Easy & Easy & Easy \\
\hline PLD & Low & hours & High & No & Moderate & Moderate & Easy/moderate \\
\hline RF sputtering & Low & hours & High & Yes & Moderate & Moderate & Easy/moderate \\
\hline CVA/ALD & Low & hours & High & Yes & Moderate & Easy/moderate & Easy/moderate \\
\hline EPD & Low & $\begin{array}{l}\text { Several } \\
\text { minutes }\end{array}$ & Low & Yes & Easy & Easy & Easy/moderate \\
\hline
\end{tabular}

\subsection{Electrophoretic deposition}

\subsubsection{Introduction}

Electrophoretic deposition (EPD) is a colloidal process by which particles could pack closely and compactly directly from a suspension under the effect of an electric field. It has the advantages of simplicity, fast deposition rate, cost-effectiveness, good uniformity and no requirement of the 
shape of the substrate, making it widely used to realize the deposition of carbon nanotubes [34], biomaterials [35], composites [36, 37], polymer [38], ceramics [39], super-capacitors [40], metal nanoparticles [41], silicon carbide [42] and functionally graded materials [43], et. al.

\subsubsection{Factors influencing the film formation}

Fig. 2-2 shows the sketch of EPD process. It reveals that the charged particles suspended in the suspension move to the oppositely charged electrode, then deposit onto it with the application of an electric field [44]. The driving force exerted on the charged particles upon migration is the interaction between the electric field and the surface charge of particles. The drag force consists of the viscous drag force from the liquid, the force exerted by the electric field on the counterions in the double layer and the distortion in the double layer caused by a displacement between the center of the negative and positive charge [45]. Hence, the deposition behavior of charged particles is influenced by two group of parameters: those related to the suspension, such as zeta potential, electrolyte conductivity, and those associated with the deposition process including voltage, deposition time.

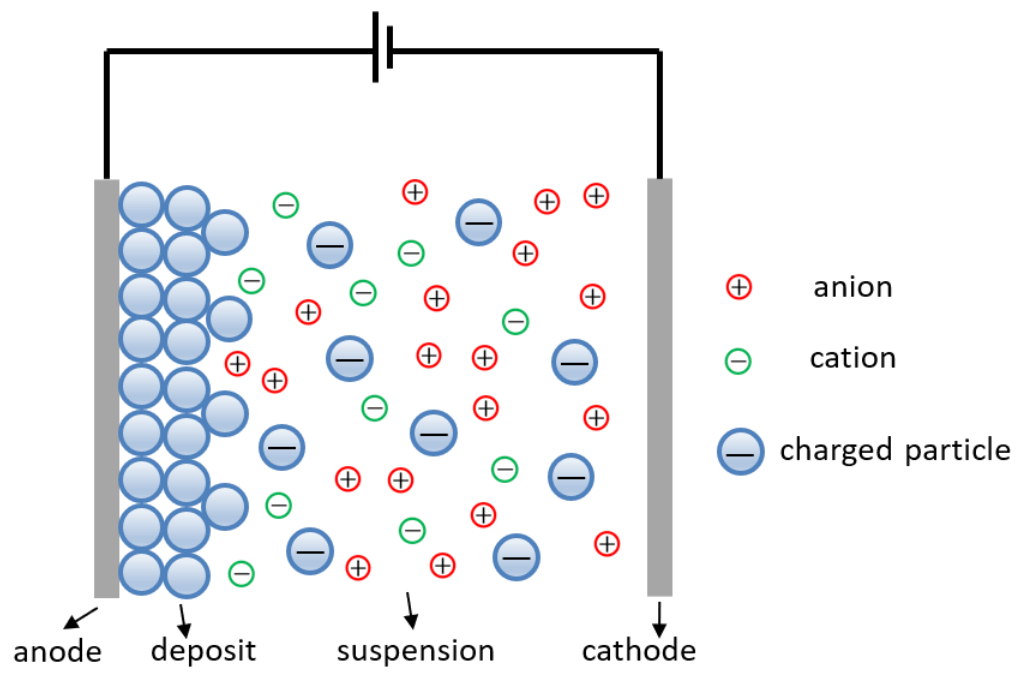


The first kinetic model (Eq. (2-4)) was proposed by Hamaker. et al in which the deposit weight, $\mathrm{m}(\mathrm{g})$, was related to particle concentration, $\mathrm{C}_{\mathrm{s}}\left(\mathrm{g} \mathrm{cm}^{-3}\right)$, electric field strength, $\mathrm{E}\left(\mathrm{V} \mathrm{cm} \mathrm{cm}^{-1}\right)$, particle mobility, $\mu\left(\mathrm{cm}^{2} \mathrm{~s}^{-1} \mathrm{~V}^{-1}\right)$, deposition area, $\mathrm{S}\left(\mathrm{cm}^{2}\right)$ and deposition time, $\mathrm{t}(\mathrm{s})$, through the following equation using a planar electrode [46]:

$$
\mathrm{m}=\mathrm{C}_{s} \mathrm{E} \mu \mathrm{St}
$$

By considering all the charge in the suspension is carried by the charged particles, a similar equation as Eq. (1) was induced by Hirata. et al using the Faradic law [47].

$$
\mathrm{m}=\frac{2}{3} C_{s} \varepsilon_{0} \varepsilon_{r} \xi \eta^{-1} E t
$$

Wherein $C_{s}\left(\mathrm{~g} \mathrm{~cm}^{-2}\right)$ is the particle concentration, $\varepsilon_{0}\left(\mathrm{~F} \mathrm{~m}^{-1}\right)$ is the permittivity of vacuum, $\varepsilon_{\mathrm{r}}$ is the relative permittivity of the solvent, $\xi(\mathrm{V})$ is the zeta potential of the particles, $\eta(\mathrm{Pa} s)$ is the viscosity of the solvent, $E\left(\mathrm{~V} \mathrm{~m}^{-1}\right)$ is the electric field strength and $t(\mathrm{~s})$ is the deposition time. This kinetic model has been widely used by other researchers [48, 49]. Since $\varepsilon_{\mathrm{r}}$ and $\eta$ are identical for the same solvent, the deposit weigh is combinedly controlled by the particle concentration $\left(C_{s}\right)$, solvent $\left(\varepsilon_{\mathrm{r}}\right.$ and $\left.\eta\right)$, electric field strength $(\mathrm{E})$ and deposition time.

\subsubsection{Factors related to the suspension}

(1) Zeta potential

The zeta potential is of significance to indicate the stability of the suspension and the direction of the movement of particles. The zeta potential can be adjusted by adding various charging agents such as acids, bases or some surface charge modifier, e.g., iodine [50-53]. Oxide surface, e.g., 
GDC, consists of some amphoteric hydroxyl groups that undergoes reaction with either $\mathrm{H}^{+}$or $\mathrm{OH}^{-}$ions in the suspension [39]:

$$
\begin{array}{ll}
{[\mathrm{M}-\mathrm{OH}]^{0}{ }_{\text {surface }}+\mathrm{H}^{+} \rightarrow\left(\mathrm{M}-\mathrm{OH}_{2}\right)^{+}{ }_{\text {surface }}} & \mathrm{pH} \text { lower than IEP } \\
{[\mathrm{M}-\mathrm{OH}]_{\text {surface }}^{0}+\mathrm{OH}^{-} \rightarrow(\mathrm{M}-\mathrm{O})^{-}{ }_{\text {surface }}+\mathrm{H}_{2} \mathrm{O}} & \mathrm{pH} \text { higher than IEP }
\end{array}
$$

The sign of zeta potential changes according to the $\mathrm{pH}$ value. The deposition rate grows with the increase of zeta potential (absolute value) since the mobility of charged particles is proportional to zeta potential when other parameters are fixed [54]. Moreover, the well dispersed suspension with a higher zeta potential is more likely to result in a denser green deposit [50].

\section{(2) Solvent}

From the viewpoint of cost, flammability and toxicity, distilled water is superior to any organic solvents. Unfortunately, the electrolysis of water which occurs at low voltages is inevitable under an electric field strength high enough to get an intact and reasonable film. The electrochemical reactions were shown in the following equations:

$$
\begin{aligned}
& \text { Anode: } 2 \mathrm{H}_{2} \mathrm{O}-4 \mathrm{e}^{-} \rightarrow \mathrm{O}_{2}+4 \mathrm{H}^{+} \\
& \text {Cathode: } 2 \mathrm{H}_{2} \mathrm{O}+2 \mathrm{e}^{-} \rightarrow \mathrm{H}_{2}+2 \mathrm{OH}^{-}
\end{aligned}
$$

During deposition, the bubble evolution associated with hydrogen evolution reaction (HER) (Eq. (2-7)) or oxygen evolution reaction (OER) (Eq. (2-6)) impairs the uniformity and quality of the deposit $[55,56]$. To mitigate bubble evolution, organic solvents with good chemical stability have been used in most conditions. Farrokhi-Rad. et al compared the deposition behavior of hydroxyapatite (HA) nanoparticles in different alcoholic suspensions (methanol, ethanol, 
isopropanol and butanol) and found the deposition rate is faster in alcohols with smaller molecular weights than those with larger molecular weights because of their higher relative permittivities [57] and smaller viscosities [58], resulting in a larger mobility of HA particles [59, 60]. However, the surfaces had less cracks as the molecular weight of alcohol increased (Fig. 2-3) [59]. The cracking was induced by mechanical stress exerted by shrinkage during drying. Alcohols with lower boiling points have higher vapor pressures, thus resulting in a faster drying rate and more cracks.
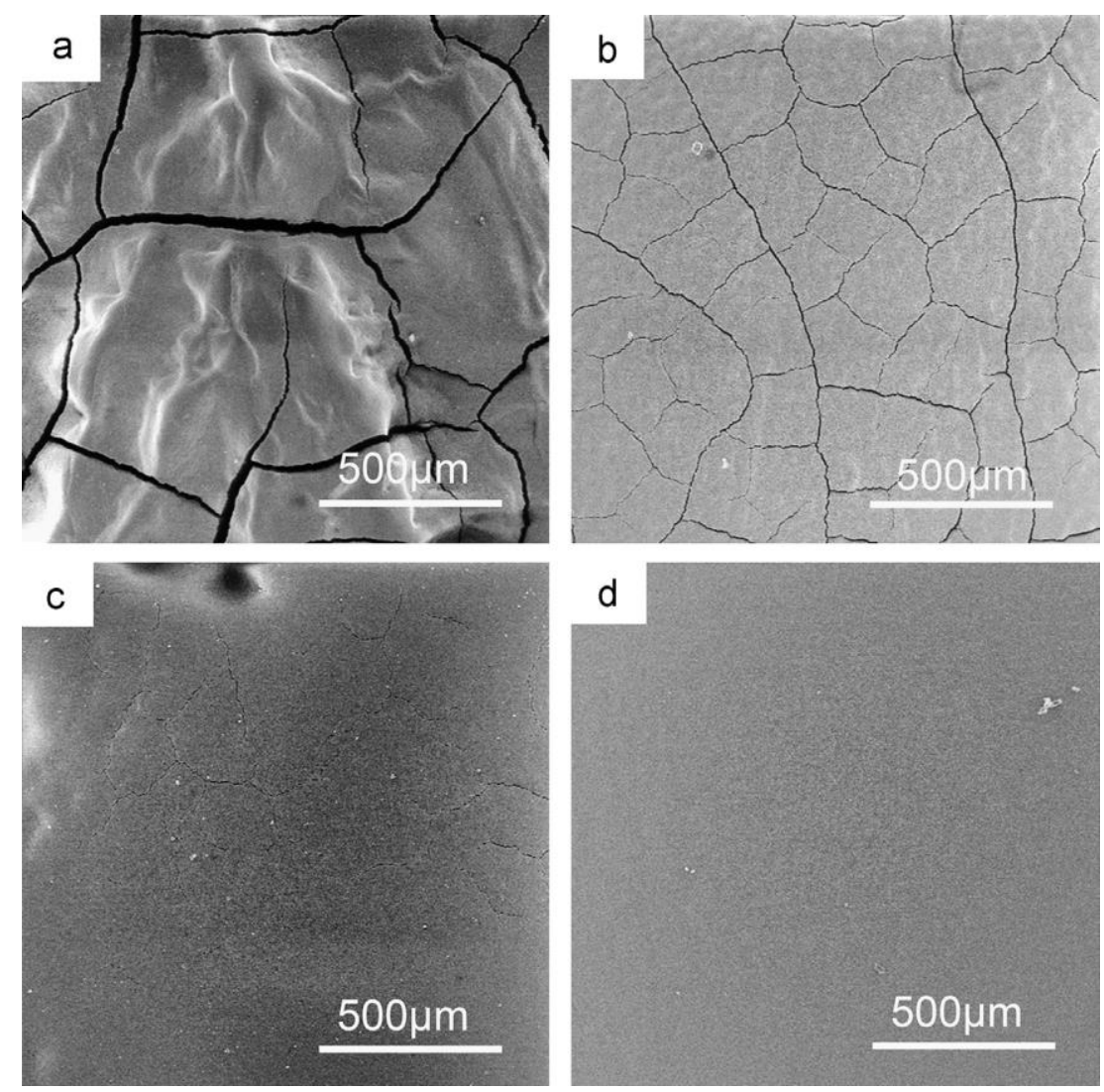

Fig 2-3 SEM images of coatings deposited at 20V/cm and 60s from (a) methanolic (b) ethanolic (c) isopropanolic and (d) butanolic suspensions

(3) Particle concentration 
Particle concentration plays an important role in the properties of film, e.g., the composition of film in the multi-component EPD. The deposition rate of each component is independent in the multi-component EPD, which grows with the increase of particle concentration [61].

Theoretically, the deposition rate is proportional to the solid loading as shown in the kinetic models (Eq. (2-4) and (2-5)). However, the linear relationship between the deposition rate and particle concentration was not reached in some experiments [62]. Moreno. et al found the green density of $\mathrm{Al}_{2} \mathrm{O}_{3}$ film deposited from the aqueous suspension grew with solid content [62] while Guo. et al observed the solid loading showed no visible effect on the packing density of yttrium stabilized zirconia (YSZ) deposit obtained from the organic suspension [51] with other parameters identical. This disagreement might be ascribed to the different properties of the solvents since the bubble evolution in aqueous suspensions is more violent than that in organic suspensions.

(4) The conductivity of the suspension

Besides these parameters discussed above, the deposition behavior of charged particles is also influenced by the conductivity of the suspension. Stappers. et al observed that highly conductive ethanolic suspensions led to uniform alumina deposits and vice versa [63]. Guo. et al found the green density of YSZ film obtained from organic suspensions increased with the increasing conductivity of the suspension initially. Then it appeared to decreases when the electrolyte conductivity was higher than one threshold value, i.e., $17.5 \mu \mathrm{S} \mathrm{cm}^{-1}$ in their system [51].

\subsubsection{Factors related to the operation}

(1) Applied voltage 
The driving force exerted on the charged particles is the product of electric field strength and the surface charge of particles. Therefore, the deposit yield in a given time increases with the increase of applied voltage generally as the driving force grows correspondingly. Collini. et al reported both the deposit mass and film thickness of $\mathrm{Ti}_{3} \mathrm{AlC}_{2}$ on fluorinated tin oxide (FTO) conductive glass electrodes were proportional to the applied voltage with a range from $5 \mathrm{~V}$ to 25 V (Fig. 2-4) [64]. At a higher voltage, particles move much faster. However, the bubble evolution associated with the electrochemical reaction, e.g., the electrolysis of water, accompanying the deposition process might impair the deposition process [55, 65]. As shown in Koura's work, the deposit mass of $\mathrm{BaTiO}_{3}$ on a platinum plate for $30 \mathrm{~s}$ decreased when the voltage increased from $300 \mathrm{~V}$ to $600 \mathrm{~V}$ using a suspension of acetone $(100 \mathrm{ml})+\mathrm{H}_{2} \mathrm{O}(0.03 \mathrm{wt} \%)$ $+\mathrm{I}_{2}(40 \mathrm{mg})$ [66]. Besu's work showed that a moderate electric strength $\left(25-100 \mathrm{~V} \mathrm{~cm}^{-1}\right)$ always resulted in more uniform films [67]. In contrast, a higher electric strength (> $\left.100 \mathrm{~V} \mathrm{~cm}^{-1}\right)$ deteriorated the quality of the film as the deposition process was disturbed by the violent bubble evolution. Moreover, the charged particles were not prone to deposit onto the optimized position due to their high moving speed. 


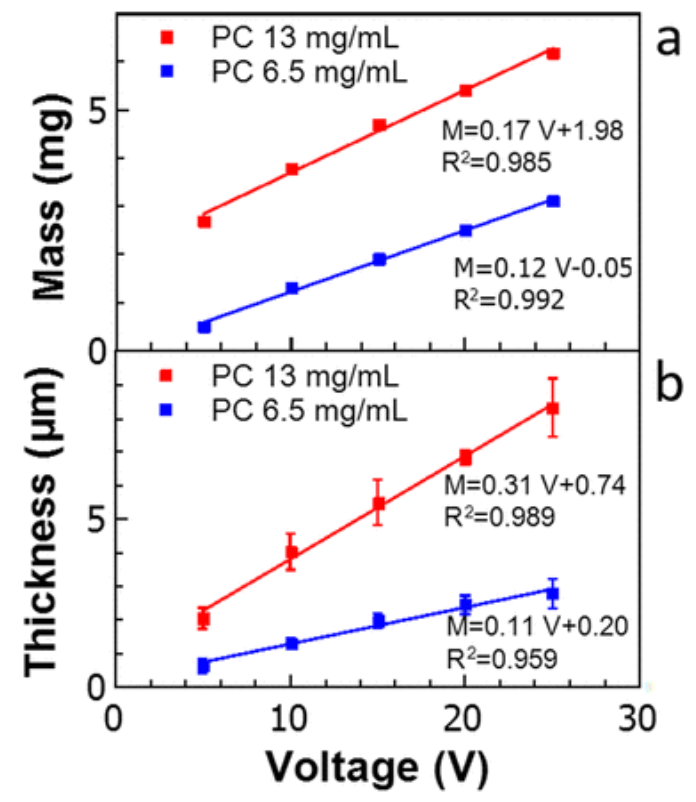

Fig 2-4 EPD as a function of voltage for fixed 30 s depositions from propylene carbonate (PC) based suspensions showing (a) deposited mass and (b) film thickness after vacuum annealing at $160{ }^{\circ} \mathrm{C}$

(2) Deposition time

Wang. et al found the deposit weight of $\mathrm{ZnO}$ coating on copper initially increased proportionally by time, then attained a plateau after a certain time under constant voltage (20, $60100 \mathrm{~V})$ (Fig. 25) [68]. A similar result was also found in other systems [66, 69]. In contrast, the deposition rate remained constant under constant current [70]. The variation of deposition rate by time would be discussed in detail in the following sections. 


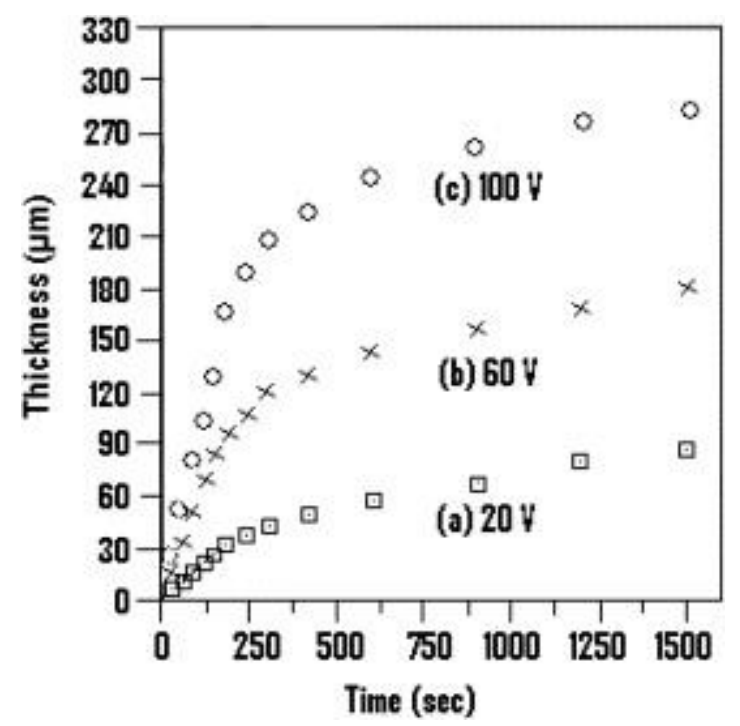

Fig 2-5 Relationship between deposit thickness and time of deposition for ZnO coatings on copper electrode at different applied potential

\subsubsection{EPD on non-conductive substrate}

The prerequisite of EPD is that the electrodes should be electrically conductive, for which most electrodes used in the literature are graphite or metal plates. To facilitate the deposition on the non-conductive substrate, some work prior to EPD is necessary to meet this requirement.

\subsubsection{Conductive agent}

Coating a thin layer of conductive agent on the surface of the non-conductive substrate is considered to be a simple method. The thickness of the agent is required to be relatively thin, e.g., $1 \mu \mathrm{m}$, so that it can be fully removed without destructing the adhesion between the deposit and the substrate during the following treatment, e.g., sintering. Hirata. et al [48] and Besra. et al [71] applied carbon/graphite as the agent since it can be easily burn out during sintering. Santillán. et al coated a thin layer of platinum on GDC surface to realize the deposition of LSCF on it [72]. However, the introduction of platinum affected the cell performance as it could not be removed 
[73, 74]. Recently, some conductive polymers, such as PPy [75] and polyaniline (PANI) [76] were widely accepted as the agent as they can be synthesized and attached readily on the surface of the substrate with the aid of some oxidants. Moreover, the thickness of this polymer could be less than 1 um [53] and the conductivity was confirmed to be high enough to carry out EPD experiments [77].

\subsubsection{Mixed electrode}

The electrically conductive electrodes are used to provide a connected electric path which could also be achieved by mixing some conductive additives with the non-conductive base powder. Will. et al reduced NiO-YSZ to Ni-YSZ by sintering NiO-YSZ in a reducing atmosphere and realized the deposition of YSZ on it [78]. Yamaji. et al mixed NiO-YSZ with some graphite powder to make a mixed electrode and deposited YSZ on it [79]. During the following sintering process, the graphite powder was fully burn out by leaving pure NiO-YSZ material. It is important to note that the percentage of the conductive additives should be large enough to provide a connected electric path [71].

\subsubsection{Porous electrode}

To provide a connected electric path, a non-conductive and porous substrate or a dialysis membrane which is only permeable to ions can also be used as the deposition electrode instead of a dense substrate. Matsuda. et al directly deposited YSZ on a non-conductive and porous NiOYSZ substrate which was coated with a thin layer of carbon on the other side (Fig. 2-6) [80]. As shown in Fig. 2-6, the carbon layer was acted as the cathode and YSZ deposit was obtained directly on the side of the NiO-YSZ substrate facing the counter electrode. Similarly, Tabellion. et al reported the deposition of $\mathrm{SiC}$ on a porous substrate which was placed between these two 
electrodes [81]. Moreover, Besra. et al found there was a threshold voltage below which no deposition occurred on the porous substrate and the threshold value was inversely proportion to the porosity of the substrate $[71,82]$.

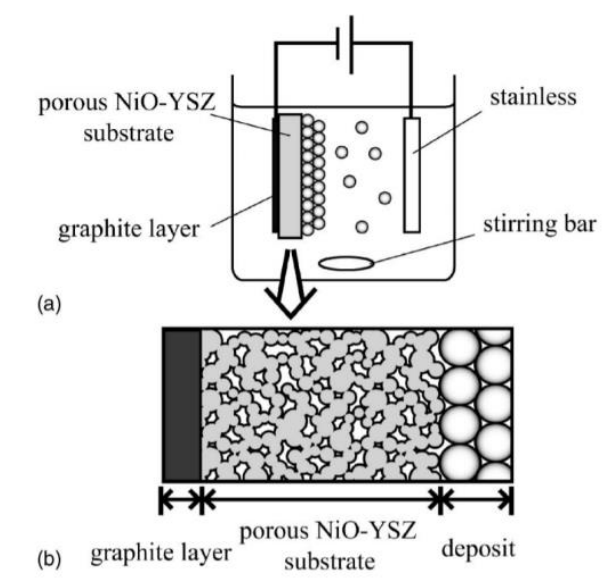

Fig 2-6 Schematic illustration of (a) experimental setup and (b) EPD of YSZ powders onto porous NiO-YSZ composite substrate coated with a thin graphite layer

\subsubsection{Methods to improve the film quality}

The bubble evolution during deposition impairs the uniformness and green density of the deposit, especially the electrolysis of water in the aqueous suspensions. The corresponding electrochemical reactions in the aqueous suspension are shown in Eq (2-6) and (2-7). Therefore, great research efforts have been devoted to eliminating the bubble evolution to improve the uniformity and green density of film obtained by EPD.

\subsubsection{Addition of chemical reactants}

As gas evolves out in the form of bubbles once its concentration is larger than its solubility in the solvent, anodic electrophoretic deposition is preferred to cathodic electrophoretic deposition in 
the aqueous suspensions since the solubility of oxygen in water $\left(0.043 \mathrm{~g} \mathrm{~L}^{-1}\right)$ is larger than that of hydrogen $\left(0.0016 \mathrm{~g} \mathrm{~L}^{-1}\right)$ at room temperature.

The bubble evolution could be eliminated by avoiding gas production. Sakurada et al. characterized the morphologies of alumina green bodies on stainless steel with the addition of different amount of hydroquinone (HQ) in the aqueous suspension [29]. The $\mathrm{pH}$ of the suspension was fixed as 12 . At this $\mathrm{pH}$, the negatively charged alumina particles deposited on the anode. In the absence of added hydroquinone, deposits exhibited many pores and defects due to water electrolysis. Added hydroquinone was oxidized to the quinone at lower potentials than water oxidation (Eq. 2-8). Deposits formed in the presence of hydroquinone clearly revealed that the size and number of the pores on the surface decreased with the increase in HQ concentration. Homogenous deposits were obtained when the HQ concentration reached 0.15 M (Fig. 2-7).

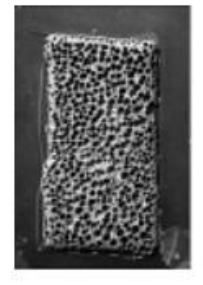

$0.01 M$

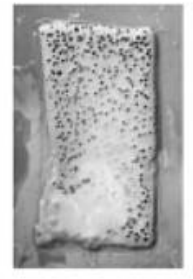

$0.05 M$

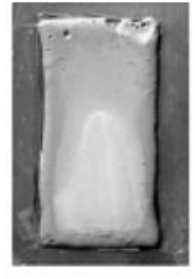

$0.10 \mathrm{M}$

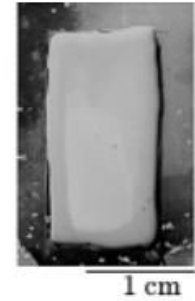

$0.15 M$

Fig 2-7 Surface morphologies of alumina green bodies as a function of HQ concentration

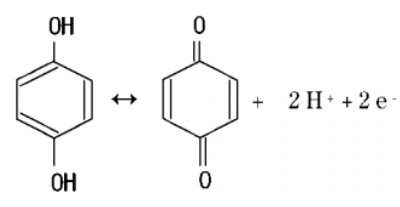

\subsubsection{Porous electrode}


Generally, both the deposition of particles and the evolution of bubble occur at the same position, i.e., deposition electrode, the impairment of bubble evolution on the deposit could be eliminated by separating the deposition from the electrochemical reaction. Tabellion. et al realized the deposition of silica on a porous mold and successfully obtained a bubble-free deposit by using a modified set-up shown in Fig. 2-8 [81]. Wherein, an ion-permeable porous mold was put between these two electrodes. After applying an electric field, the charge particles deposited on the porous mold while the bubbles evolve out at cathode or anode. The bubble evolution had no effect on the density and uniformity of the deposit regardless of the amplitude of the voltage. The direct deposition of YSZ on porous NiO-YSZ coated with a thin layer of carbon on the other side in Matsuda's work [80] is similar to this set-up. YSZ particles deposited on the side of porous NiO-YSZ facing the other electrode while the bubbles evolved out at the other side of the NiOYSZ substrate coated with carbon. Another similar result was found by Sarkar and Nicholson in which a dense deposit was obtained on a dialysis membrane [39]. The membrane which was put between these two electrodes is permeable to ions.

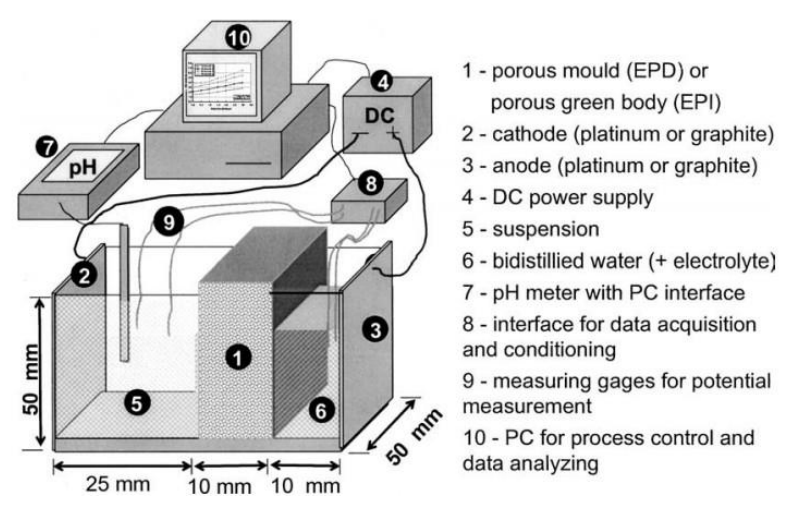

Fig 2-8 Experimental set-up for the electrophoretic deposition/ impregnation process from aqueous suspensions

\subsubsection{Modulated electric field}


The addition of chemical reactant and the utilization of porous electrode could eliminate the bubble evolution in some EPD baths. However, these two methods can significantly increase the cost and inhibit the application of EPD. Recently, much attention has been paid on the deposition under a modulated electric field, i.e., direct current pulse EPD (DCP-EPD) and alternating current EPD (AC-EPD).

(1) DC pulse electric field

Besra. et al applied constant current pulse and constant voltage pulse EPD to deposit alumina on stainless steel plates and found the pits on the surface of the deposit reduced with decreasing pulse time (Fig. 2-9 and 10) [56,84]. There was a threshold value of pulse time below which bubble free deposits could be obtained and this value increased with the decrease of the current density or voltage. The applications of pulse electric field successfully encouraged the uniform dissipation of gas bubbles and minimized their coalescence to form bigger bubbles. Moreover, the gas-forming product at the electrode interface can diffuse away during the off time, thus avoiding bubble nucleation [85].
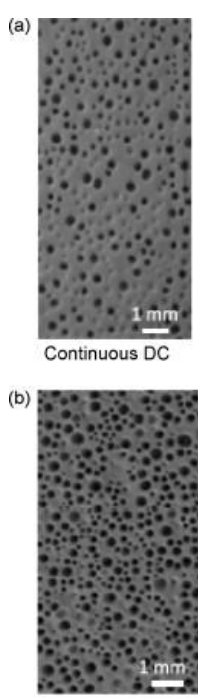

Continuous DC
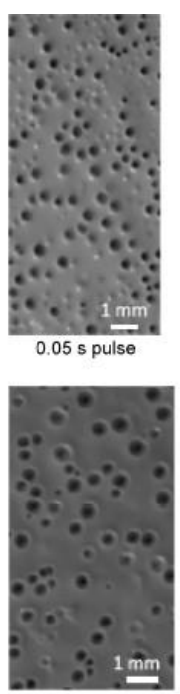

0.01 s pulse

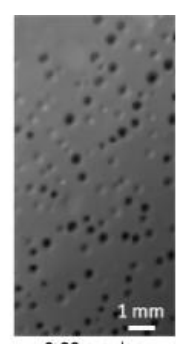

$0.03 \mathrm{~s}$ pulse

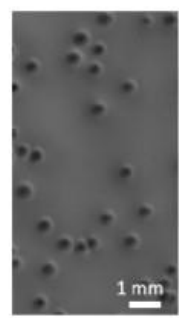

$0.005 \mathrm{~s}$ pulse
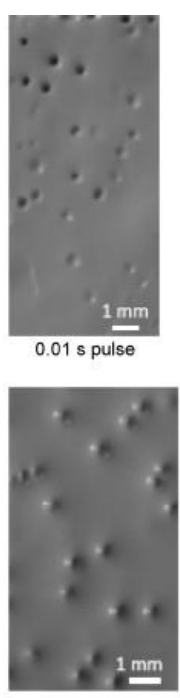

0.003 s pulse
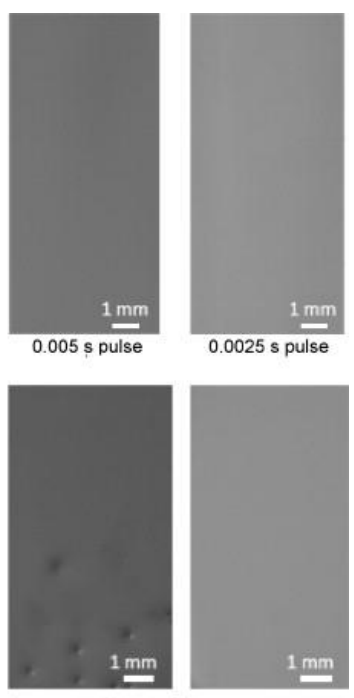

0.002 s pulse

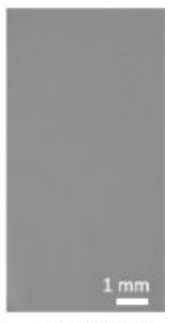

0.001 s pulse 
Fig 2-9 Surface morphology of deposits obtained by pulsed DC EPD in constant current mode (a) applied current: 0.004 A, (b) applied current: 0.006 A (suspension: 5 vol\%, pH 4.5, substrate: stainless steel (316 L), pulse ON time: $3 \mathrm{~min}$, pulse duty cycle: $50 \%$, inter-electrode distance: $20 \mathrm{~mm}$ )

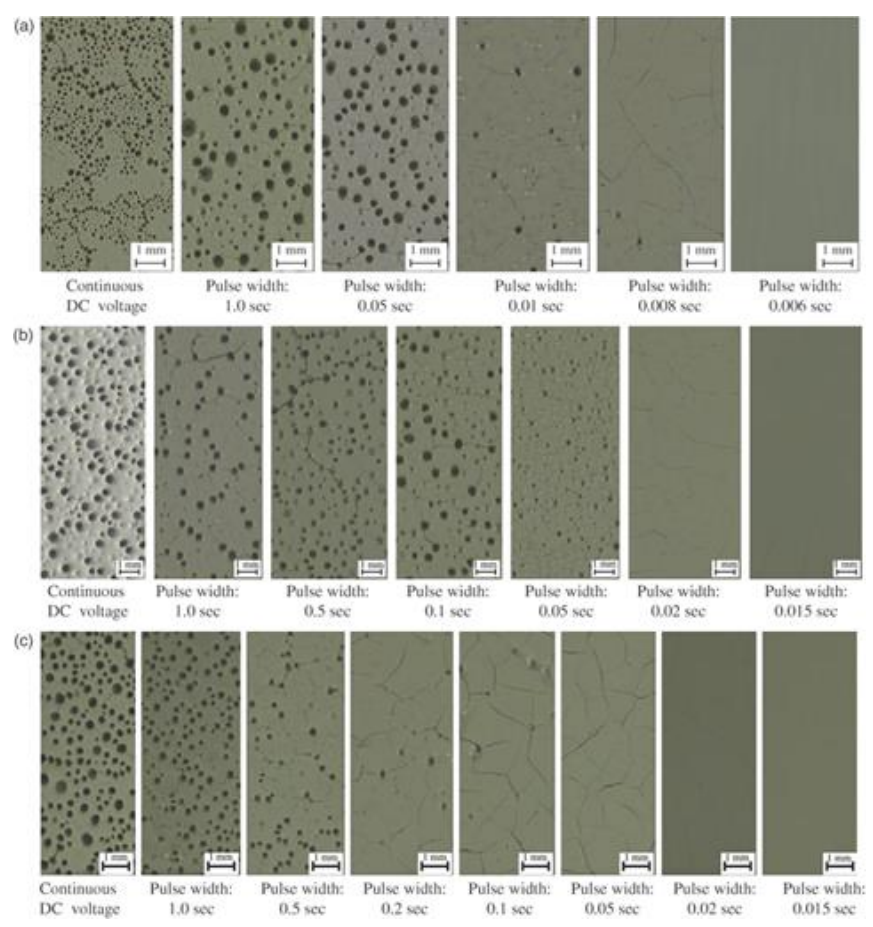

Fig 2-10 Photograph of the top surface of as-deposited alumina obtained by pulse electrophoretic deposition from a 5 vol\% suspension at pH 4.5 on (a) stainless steel (316 L) substrate (applied potential $=40 \mathrm{~V}$ ), (b) stainless steel $(316 \mathrm{~L})$ substrate (applied potential $=20 \mathrm{~V}) ;(\mathrm{c})$ nickel substrate (applied potential $=20 \mathrm{~V}$ ).

(2) Asymmetric AC electric field

Different from the direct current (DC) electric field, the alternating current (AC) one which drives the electrochemical reaction also charges the double layer. With the increase of the frequency, more current flows through the capacitance of the double layer with less gas bubbles associated with the electrochemical reaction. There is a frequency threshold value above which almost all the current flows through the double layer with negligible bubble evolution $[55,65]$. 
Neirinck. et al observed the morphologies of $\mathrm{Al}_{2} \mathrm{O}_{3}$ deposit on stainless steel from an aqueous suspension obtained by DC-EPD (Fig. 2-11b) and AC-EPD (Fig. 2-11c) using the signal shown in Fig. 2-11a [65]. It is clearly shown that the deposit obtained by DC-EPD was rough with many pits due to water electrolysis. By contrast, the surfaces of the deposit obtained by AC-EPD was homogeneous and bubble-free. It is important to note that no deposit is obtained regardless of the deposition time in a symmetric AC electric field since the net electrophoretic current is zero $[55,65]$.
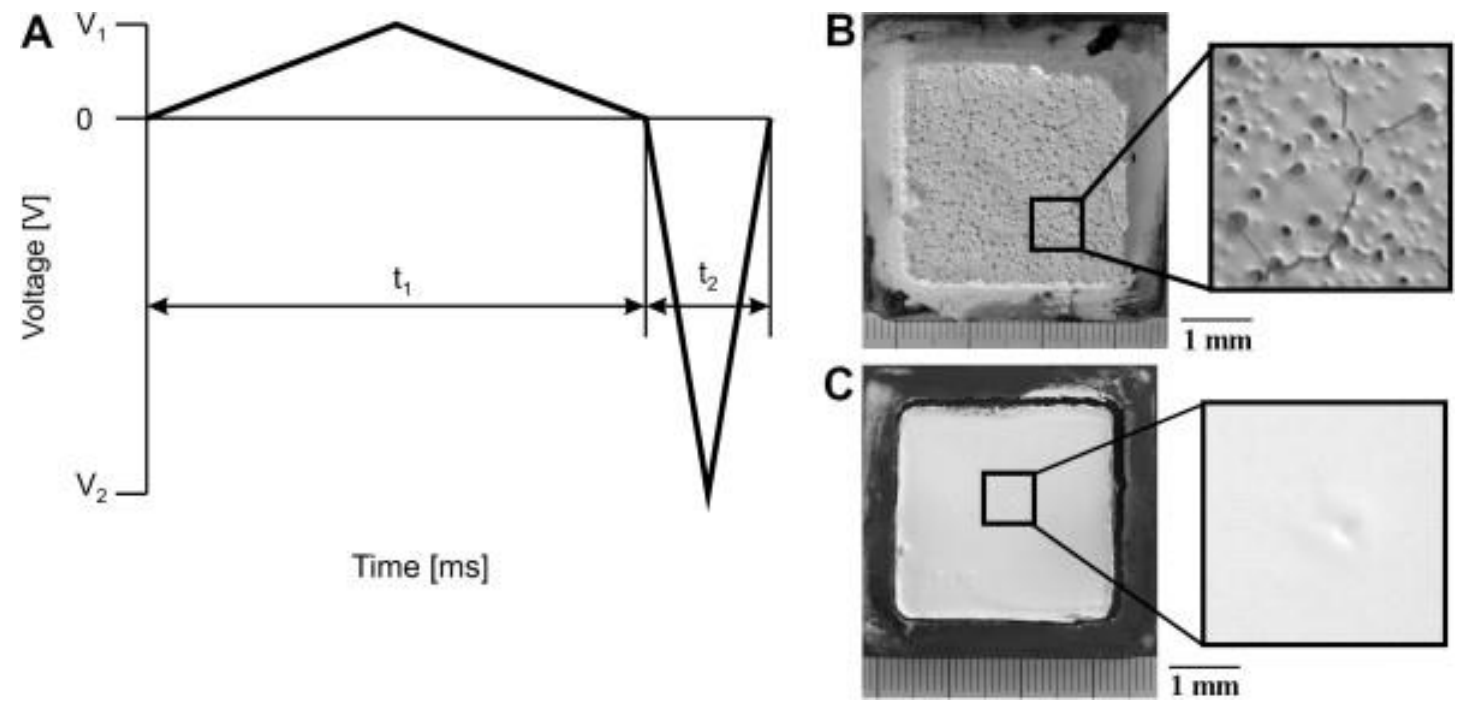

Fig 2-11 (A) One period of the applied asymmetric AC signal and $\alpha-\mathrm{Al}_{2} \mathrm{O}_{3}$ deposits formed using. (B) $100 \mathrm{~V}$ DC for $1200 \mathrm{~s}$. (C) A $50 \mathrm{~Hz} 500 \mathrm{~V}_{p-p}$ asymmetric AC field with asymmetry factor of 4.

Besides these methods summarized above, for research interest, Uchikoshi. et al observed the morphologies of green deposit on various metal substrates for research interest and found a homogeneous deposit without any defects was achieved on palladium because of its excellent hydrogen absorbability. Moreover, the green density and the properties of the deposit on a palladium substrate were the same as the other deposit [86]. 


\subsubsection{Applications of EPD in solid oxide fuel cells (SOFCs)}

Due to severe environment problem and high fuel need, the exploitation and optimization of clean and regenerative energy is one of the major challenges for the government and researchers. Solid oxide fuel cells (SOFC) have gained a lot of attention as one promisingly substitute energy source because of their advantages of excellent long time stability, high energy conversion efficiency, low operation and maintenance cost, fuel flexibility, negligible pollution, high reliability and versatility of converting chemical energy directly to electrical power [14]. Unfortunately, the high fabrication cost might hinder its application. To make SOFCs commercially competitive, the cost-effective technology, EPD, has been widely used in SOFCs fabrication process to reduce the cost. Moreover, SOFCs with the components formed by EPD show remarkable performance due to the intrinsic merits of EPD [79, 87, 88].

\subsubsection{Fabrication of electrode}

Zhitomirsky. et al reported the technological feasibility of utilization of EPD to prepare different ceramic materials for SOFC fabrication [89]. Asamoto. et al electrophoretically deposited Ni/ scandia doped ceria (SDC) anode with a thickness less than $20 \mu \mathrm{m}$ on carbon coated scandia stabilized zirconia (SSZ) [90]. Moreover, compared with the Ni/ SDC anode formed by the conventional slurry coating technology, this Ni/ SDC anode obtained by EPD was much denser and showed superior suppression ability of carbon deposition.

Santillán. et al characterized the effect of solvent, additives and iodine concentration on the stability of the suspension and the deposition rate of $\mathrm{La}_{0.8} \mathrm{Sr}_{0.2} \mathrm{Co}_{0.2} \mathrm{Fe}_{0.8} \mathrm{O}_{3-\delta}$ (LSCF) on a stainless steel plate or a carbon coated gadolinium doped ceria (GDC) substrate [72]. Also, the effect of applied voltage and deposition time on the morphology, density and thickness of the 
LSCF layer was probed. A uniform layer of LSCF with different thickness could be obtained by adjusting the parameters related to EPD process. To optimize the microstructure of the EPDed LSCF cathode, Santillán. et al also deposited LSCF/ carbon nanotube composite film on GDC substrate by EPD [91]. A highly porous LSCF cathode was successfully obtained after the carbon nanotube was burn out during the following sintering process. Moreover, lanthanum strontium manganite (LSM)-yttrium stabilized zirconia (YSZ), a mixed cathode which showd superior cathode performance than LSM, with different thickness could also be electrophoretically deposited on YSZ by adjusting deposition time or applied voltage [92].

\subsubsection{Fabrication of function layer}

Generally, a graded function layer was adopted between the electrode and the electrolyte to maximize the triple phase boundary (TPB) to further improve the electrode performance. Wang. et al electrophoretically deposited continuously graded anode function layer on Ni-YSZ anode [93]. A single cell was constructed based on this functional layer with a thickness of $9.8 \mu \mathrm{m}$ and a maximum power density of $1.10 \mathrm{~W} \mathrm{~cm}^{-2}$ was obtained at $800{ }^{\circ} \mathrm{C}$ by using LSM-YSZ and YSZ as the cathode and electrolyte, respectively. Zarabian. et al systematically evaluated the effect of different parameters, including particle concentration, NiO: YSZ ratio, type of solvents and the concentration of additives, on the stability of the suspension and the deposition rate [94]. Itagaki. et al prepared cathode/ cathode function bi-layer, LSM/LSM-YSZ, on YSZ by EPD [92]. A structure of $10 \mu \mathrm{m}$ LSM and $4 \mu \mathrm{m}$ LSM-YSZ led to the minimal polarization resistance at $600{ }^{\circ} \mathrm{C}$, suggesting the thickness of the active layer was about $4 \mu \mathrm{m}$ in the current cathode.

\subsubsection{Fabrication of electrolyte}


YSZ is the state-of-art electrolyte because of its pure ion conductivity, excellent stability in reducing and oxidizing atmosphere, long-time stability and mechanical stability [95]. SOFCs based on YSZ were usually used around $1000{ }^{\circ} \mathrm{C}$ to achieve a high efficiency [96]. However, operating at such a high temperature decreases the cell lifetime and long-time stability. The main issue in SOFCs recognized worldwide is to decrease the operating temperature to an intermediate temperature in the range of $500{ }^{\circ} \mathrm{C} \sim 800{ }^{\circ} \mathrm{C}$. The motivation of reducing the operating temperature includes lowering fabrication cost, broadening the selection scope of materials and reducing the maintenance cost. Unfortunately, the cell performance is sensitive to temperature. A decrease of $10 \%$ in temperature results in about $12 \%$ drop in cell performance due to the decrease of oxygen ion conductivity of electrolyte [97]. To address this problem, an electrolyte with a relatively low thickness, e.g., $10 \mu \mathrm{m}$, is always adopted to lower the electrolyte resistance. Table 2-1 summaries the possible coating methods to deposit thin electrolyte layer with a thickness around $10 \mu \mathrm{m}$. As shown in Table 2-1, EPD is superior to other coating technologies in terms of the fabrication cost or green-body density. To our best knowledge, Ishihara. et al is the first one to obtain the YSZ thin film by EPD [48]. A uniform YSZ layer was successfully achieved by using acetone or cyclohexanone as the solvent. The thickness of this dense YSZ layer was about $5 \mu \mathrm{m}$ after sintering at $1400{ }^{\circ} \mathrm{C}$. An open circuit voltage of $1.05 \mathrm{~V}$ and a maximum power density of $1.84 \mathrm{~W} \mathrm{~cm}^{-2}$ were achieved at $1000{ }^{\circ} \mathrm{C}$ by using LSM and $\mathrm{Pt}$ as the cathode and anode, respectively. Xu. et al systematically studied the effect of solvent, powder concentration, current density and deposition time on the quality and weight of YSZ layer [98]. Besra and Liu demonstrated the feasibility of direct deposition of YSZ on non-conductive porous NiO-YSZ substrate by coating a thin layer of carbon on the other side of NiO-YSZ substrate [71, 82]. The porosity of NiO-YSZ substrate was required to be higher than a threshold value to 
provide a connected electric path. And the threshold value was reversely proportional to applied voltage. Moreover, Chen. et al reported the deposition of YSZ on LSM or LSM-YSZ substrate [49]. The application of EPD of YSZ could be also found in literature [7, 99, 100].

The other method to minimize the ohmic resistance is or replace YSZ by other electrolyte material with superior ionic conductivity. It has been reported that $\mathrm{LaGaO}_{3}$-based oxides and ceria-based oxides exhibit higher ion conductivity than YSZ [101, 102]. Bozza. et al reported a dense $\mathrm{La} 0.8 \mathrm{Sr}_{0.2} \mathrm{Ga}_{0.8} \mathrm{Mg}_{0.2} \mathrm{O}_{2.8}$ (LSGM) with a thickness of $20 \mu \mathrm{m}$ on porous $\mathrm{Ce}_{0.6} \mathrm{La}_{0.4} \mathrm{O}_{1.8}$ (LDC) was obtained by EPD followed by sintering at $1490{ }^{\circ} \mathrm{C}$ [103]. Moreover, a maximum power density of $0.78 \mathrm{~W} \mathrm{~cm}^{-2}$ at $700{ }^{\circ} \mathrm{C}$ was obtained by using Ni-LDC and $\mathrm{La} 0.8 \mathrm{Sr}_{0.2} \mathrm{Co}_{0.2} \mathrm{Fe}_{0.8} \mathrm{O}_{3-\delta}$ (LSCF) as the anode and cathode, respectively [87]. Hu. et al achieved a dense GDC layer with a thickness about $8 \mu \mathrm{m}$ by EPD after sintering $1300{ }^{\circ} \mathrm{C}$ with the aid of 2 at $\% \mathrm{FeO}_{1.5}$ as sintering aid [53]. Moreover, the ohmic resistance of the GDC layer obtained by EPD was smaller than that with the same thickness made by conventional spin coating method because of larger density of GDC layer and the better adhesion between YSZ and GDC.

\subsubsection{Fabrication of barrier layer}

The conventional SOFC consists of NiO-YSZ anode, YSZ electrolyte and lanthanum strontium manganite (LSM) cathode. LSM cathode shows relatively good stability under oxidizing atmospheres, high electronic conductivity and a coefficient of thermal expansion (CTE) matching well with YSZ. However, its oxygen ion conductivity and oxygen trace diffusion coefficient are extremely low. Hence, the LSM cathode is always replaced by a mixed ionelectron conductive material, e.g., LSCF, to enhance the performance of the cathode. Unfortunately, the reaction between YSZ and LSCF, which yields some insulating phases, 
impairs the cell performance. To address this problem, a dense barrier layer for doped ceria is adopted between YSZ and LSCF to eliminate the reaction, as well as to boost the cell performance [104] because of its good chemical and thermal compatibility. Matsuda. et al reported the fabrication of YSZ/ SDC bi-layer on NiO-YSZ by EPD followed by co-sintering with NiO-YSZ substrate [12]. By using LSCF as the cathode, a maximum power density larger than $0.6 \mathrm{~W} \mathrm{~cm}^{-2}$ was obtained at $700{ }^{\circ} \mathrm{C}$ with this bi-layer composing of $4 \mu \mathrm{m} \mathrm{YSZ}$ and $1 \mu \mathrm{m}$ SDC. Suzuki. et al demonstrated the fabrication of GDC/LSGM/GDC tri-layer on NiO-YSZ [105]. Moreover, this tri-layer electrolyte could be easily sintered together along with NiO-YSZ anode without cracking.

\subsubsection{Fabrication of interconnect coating}

As the output voltage of one single SOFC cell is around $1 \mathrm{~V}$, to provide a reasonable voltage, multiple cells are usually connected together acted as a SOFC stack by interconnects joining the anode and cathode of adjacent single cell [106]. Metallic alloys are superior to the commonly used ceramic interconnects because of their high oxidation resistance when the operating temperature of SOFC stacks is in the range of $600{ }^{\circ} \mathrm{C} \sim 800{ }^{\circ} \mathrm{C}$ [107]. Ferritic stainless steel is a promising connect candidate [108]. However, it's susceptible to rapid chromia growth which impairs the cell performance. This limitation can be addressed by applying protective coatings. A dense, uniform and well-adherent $\mathrm{Mn}$ - Co spinel coating was successfully prepared by EPD after sintering at $1150{ }^{\circ} \mathrm{C}$ and it showed excellent compatibility with Crofer 22 APU metal interconnect and the glass-ceramic sealant in the long-time stability test of $2500 \mathrm{~h} \mathrm{[109].}$ Moreover, Zhang. et al evaluated the effect of voltage on the ratio of Co : Mn and the effect of sintering atmosphere on morphology, area specific resistance (ASR) and the stability of the deposited $\mathrm{Co}-\mathrm{Mn}$ spinel coating, and found the $\mathrm{Co}-\mathrm{Mn}$ spinel coating sintering in $\mathrm{H}_{2} / \mathrm{H}_{2} \mathrm{O}$ 
resulted in a lower ASR and a much better long-time stability than that sintering in air [110]. Other spinel coating deposited by EPD could also be found in the literature [111-113].

\subsubsection{Fabrication of semi cell or full cell}

It is important to note that a semi cell or a full cell could also be fabricated by subsequent deposition followed by one-time sintering. Bresa. et al electrophoretically deposition a semi-cell with the construction of NiO-YSZ/ YSZ [114]. A peak power density of $434 \mathrm{~mW} \mathrm{~cm}^{-2}$ was achieved by using LSM as the cathode. A full cell with the construction of NiO-YSZ/YSZ/LSM was fabricated by subsequent deposition of YSZ and NiO-YSZ on a LSM substrate followed by one-time co-sintering [115]. This significantly reduces the fabrication cost by minimizing the sintering time.

Table 2 summaries the application of EPD to in SOFCs' fabrication. Moreover, EPD can also be applied for tubular SOFCs fabrication $[67,115]$ as it allows coating of non-planar surface. 
Table 2-2 The application of EPD in SOFCs

\begin{tabular}{|c|c|c|c|c|c|}
\hline Component & Film & Substrate & Solvent & Additives & Reference \\
\hline \multirow{10}{*}{ Electrolyte } & YSZ & NiO-YSZ & Distilled water & $\begin{array}{c}\text { PAA- } \\
\mathrm{NH}_{4}(\text { Ammoniu } \\
\text { m polyacrylate) }\end{array}$ & [99] \\
\hline & YSZ & $\mathrm{NiO}-\mathrm{YSZ}$ & Ethanol & PEI & [78] \\
\hline & YSZ & $\mathrm{NiO}-\mathrm{YSZ}$ & Ethanol & Iodine & [7] \\
\hline & YSZ & LSM & Acetone & Iodine & {$[49,116]$} \\
\hline & SSZ & NiO-SSZ & Acetyl acetone & Iodine & [117] \\
\hline & GDC & YSZ & Ethanol & Iodine & [53] \\
\hline & YSZ/SDC & $\mathrm{NiO}-\mathrm{YSZ}$ & Ethanol & PVB & [12] \\
\hline & LSGM & LDC & Acetone & Iodine & {$[103,118]$} \\
\hline & GDC/LSGM/GDC & NiO-YSZ & Ethanol & PEI & [105] \\
\hline & $\begin{array}{c}\mathrm{BCY} 10 \\
\left(\mathrm{BaCe}_{0.9} \mathrm{Y}_{0.1} \mathrm{O}_{3-\mathrm{X}}\right)\end{array}$ & NiO-BCY10 & Acetyl acetone & Iodine & [119] \\
\hline \multirow{4}{*}{ Anode } & $\mathrm{NiO}-\mathrm{YSZ}$ & Stainless steel & Ethanol & Iodine & [94] \\
\hline & NiO-YSZ & NiO-YSZ & Acetone & Iodine & [93] \\
\hline & $\mathrm{Ni}-\mathrm{SDC}$ & SSZ & Acetyl acetone & Iodine & [90] \\
\hline & $\mathrm{Sr}_{2} \mathrm{FeMoO}_{6}$ & Stainless steel & $\begin{array}{c}\text { Acetyl acetone }+ \\
\text { Ethanol }\end{array}$ & PEI or Iodine & [120] \\
\hline \multirow{3}{*}{ Cathode } & LSM+ YSZ / LSM & YSZ & Acetyl acetone & Iodine & [92] \\
\hline & LSCF & GDC & Ethanol or Acetone & Iodine & [72] \\
\hline & LSCF+ carbon & GDC & Acetyl acetone & Iodine & [91] \\
\hline
\end{tabular}




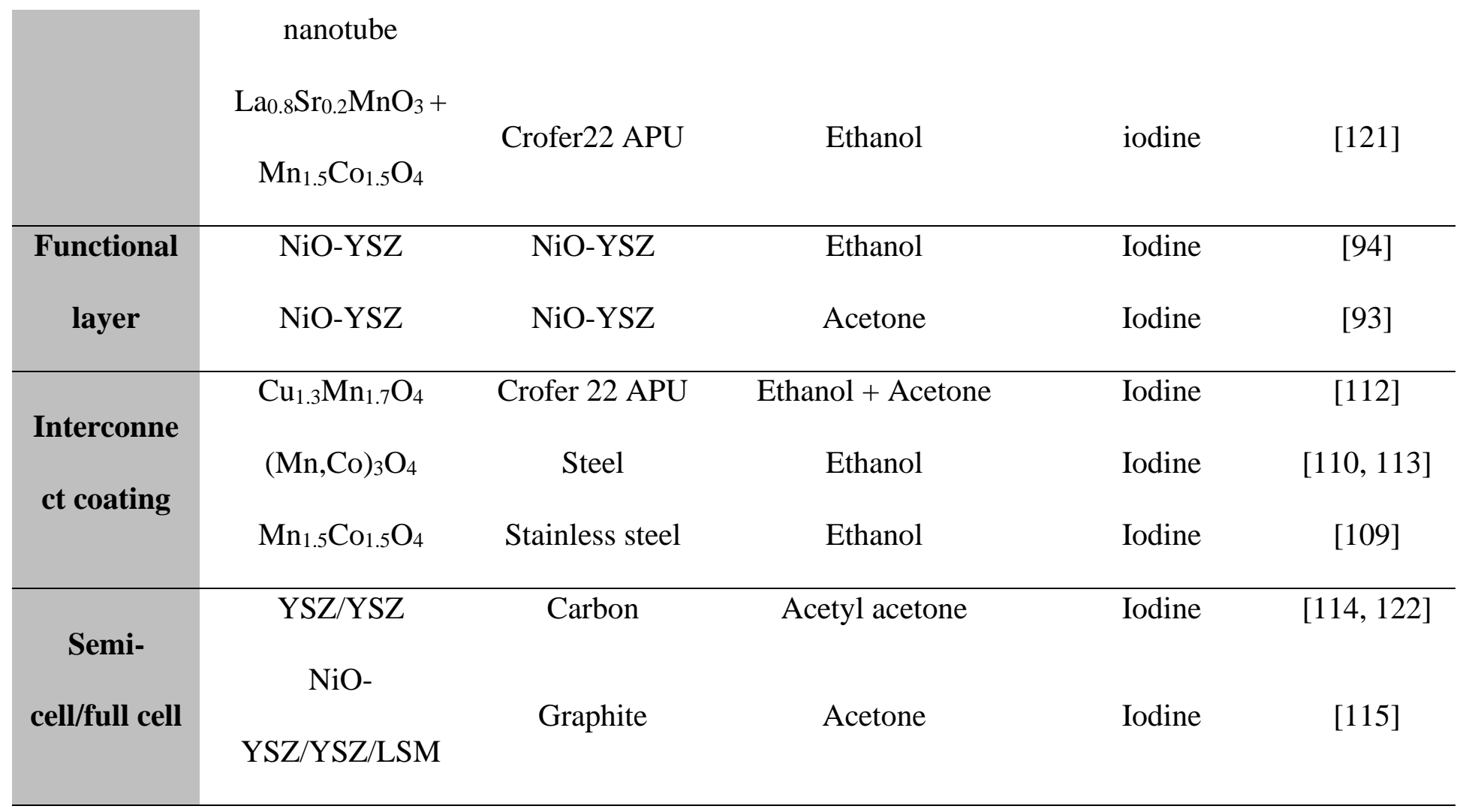




\section{Chapter 3 Research Objectives}

The study plans to electrophoretically deposit GDC on a non-conductive YSZ substrate, and to accomplish the following objectives:

Realize the deposition of GDC on YSZ and obtain a dense GDC layer with controllable thickness, desirable density and good adhesion with YSZ substrate after sintering at a relatively low temperature, e.g., $1300^{\circ} \mathrm{C}$.

- Prepare a stable suspension

- Make non-conductive YSZ substrate conductive

- Optimize the working parameters

- Compared with the GDC layer formed by classic spin coating

Characterize the fundamental aspects of EPD including the deposition rate, increasing resistance, deposition efficiency and the competitive role between electrochemical reaction and deposition.

- Probe the main reason resulting in the increasing resistance

- Characterize the relationship between the deposition and electrochemical reaction

- Study the EPD mechanism

Further decrease the densification temperature of GDC to a lower temperature, e.g., 1250 ${ }^{\circ} \mathrm{C}$, by using AC power supply to eliminate the bubble evolution. 
- Obtained bubble free and homogeneous GDC layer by EPD

- Optimize the working parameters

- AC-EPD mechanism study

Obtain a bubble free and homogeneous GDC layer from aqueous suspensions.

- Prepare a stable aqueous suspension

- Characterize the effect of parameters associated with AC signal on the green density of GDC layer 


\section{Chapter 4 Direct Current Electrophoretic Deposition (DC-EPD) of}

\section{Gadolinium-doped Ceria as a Barrier Layer on Yttrium-stabilized}

\section{Zirconia Electrolyte}

\subsection{Introduction}

The prerequisite of EPD is that the substrate must be electronically conductive. To meet this requirement, many attempts have been done by co-workers $[7,78,123,124]$. To make NiO-YSZ conductive, Hosomi [7] and Li [123] coated the material with a thin layer of graphite before EPD; the graphite was burnt out during sintering leaving a dense YSZ layer on the NiO-YSZ pellet. Liu [124] coated a layer of graphite on one side of the porous NiO-YSZ pellet where the connected pores worked as a "current path" through the substrate and then deposited YSZ on the other side without carbon deposit. Will [78] sintered NiO-YSZ substrate in a reducing atmosphere to reduce $\mathrm{NiO}$ to $\mathrm{Ni}$ before EPD. And Yamaji [125] mixed base powder with graphite powder to make a conductive substrate on which to carry out the EPD experiments. In recent years, conductive polymers, such as PPy, have been used in the EPD process [126, 127]. Suzuki et al. electrophoretically deposited GDC/LSGM/GDC tri-layers on polypyrrole coated NiO-YSZ pellet [105]. Such polymers can be synthesized and attached readily to the surface of substrates by chemical polymerization with the aid of some oxidants [126]. In this regard, a thin layer of conductive polymer, PPy, is adopted as the conductive agent to facilitate the EPD process on YSZ substrates in our experiment. The maximum conductivity of PPy is $48 \mathrm{~S} \mathrm{~cm}^{-1}$ $[128,129]$ which is far less than that of commonly used electrodes, e.g., a graphite plate or a metal plate, about $10^{3} \mathrm{~S} \mathrm{~cm}^{-1}$. It has been shown that the conductivity of the electrode plays an important role in the deposition rate and the uniformity of the deposit $[116,130]$. However, to 
the best of our knowledge, there are few reports focusing on the systematic study of EPD behaviour on a poor conductor, e.g., PPy. To enhance EPD techniques for the fabrication of GDC barrier layer in SOFCs and to deepen the understanding of EPD, the feasibility and behaviour of EPD of GDC on PPy coated YSZ is also systematically investigated in the chapter.

\subsection{Experimental details}

\subsubsection{EPD coating}

YSZ pellet was made by pressing $2.5 \mathrm{~g}$ YSZ powders (TZ-8Y, Tosho) in a $31 \mathrm{~mm}$ mold and sintered it at $1400{ }^{\circ} \mathrm{C}$ for $4 \mathrm{~h}$. Prior to use, a thin layer of conductive polymer, PPy, was chemically synthesized on both sides of YSZ pellet to make it conductive. 0.002 mol of 2, 6naphthalenedisulfonic acid disodium salt (Sigma-Aldrich, 97\%) and 0.002 mol of ammonium persulfate (Sigma-Aldrich, 98\%) were dissolved in $300 \mathrm{~mL}$ of distilled water and stirred for 20 min. Then YSZ pellet was soaked in the solution and $6 \mathrm{ml}$ of pyrrole (Sigma-Aldrich, 98\%) was added. Synthesis took $6 \mathrm{~h}$ to complete. Next, the YSZ pellet was removed from the solution and dried at room temperature. The conductivity of PPy depends on the polymerization temperature. with highest conductivity obtained at about $0^{\circ} \mathrm{C}[131]$. Therefore, the temperature was kept at 0 ${ }^{\circ} \mathrm{C}$ throughout the process. The synthesized polymer was examined by Fourier transform infrared spectroscopy (FTIR) using an FTS 7000 FTIR spectrometer.

The stable suspension was prepared by adding $1.0 \mathrm{~g}$ iodine (Sigma-Aldrich, 98\%) and $2.5 \mathrm{~g}$ GDC powder (Fuel cell material, with a surface area of $12.0 \mathrm{~m}^{2} / \mathrm{g}$ ) in $100 \mathrm{ml}$ ethanol (Carolina, 95\%) and dispersed for 45 mins using ultrasonic stirring. According to Panigrah's study [132], GDC particles in the suspension were positively charged because of the absorbed hydrogen ions and deposit on the cathodic electrode under the effect of an electric field. The Zeta-potential of 
the suspension was $+18 \mathrm{mV}$ measured by Zetasizer Nano ZS which indicated the suspension was stable. The polymer coated YSZ pellet acting as the cathode was placed $1 \mathrm{~cm}$ away from the counter electrode (graphite plate). The formed GDC layer along with YSZ was sintered at 1300 ${ }^{\circ} \mathrm{C}$ for $4 \mathrm{~h}$.

\subsubsection{Characterization}

The obtained GDC layer was checked by scanning electron microscope (SEM, Hitachi S-4700) and X-ray diffraction (XRD, PANalytical X'pert $\mathrm{PRO}, \mathrm{Cu} \mathrm{K} \alpha$ radiation).

As shown in Mishra's work [133], $30 \mu \mathrm{L}$ of solvent in the vicinity of the cathode was taken out by micro-pipette with a sharp tip at different time intervals during the EPD process. Then the solvent was dropped onto an ion sensitive field effect transistor (IS-FET) pH meter (Model No: Hach H138). The $30 \mu \mathrm{L}$ of solvent is enough to obtain accurate $\mathrm{pH}$ values.

To characterize the ohmic resistance of the blank EPD cell, EIS tests were carried out using a Metrohm Autolab test station (AUT85484) with a frequency range from $100 \mathrm{~Hz}$ to $100 \mathrm{KHz}$ and an input sinewave with an amplitude of $10 \mathrm{mV}$. The voltage and the current were recorded during the deposition process. The quantity of deposit was determined by weighing the deposition electrode after drying at $100{ }^{\circ} \mathrm{C}$ in air for $24 \mathrm{~h}$. Every reported data is an average of three measurements.

\subsubsection{Cell fabrication}

Symmetric cells were prepared with the LSCF cathode. $20 \mu \mathrm{m}$ of LSCF was coated on both sides of a GDC/YSZ/GDC tri-layer electrolyte by spin coating and then sintered at $1050{ }^{\circ} \mathrm{C}$ for $2 \mathrm{~h}$. The cell area was $0.51 \mathrm{~cm}^{2}$. A thin layer of platinum (Fuel cell material) was coated on LSCF as the current collector. The microstructure of the synthesized polymer and deposited GDC was 
examined by scanning electron microscope (SEM). EIS tests were carried out in air at temperatures ranging from $600{ }^{\circ} \mathrm{C}$ to $800{ }^{\circ} \mathrm{C}$ using a Metrohm Autolab test station (AUT85484). The frequency scope was $0.1 \mathrm{~Hz}$ to $100 \mathrm{KHz}$, and the amplitude of the input sinewave was 10 $\mathrm{mV}$.

\subsection{Results}

\subsubsection{Stable suspension}

GDC particles are positively charged because of the absorbed $\mathrm{H}^{+}$ions produced by the following reaction:

$$
\mathrm{CH}_{3} \mathrm{CH}_{2} \mathrm{OH}+\mathrm{I}_{2} \rightarrow \mathrm{H}^{+}+\mathrm{I}^{-}+\mathrm{CH}_{3} \mathrm{CH}_{2} \mathrm{OI}
$$

Hence, the amount of iodine plays an important role on zeta potential and the deposition rate. By fixing the GDC concentration at $15 \mathrm{~g} \mathrm{~L}^{-1}$, the effect of the amount of iodine on the deposition rate and zeta potential was characterized. As depicted in Fig. 4-1, with the increase of iodine concentration, the zeta potential grows while the deposit mass decreases. The suspension with a zeta potential about $20 \mathrm{mV}$ is stable enough to carry out EPD experiments when the iodine

concentration reaches $10 \mathrm{~g} \mathrm{~L}^{-1}$. To achieve a relatively fast deposition rate, the iodine concentration is fixed as $10 \mathrm{~g} \mathrm{~L}^{-1}$ in the following experiments. 


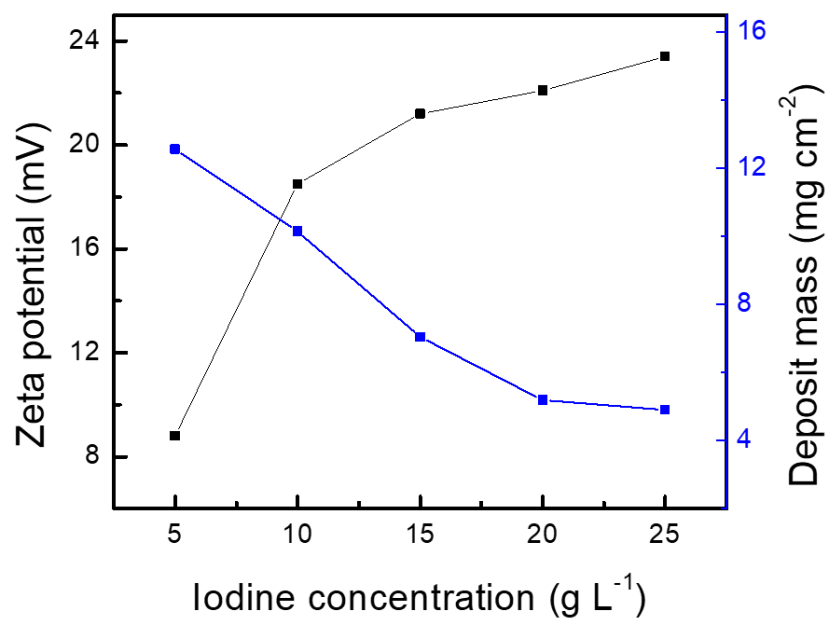

Fig 4-1 Zeta potential and the deposit mass on PPy coated YSZ for 5 mins as a function of the concentration of iodine under constant voltage $(60 \mathrm{~V})$

Fig. 4-2 shows the macroscopy and XRD pattern of the deposited GDC layer on the 316L stainless steel plate. As shown in Fig. 4-2a, the green GDC layer formed on stainless steel is uniform. Before sintering, XRD was carried out to confirm the successful obtainment of GDC layer on the stainless plate.
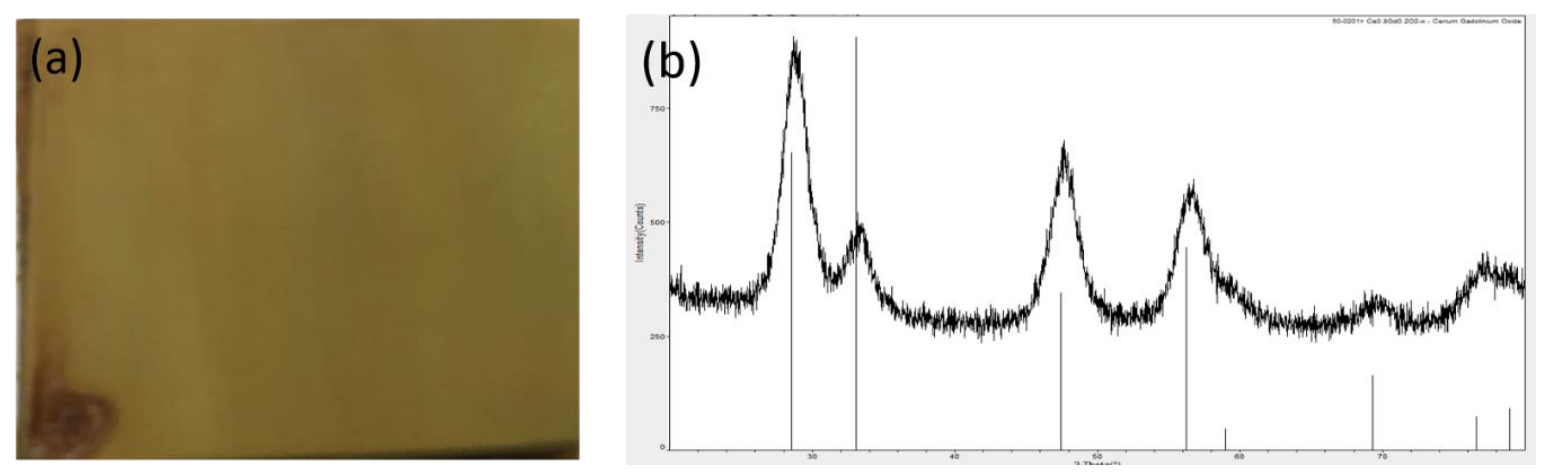

Fig 4-2 Macroscopy and XRD pattern of the deposited GDC layer

\subsubsection{Characterization of conductive polypyrrole}

As YSZ is not electrically conductive, no deposit is found on YSZ regardless of the deposition time. To make YSZ, a thin layer of conductive polymer, PPy, was chemically synthesized on 
both sides of YSZ pellet to make it conductive. The synthesis process was shown in Fig. 4-3. As shown in Fig. 4-3, 0.002 mol of 2, 6-naphthalenedisulfonic acid disodium salt (Sigma-Aldrich, 97\%) and $0.002 \mathrm{~mol}$ of ammonium persulfate (Sigma-Aldrich, 98\%) were dissolved in $300 \mathrm{~mL}$ of distilled water and stirred for $20 \mathrm{~min}$. Then YSZ pellet was soaked in the solution and $3 \mathrm{ml}$ of pyrrole (Sigma-Aldrich, 98\%) was added. After $24 \mathrm{~h}$, the PPy coated YSZ pellet was taken out. Then EPD was carried out by using this PPy coated YSZ as the cathode under a constant voltage of $60 \mathrm{~V}$. The cross-section and surface morphology of GDC layer was shown in Fig. 4-4. It was clearly shown that the thickness of the polymer and the GDC layer are about 300um and 10um, respectively and there are many cracks. This thick film with poor conductivity suggests the failed synthesize of PPy, which might be ascribed to the insufficient pyrrole added in this solvent and inaccurately experimental temperature.

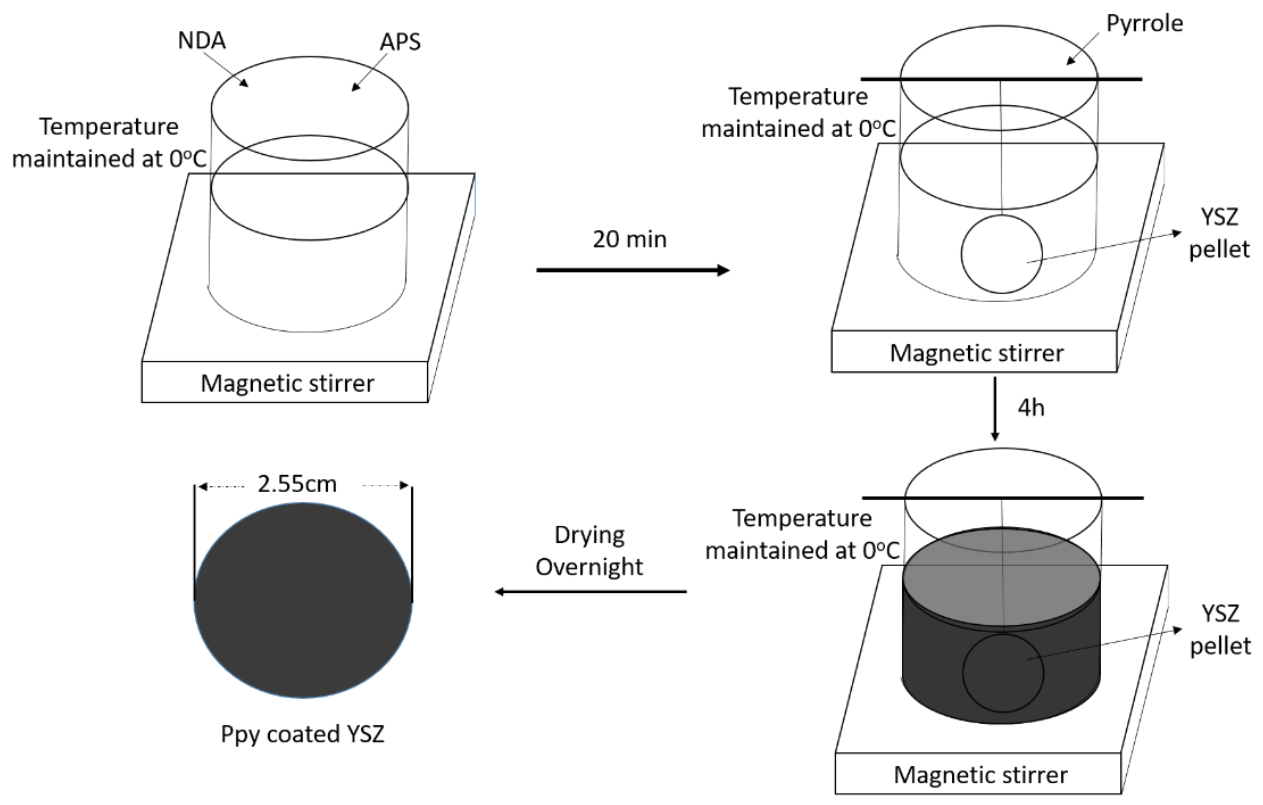

Fig 4-3 Schematic of polypyrrole synthesis process 

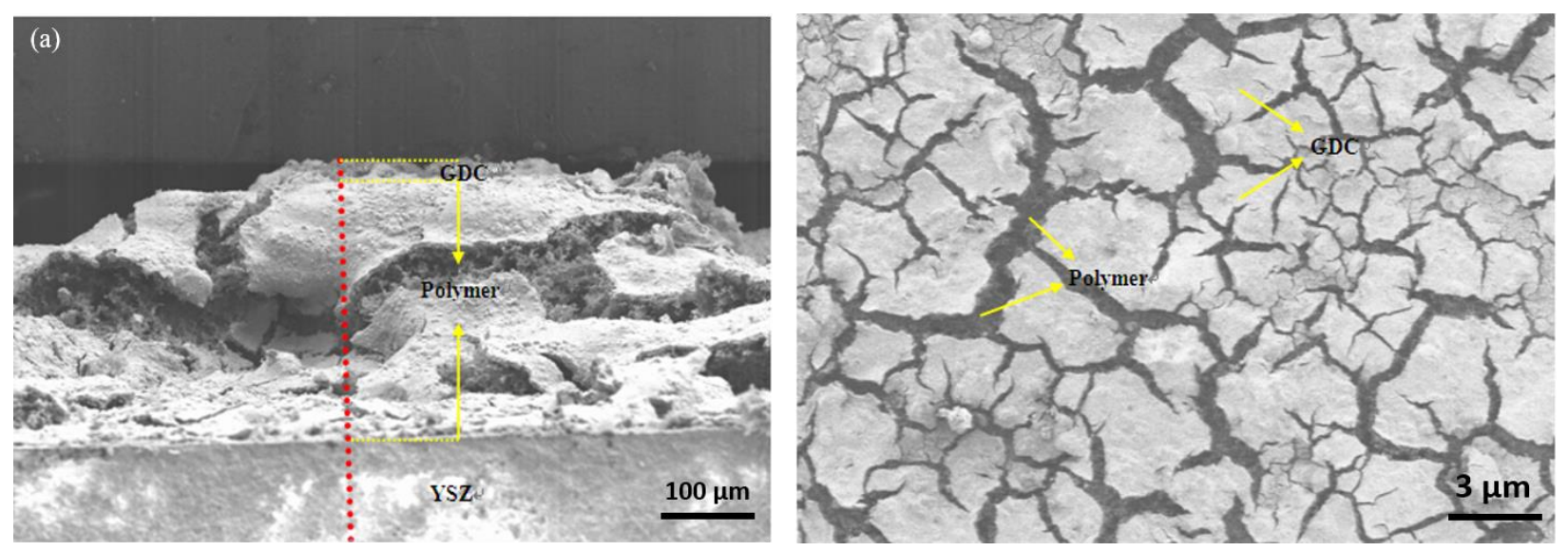

Fig 4-4 (a) Cross-section and (b) surface morphology of GDC layer on YSZ substrate

To improve the quality of polypyrrole synthesized, more $(6 \mathrm{~mL})$ polypyrrole was added in the solvent and the temperature was accurately kept at $0{ }^{\circ} \mathrm{C}$.

Fig. 4-5 shows the FTIR spectra of synthesized PPy coated on a YSZ pellet. The characteristic peaks at $1580 \mathrm{~cm}^{-1}, 1484 \mathrm{~cm}^{-1}$ are attributed to C-C stretching of pyrrole ring [134]. The peak at $1340 \mathrm{~cm}^{-1}$ corresponds to the $\mathrm{C}-\mathrm{N}$ stretching vibration in the ring. The band of $\mathrm{C}-\mathrm{H}$ and $\mathrm{N}-\mathrm{H}$ inplane deformation vibrations appears at $1226 \mathrm{~cm}^{-1}$ and $1099 \mathrm{~cm}^{-1}$ respectively. The peak at 931 $\mathrm{cm}^{-1}$ is assigned to the presence of $\mathrm{C}-\mathrm{H}$ out of plane deformation. The band associated with C-C out of plane ring vibration is situated at $665 \mathrm{~cm}^{-1}[135]$. The peaks observed in the present work match well with the reported results in the literature [134, 135], confirming the formation of PPy.

Fig. 4-6a and $b$ show the surface and cross-sectional morphology of the synthesized polymer. The cross-sectional view (Fig. 4-6a) reveals that the synthesized polymer is uniform, with a thickness less than $1 \mu \mathrm{m}$. The YSZ grain boundaries can be easily seen form the top view (Fig. 4-6b). According to Nicholson's study [131], the electrical conductivity of PPy synthesized at 0 ${ }^{\circ} \mathrm{C}$ is about $24 \mathrm{~S} \mathrm{~cm}^{-1}$. The PPy synthesized in this study was measured to be $18 \mathrm{~S} \mathrm{~cm}^{-1}$, in consistence with that report value. As the polymer is burnt out at $700{ }^{\circ} \mathrm{C}$ during sintering [126], a 
carefully adjusted heating process, a slow heating rate of $1.0^{\circ} \mathrm{C} / \mathrm{min}$ from $650{ }^{\circ} \mathrm{C}$ to $750{ }^{\circ} \mathrm{C}$ and a 30 min dwelling at $750^{\circ} \mathrm{C}$, was used to ensure a complete but non-destructive removal of the polymer after the deposition of GDC.

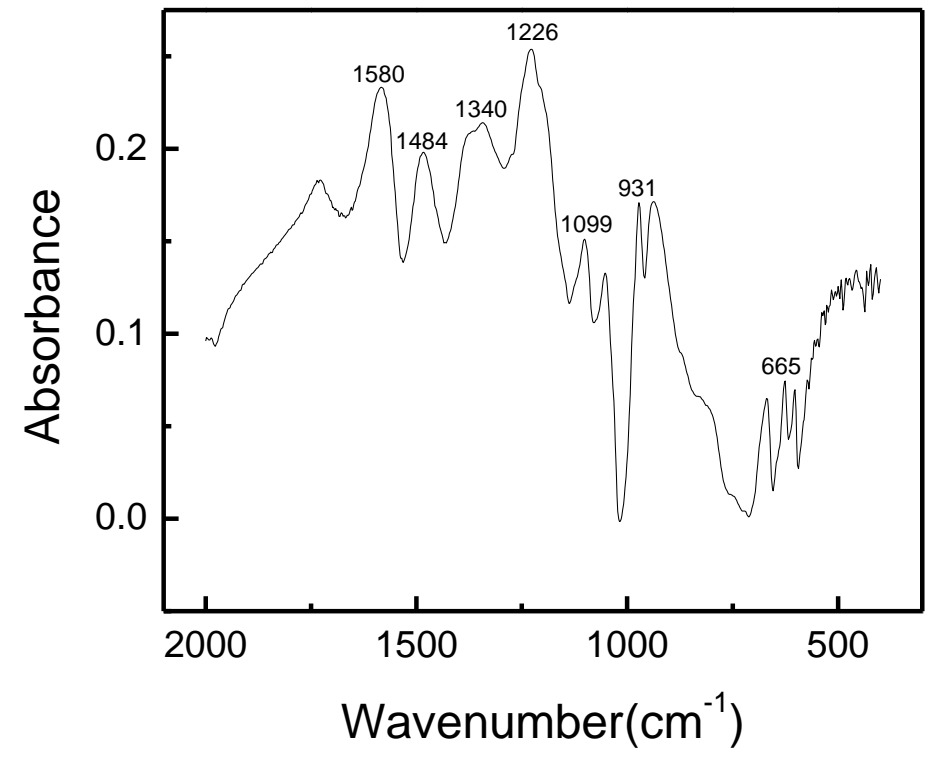

Fig 4-5 FTIR spectra of synthesized PPy
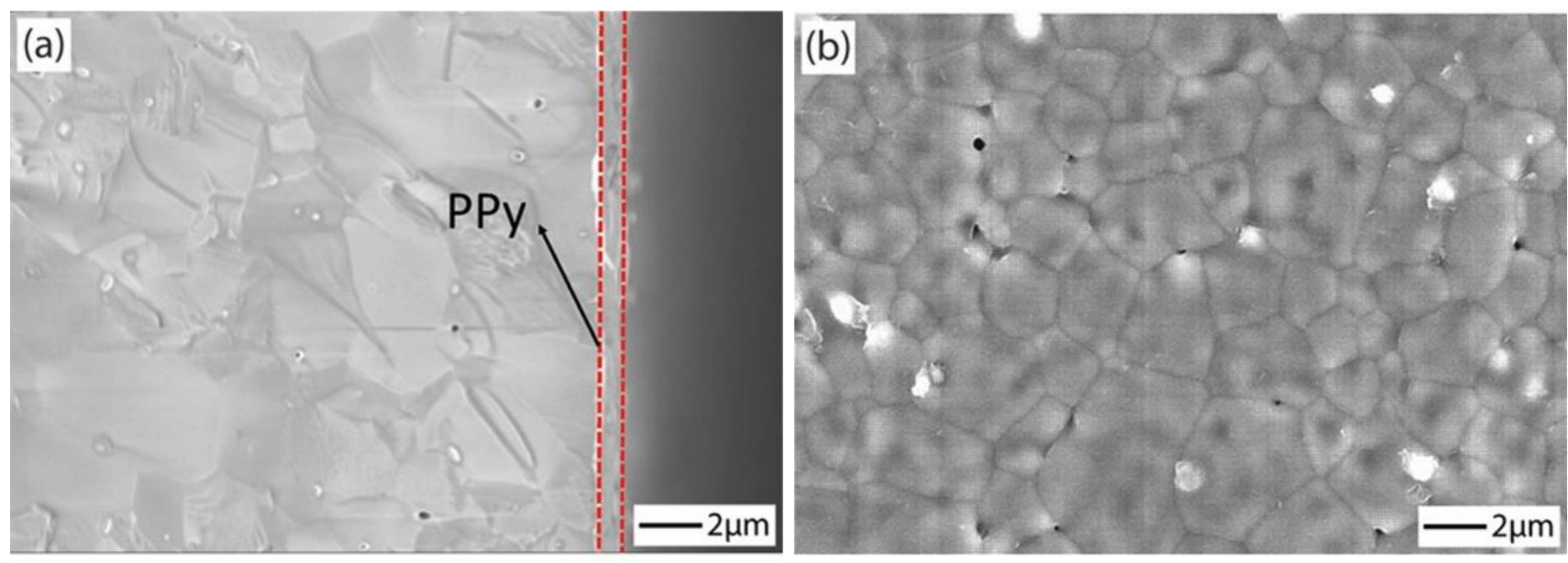

Fig 4-6 (a) Cross-section and (b) surface morphology of PPy coated on YSZ 
Fig. 4-7 shows the EIS spectra of the suspension using graphite or PPy coated YSZ as the working electrode. The Nyquist plot for the graphite contains a single arc which can be fitted with a $R_{s}\left(R_{p} Q\right)$ equivalent circuit, where $R_{s}$ is the ohmic resistance of the suspension, $R_{p}$ is the polarization resistance of faradic current at the electrode surfaces, and Q is the constant phase element of the interfaces with double layers. The ohmic resistance due to the $1 \mathrm{~cm}$ of solution between these two electrodes is obtained by fitting the arc to an equivalent circuit (series resistance, parallel resistance and constant phase element) and is about $450 \Omega\left(1800 \Omega \mathrm{cm}^{2}\right)$. The Nyquist plot for the PPy coated YSZ electrode shows the beginning of an unresolved arc or possibly a Warburg impedance. The high frequency intercept is about $2500 \Omega\left(10 \mathrm{k} \Omega \mathrm{cm}^{2}\right)$. This much higher value reflects the poor conductivity of the thin PPy layer. Hence, the contact resistance of PPy is about $2050 \Omega\left(8200 \Omega \mathrm{cm}^{2}\right)$.

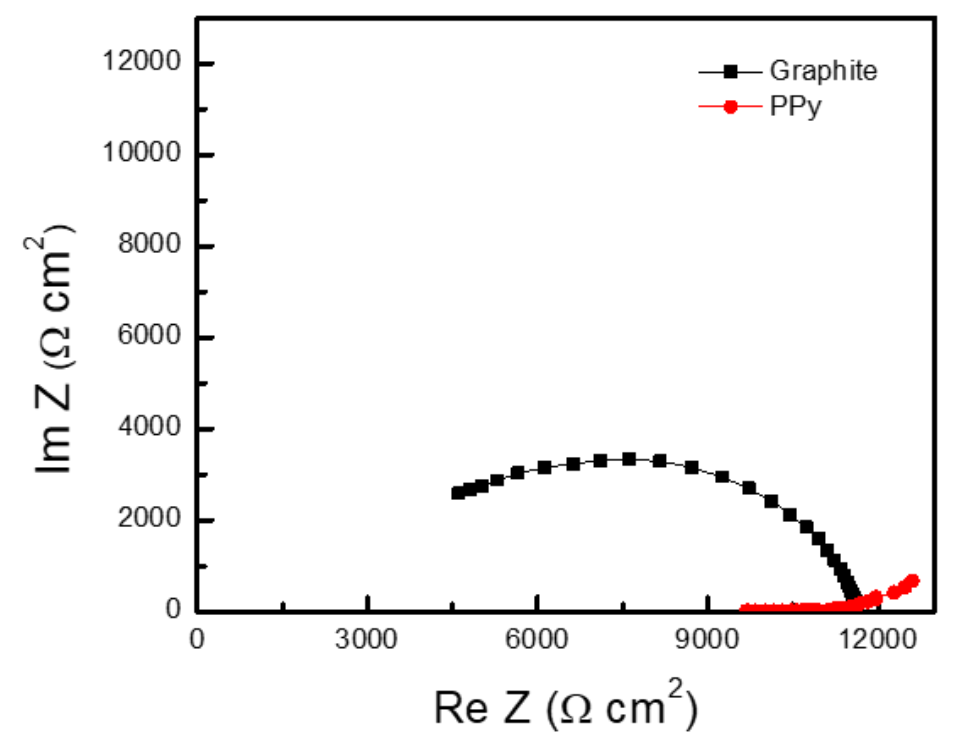

Fig 4-7 EIS spectra of the suspension using graphite and PPy coated YSZ as the working electrode. 


\subsubsection{Deposition of GDC on PPy coated YSZ}

Fig. 4-8a shows the deposit yield as a function of time under constant voltage $(60 \mathrm{~V})$ by using the graphite plate and the PPy coated YSZ as the cathode, respectively. As shown in Fig. 4-8a, the deposition yield on graphite is proportional to time during the initial deposition time (i.e., 50 s), then quickly approaches a plateau. In contrast, the deposition yield on PPy coated YSZ is almost linear with respect to time. Moreover, the deposition rate of GDC on the PPy coated YSZ is much slower than that on the graphite plate at $60 \mathrm{~V}$. Fig. $4-8 \mathrm{~b}$ shows the corresponding time dependence of current density. The current density using the graphite plate is initially larger than that using the PPy coated YSZ cathode and decays with time.
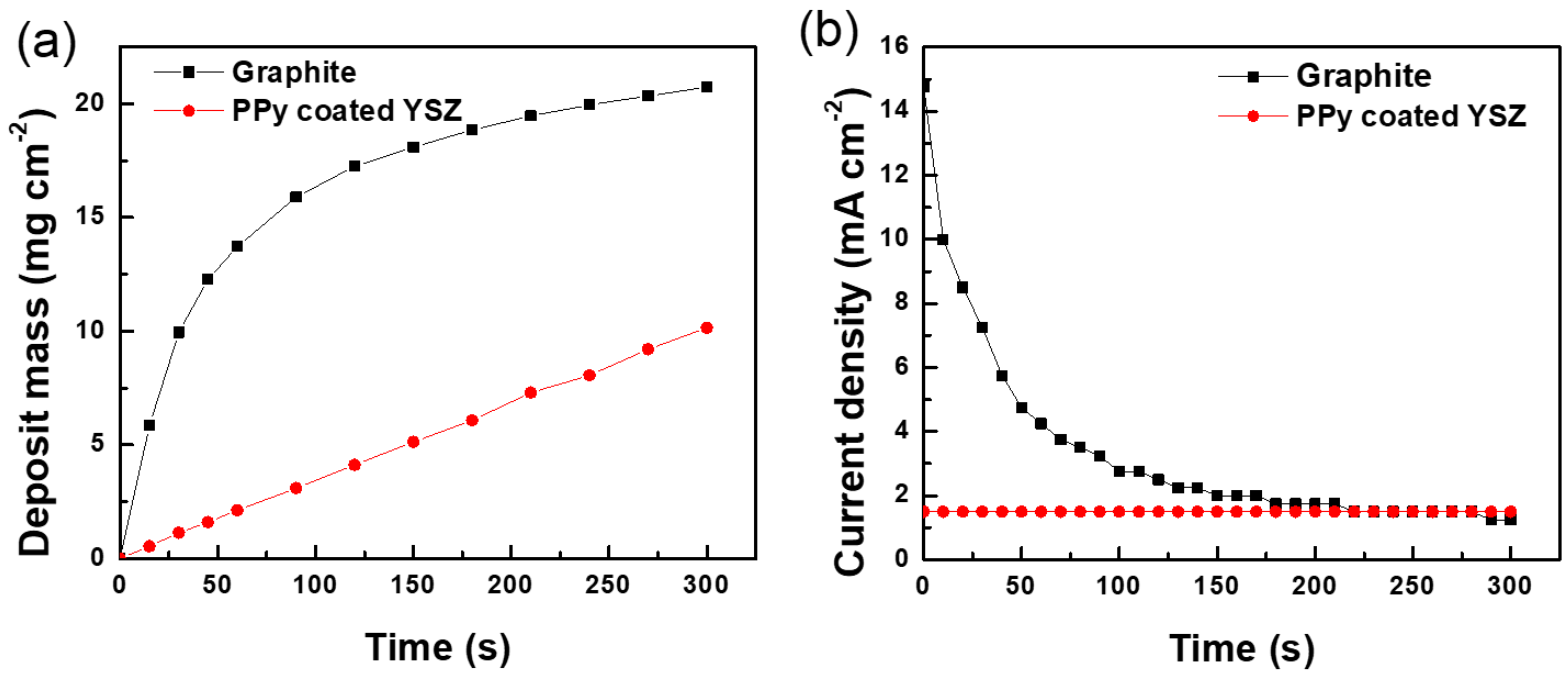

Fig 4-8 (a) The deposit yield and (b) the current density as a function of time under constant voltage (60 V)

Fig. 4-9a and $b$ show the deposition rate and the current density as a function of time under constant voltage $(60 \mathrm{~V})$ from the data in Fig. 4-8a and b, respectively. The deposition rate tracks the current density regardless of the cathode conductivity. To further probe the relationship between the deposit yield and charge passed during the deposition process, the deposit weight as 
a function of current density was characterized under constant current with an identical electric charge of 2.4 C for both the PPy coated YSZ and the graphite plate as the cathode, respectively. As shown in Fig. 4-10, the deposit mass decreases with increasing current density regardless of the cathode. Furthermore, the deposit yield on graphite is smaller than that on PPy coated YSZ under the same current density.
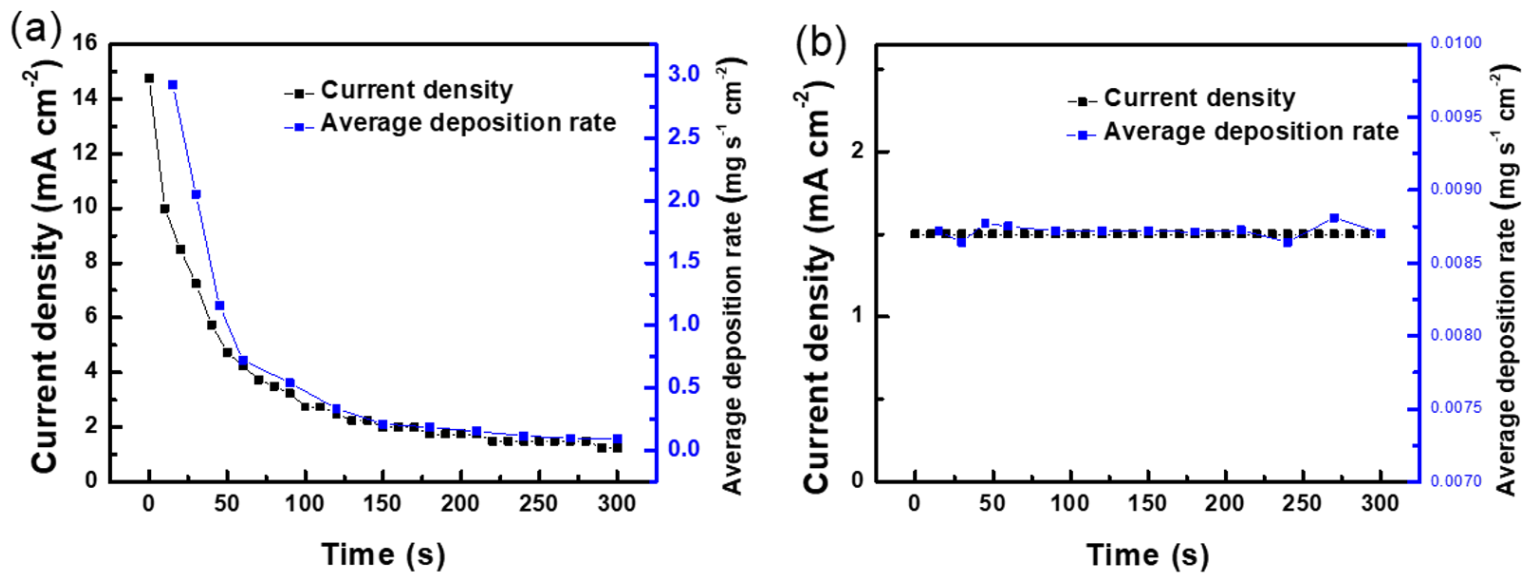

Fig 4-9 The average deposition rate and the current density as a function of time under constant voltage (60 V) when using (a) the graphite plate and $(b)$ the PPy coated YSZ pellet as the cathode.

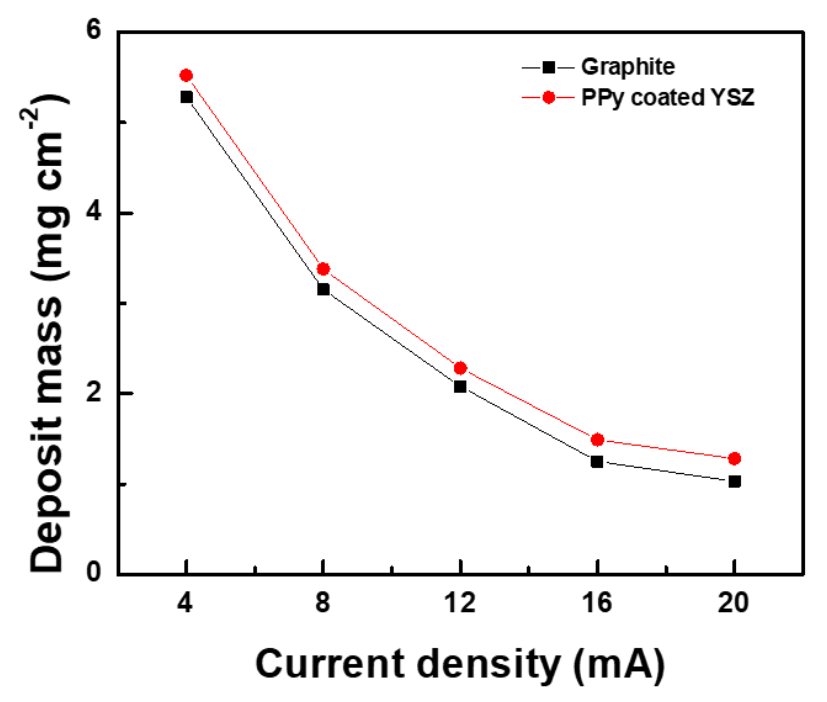


Fig 4-10 Deposit mass per area as a function of current density under constant current and same quantity of electric charge by using PPy coated YSZ and graphite as the cathode.

\subsubsection{Dynamic process during deposition}

As shown in Fig. 4-9b, the variation of resistance for the PPy coated YSZ cathode is imperceptible under a constant voltage of $60 \mathrm{~V}$. To track its variation, the voltage under a constant current of $16 \mathrm{~mA}$ was recorded by an oscilloscope (Siglent SDS1102CML). A higher current density was used to minimize the experimental error. The corresponding voltage plotted as a function of time is shown in Fig. 4-11. The plot exhibits four domains. The voltage suddenly rises from A to B with onset of current following by slowly increasing from B to C, then slowly decreasing from $\mathrm{C}$ to $\mathrm{D}$, and finally gradually rising from $\mathrm{D}$ to $\mathrm{E}$. The plot of voltage at constant current is equivalent to a plot of resistance of the EPD cell vs time. From the EIS study, about 40 V (16 mA x 2500 ohms) in Fig. 5 is due to ohmic losses.

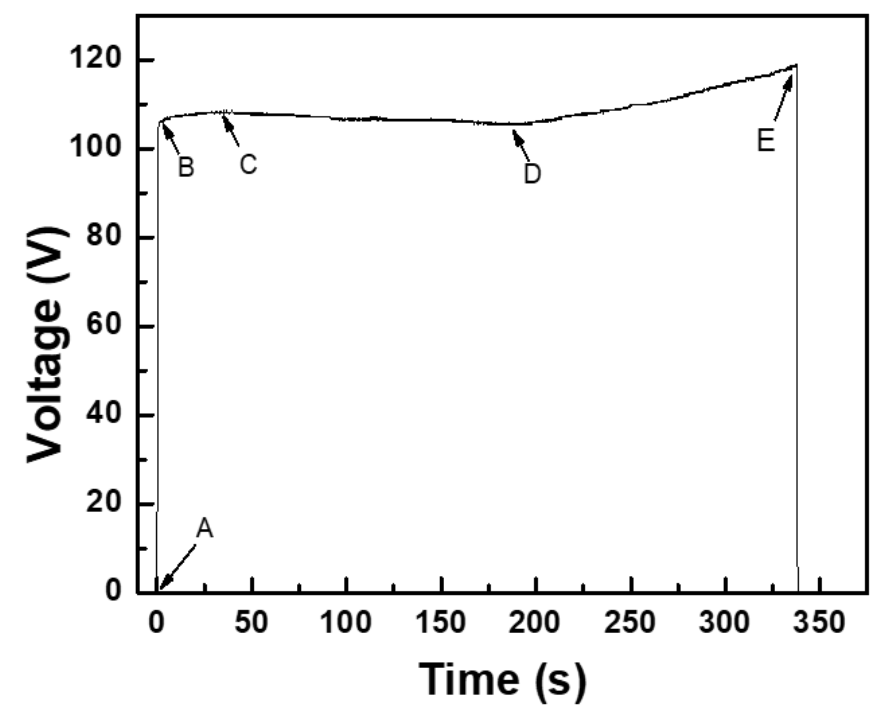

Fig 4-11 The voltage as a function of time under constant current (0.016 A) using PPy coated YSZ as the cathode. 
Fig. 4-12 shows the $\mathrm{pH}$ in the vicinity of PPy coated YSZ at different time intervals under a constant current of $16 \mathrm{~mA}$. The initial $\mathrm{pH}$ of the suspension is 2.94. After 2 minutes, the $\mathrm{pH}$ value in the vicinity of PPy coated YSZ is lower than the initial value, suggesting there is an $\mathrm{H}^{+}$ ion accumulation zone. After a certain time (i.e., 8 mins), the $\mathrm{pH}$ value is larger than the initial value, implying the formation of an ion depletion zone.

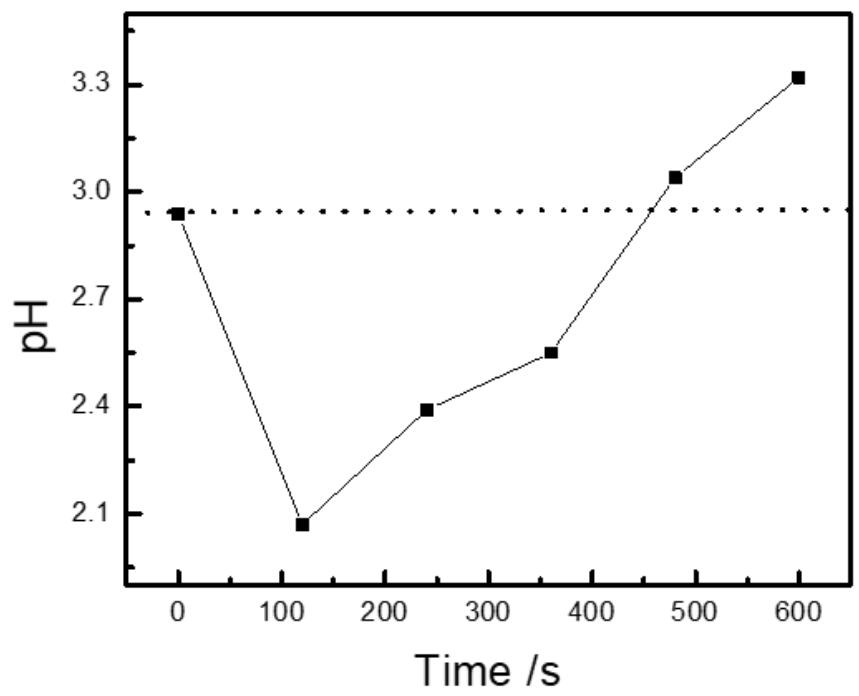

Fig 4-12 The $\mathrm{pH}$ in the vicinity of cathode as a function of time under a constant current of $16 \mathrm{~mA}$

\subsubsection{Morphology of GDC on YSZ by EPD}

The driving force for migration of the particle in the suspension depends on applied voltage and zeta-potential. For the same suspension, the deposition rate and morphology of deposit are closely related to the voltage. The cross-sectional morphology of the deposit for 10 mins as a function of voltage is shown in Fig. 4-13. When the voltage increases from $60 \mathrm{~V}$ to $100 \mathrm{~V}$, the thickness of the GDC deposit increases because of the higher deposition rate. However, when the voltage increases to $120 \mathrm{~V}$, the gas evolution produced by the electrolysis of water results in the 
drop of the thickness and impairs the connection between the deposited GDC and YSZ as shown in 4-13(d). Further increase of voltage will enlarge this effect shown in 4-13(e) and 4-13(f). In order to get 5-8 $\mu \mathrm{m}$ of GDC with good adhesion with YSZ in a short time, the EPD experiment was carried out for 5 min under $100 \mathrm{~V}$ using DC power supply. After 5 min, the YSZ pellet was turned over to coat the other side of the pellet at the same condition.
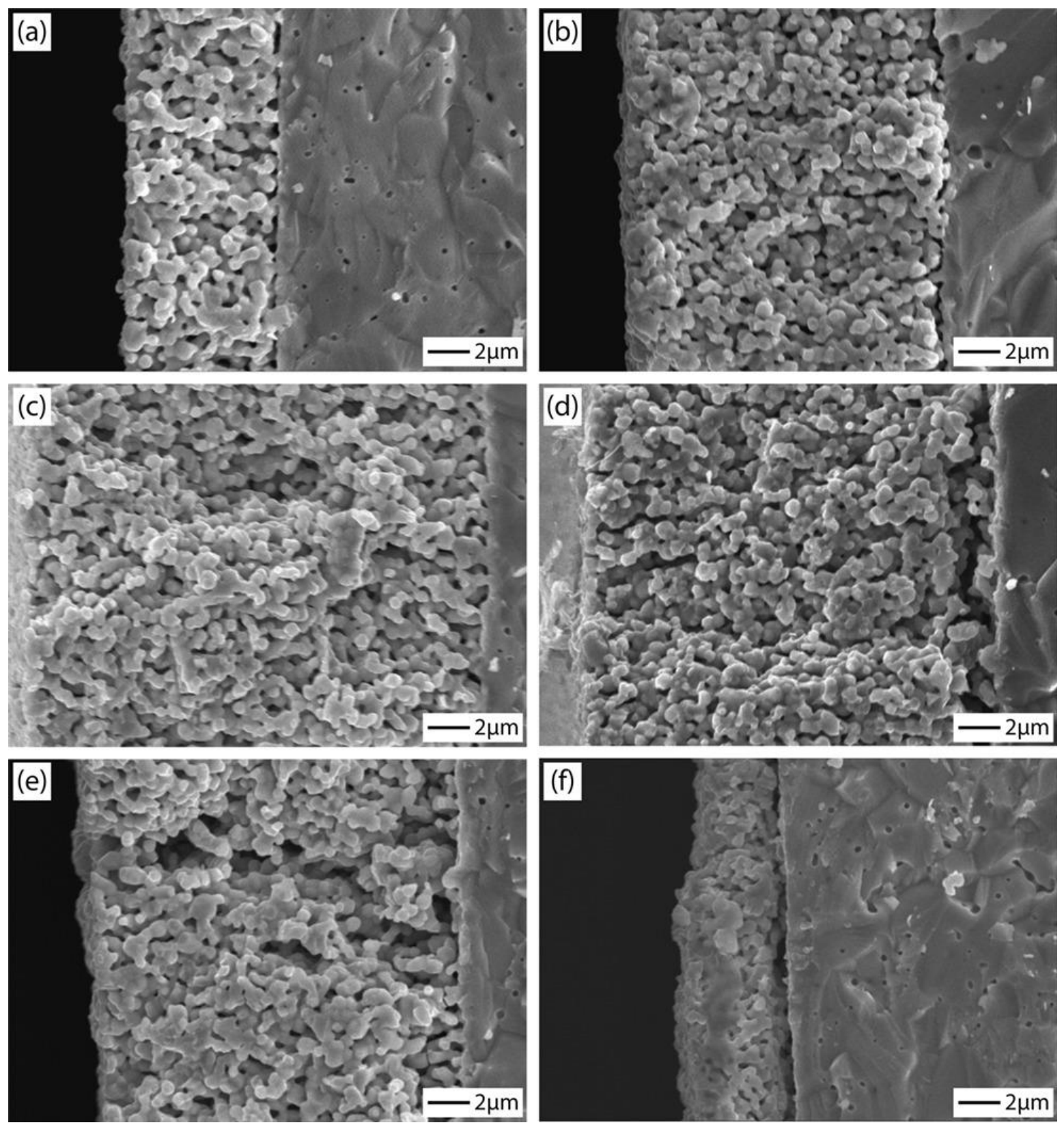
Fig 4-13 Cross-sectional morphology of GDC deposited on YSZ for 10 minutes as a function of applied voltage (a) $60 \mathrm{~V}$, (b) $80 \mathrm{~V}$, (c) $100 \mathrm{~V}$, (d) $120 \mathrm{~V}$, (e) $140 \mathrm{~V}$ and (f) $160 \mathrm{~V}$ after sintering at $1300^{\circ} \mathrm{C}$.

The top and cross-sectional view of GDC green layer are displayed in Fig. 4-14a and b, respectively. After sintering at $1300{ }^{\circ} \mathrm{C}$ for $4 \mathrm{~h}$, the corresponding morphology is shown in Fig. 4-14c and d, respectively. As can be seen in Fig. 4-14b, the GDC particles are packed densely on YSZ pellet. After sintering, the polymer is completely removed, leaving a uniform GDC layer with a thickness of $8 \mu \mathrm{m}$. The adhesion between YSZ and GDC is good. However, there are still a number of pores in the GDC layer which could undermine the effect in preventing the reaction between YSZ and LSCF. In regard of this, a sintering aid is added into GDC to improve its sintering ability.

Many kinds of sintering aid, including transition metal oxide ( $\mathrm{CoO}, \mathrm{MnO}$ and $\left.\mathrm{FeO}_{1.5}\right), \mathrm{Bi}_{2} \mathrm{O}_{3}$ and $\mathrm{Li}_{2} \mathrm{O}[136,137]$, have been used to improve the sintering ability of GDC. Given the goal here is to use $\mathrm{LSCF}$ as the cathode, $\mathrm{FeO}_{1.5}$ was used as the sintering aid to avoid the introduction of a new element. A small amount of $\mathrm{FeO}_{1.5}$ can reduce the sintering temperature by about $200{ }^{\circ} \mathrm{C}$ and enhance densification rate by increasing the contact area of particles in a compact solid [136, 138]. Also, it can act as a grain boundary scavenger of $\mathrm{SiO}_{2}$ impurity [138]. The ion conductivity of GDC increases correspondingly because of larger oxygen vacancies concentration resulted from the doped iron atoms $[136,138]$. In this study, $2 \mathrm{~mol} \% \mathrm{FeO}_{1.5}$ was added to GDC in the form of iron nitrate dissolved in ethanol. The wet powders were dried after grinding for about $2 \mathrm{~h}$. Subsequent calcining was carried out in air at $450{ }^{\circ} \mathrm{C}$ for 30 mins. The obtained Fe-GDC powders were deposited to YSZ by the same EPD procedure.

Fig. 4-15a and $\mathrm{b}$ shows the morphology of GDC with $\mathrm{FeO}_{1.5}$ sintering aid formed by EPD after sintering at $1300^{\circ} \mathrm{C}$ for $4 \mathrm{~h}$. After adding $\mathrm{FeO}_{1.5}$, the density of the deposited GDC layer has been 
largely improved. Although the GDC layer is not completely dense, these few pinholes inside are discontinuous and isolated. This indicates the GDC layer is adequate to act as a barrier layer to prevent the reaction of LSCF and YSZ.
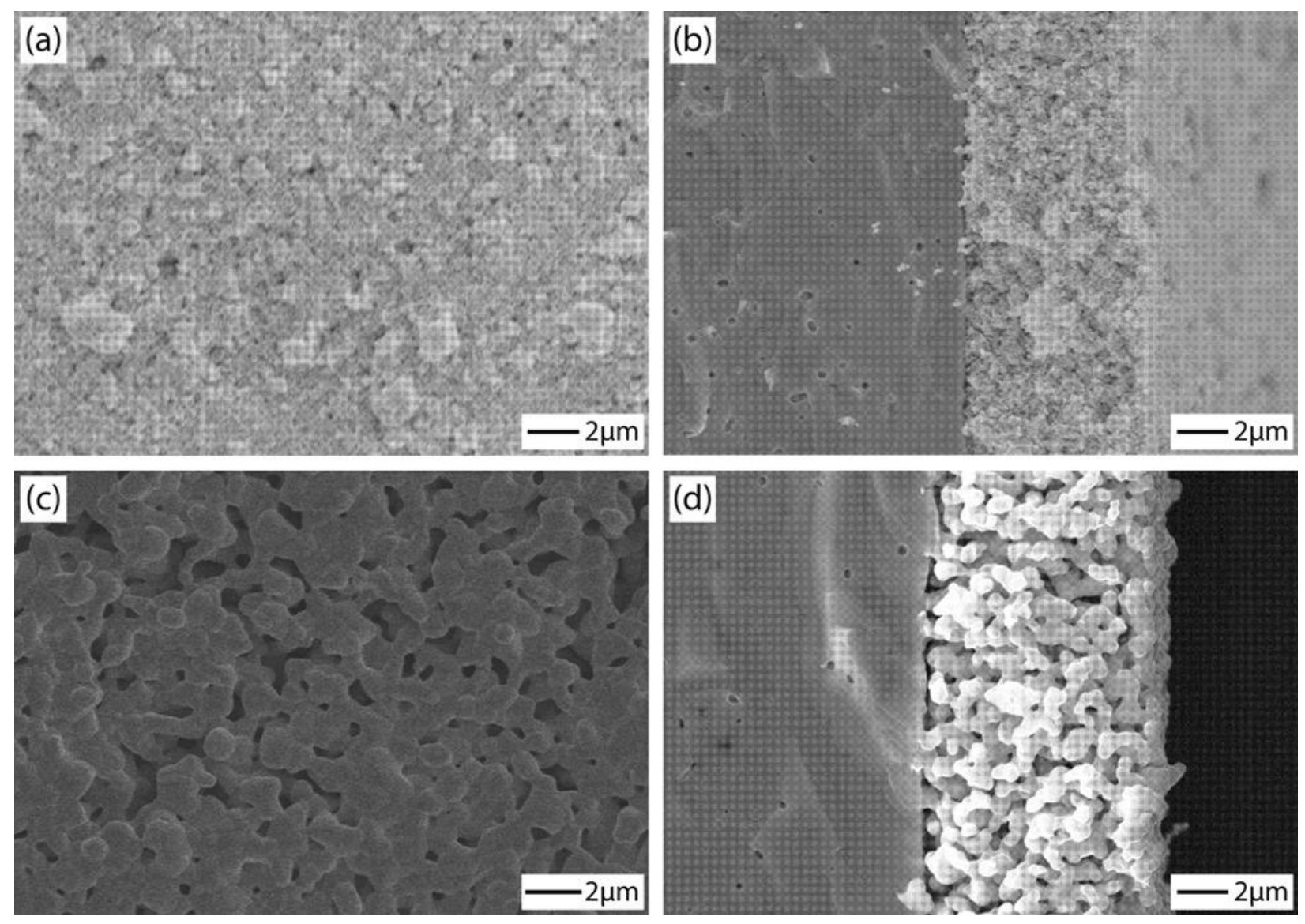

Fig 4-14 SEM view of (a) green, (c) sintered GDC surface and cross-sectional view of (b) green, (d) sintered GDC layer. 

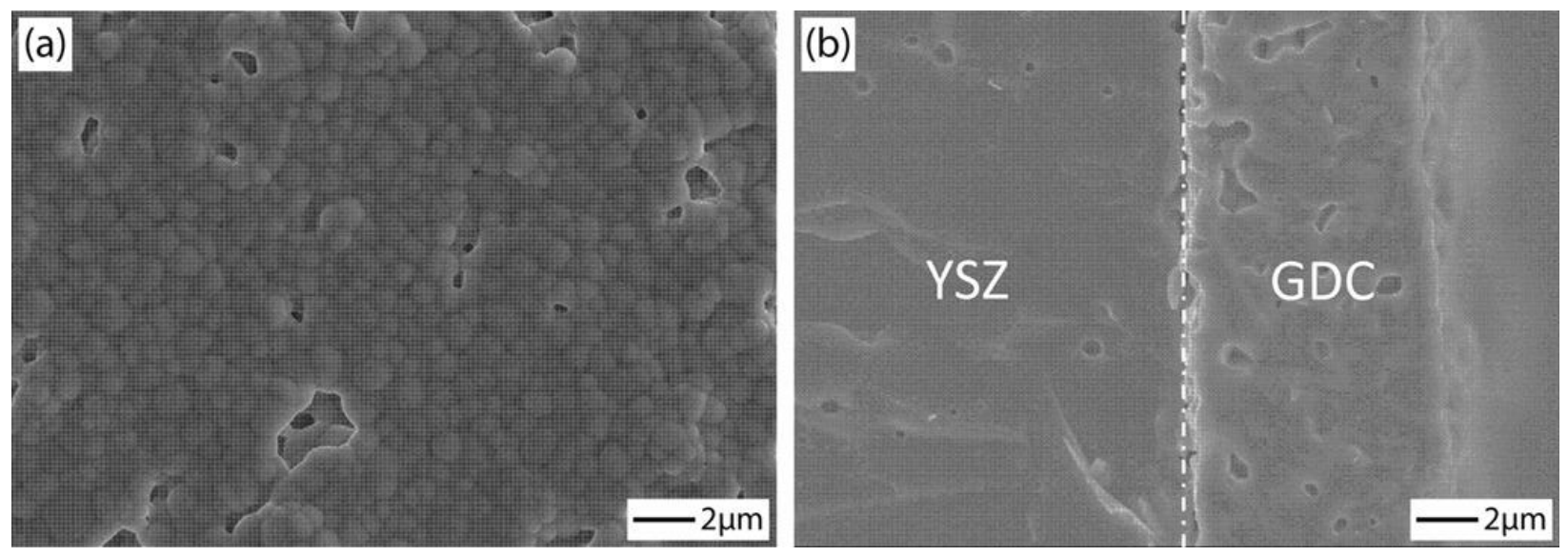

Fig 4-15 (a) SEM view of the surface and (b) cross-sectional view of the sintered GDC layer with 2 mol.\% FeO ${ }_{1.5}$.

\subsubsection{Performance and long-term stability}

The EIS at $750^{\circ} \mathrm{C}$ and temperature dependence of ohmic resistance of symmetric cell with GDC layer formed by spin coating and EPD are shown in Fig. 4-16a and b. The green density of this GDC layer formed by DC-EPD is 54.04, which is larger than that formed by spin coating, i.e., 52.47. The GDC layer formed by EPD is much denser than that formed by spin coating since there is no pore former in the EPDed green GDC layer. The spectra were fitted by the equivalent circuit shown in Fig. 4-17, where $\mathrm{L}_{1}$ represents the inductance from the silver lead, $\mathrm{R}_{1}$ represents the total ohmic resistance, $\mathrm{R}_{2}$ and $\mathrm{R}_{3}$ represents the polarization resistance in high frequency (HF) and low frequency (LF). The constant phase element (CPE) is used because of the frequency dispersion phenomenon in electrode process. The polarization resistance $\left(\mathrm{R}_{2}+\mathrm{R}_{3}\right)$ of LSCF at 750 ${ }^{\circ} \mathrm{C}$ is about $0.35 \Omega \mathrm{cm}^{2}$ which is larger compared with the prior result [139]. That's most probably because of the non-optimized cathode microstructure as displayed in Fig. 4-18a and b, which shows large particle size $(1 \mu \mathrm{m})$ and low porosity when fabricated without pore former. However, compared with spin coating, the ohmic resistance $\left(\mathrm{R}_{1}\right)$ of the symmetric cell for GDC formed by EPD is reduced by $0.09 \Omega \mathrm{cm}^{2}$. In the present case, total $R_{1}$ consists of three parts: the ohmic 
resistance of YSZ, the ohmic resistance of GDC and YSZ/GDC interface resistance. Considering the YSZ substrates are the same in the parallel experiment, the differences lie in the density of deposited GDC layer and the adhesion between YSZ and GDC. As those properties are improved by EPD, $\mathrm{R}_{1}$ decreases consequently. Moreover, as reported in the literature $[140,141]$, the ohmic resistance for an electrode-supported GDC/YSZ cell is about $0.30 \Omega \mathrm{cm}^{2}$. In other words, such reduction could represent a $30 \%$ improvement of the total ohmic resistance.

The cross section of symmetric cell with GDC layer formed by spin coating and EPD is shown in Fig. 4-18a and b, compared with spin coating (Fig. 4-18a), the GDC layer formed by EPD (Fig. 4-18b) is denser and the adhesion between YSZ and GDC is better, which is in good agreement with the resistance results in Fig. 4-16b.

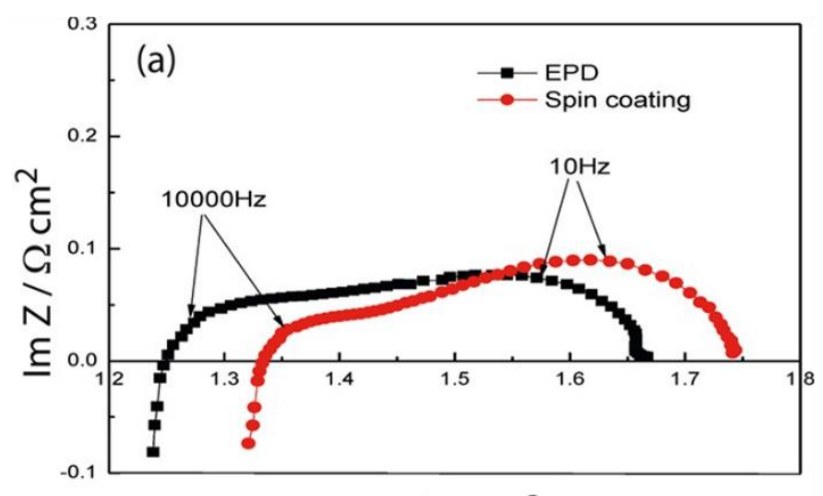

$\operatorname{Re} Z / \Omega \mathrm{cm}^{2}$

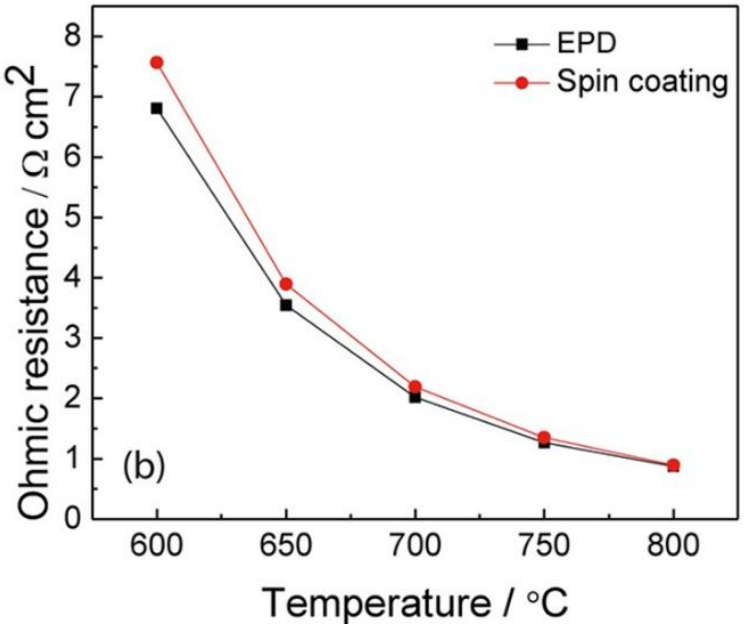

Fig 4-16 (a) EIS at $750^{\circ} \mathrm{C}$ and (b) temperature dependence of ohmic resistance of symmetric cell with GDC layer formed by spin coating and EPD. 


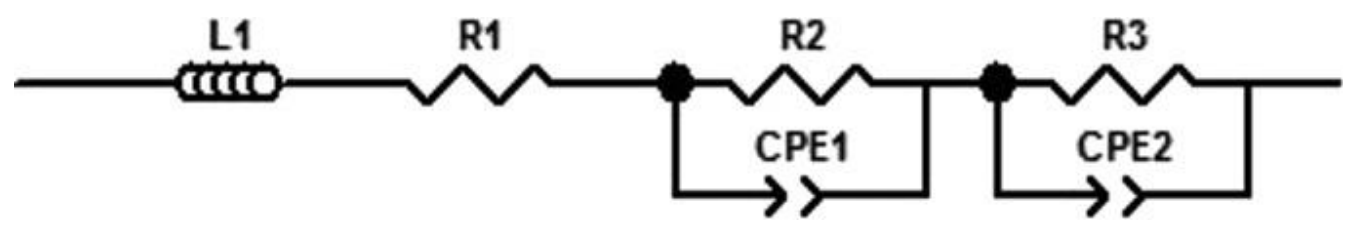

Fig 4-17 Equivalent circuit used to fit the EIS data.
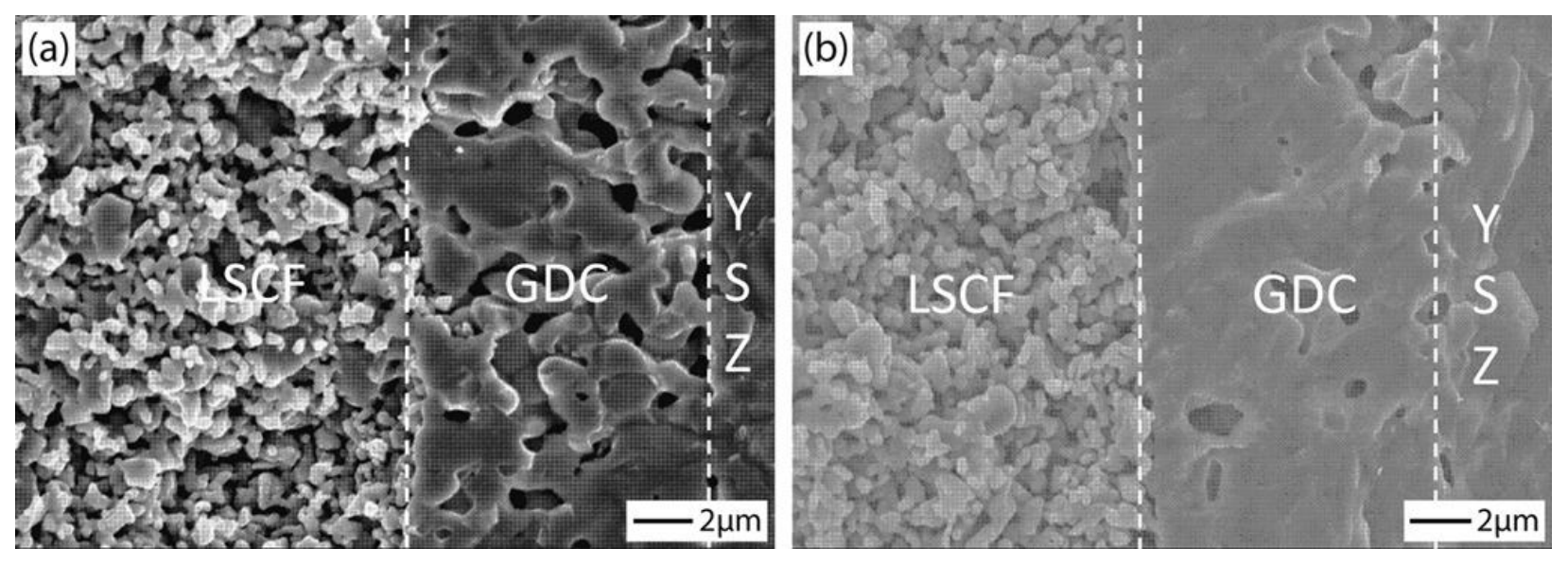

Fig 4-18 Cross-section morphology of symmetric cell with GDC layer formed by (a) spin coating and (b) EPD.

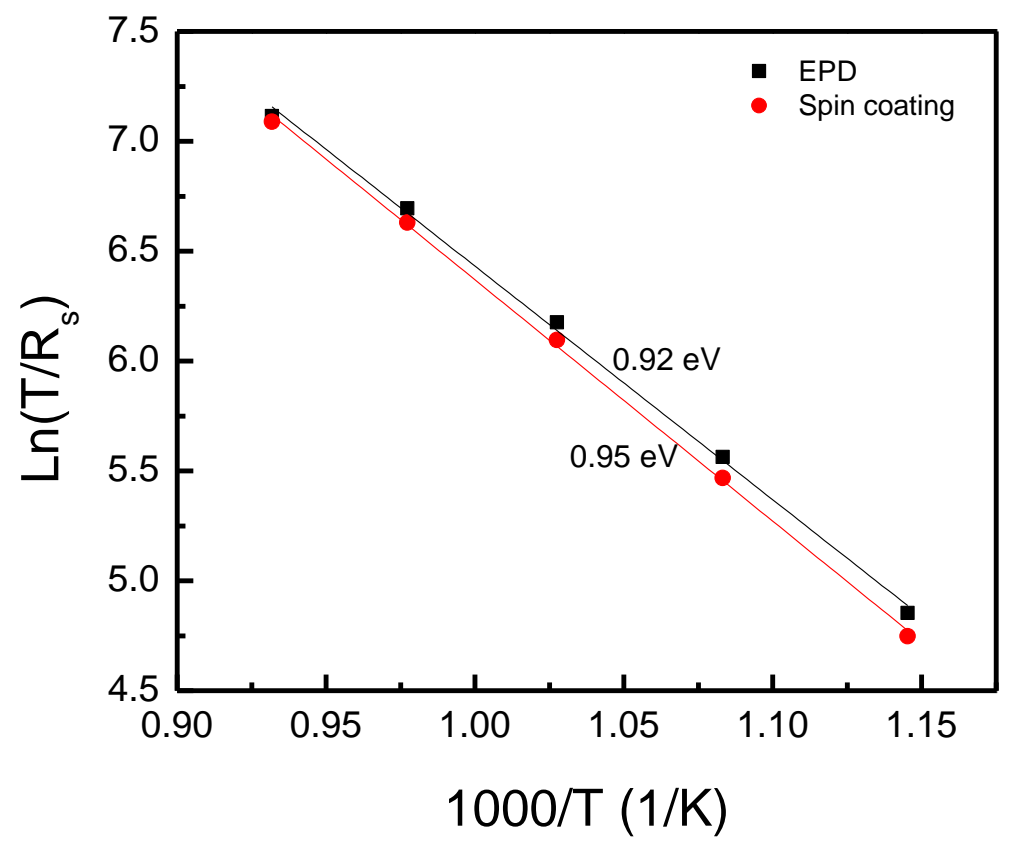

Arrhenius plots for ohmic resistances of symmetric cell with GDC layer formed by spin coating and EPD. 
Fig. 4-19 shows the SEM image and EDX line scanning along the cross-section of $\mathrm{LSCF}+\mathrm{GDC} / \mathrm{GDC} / \mathrm{YSZ}$. It clearly reveals that the GDC layer is almost dense after sintering at a relatively low temperature, i.e., $1300^{\circ} \mathrm{C}$, demonstrating the great potential of EPD in SOFCs barrier layer fabrication. Moreover, no visible Sr diffusion was observed after 500 h, suggesting this GDC layer is adequate to prevent the reaction between LSCF and YSZ.
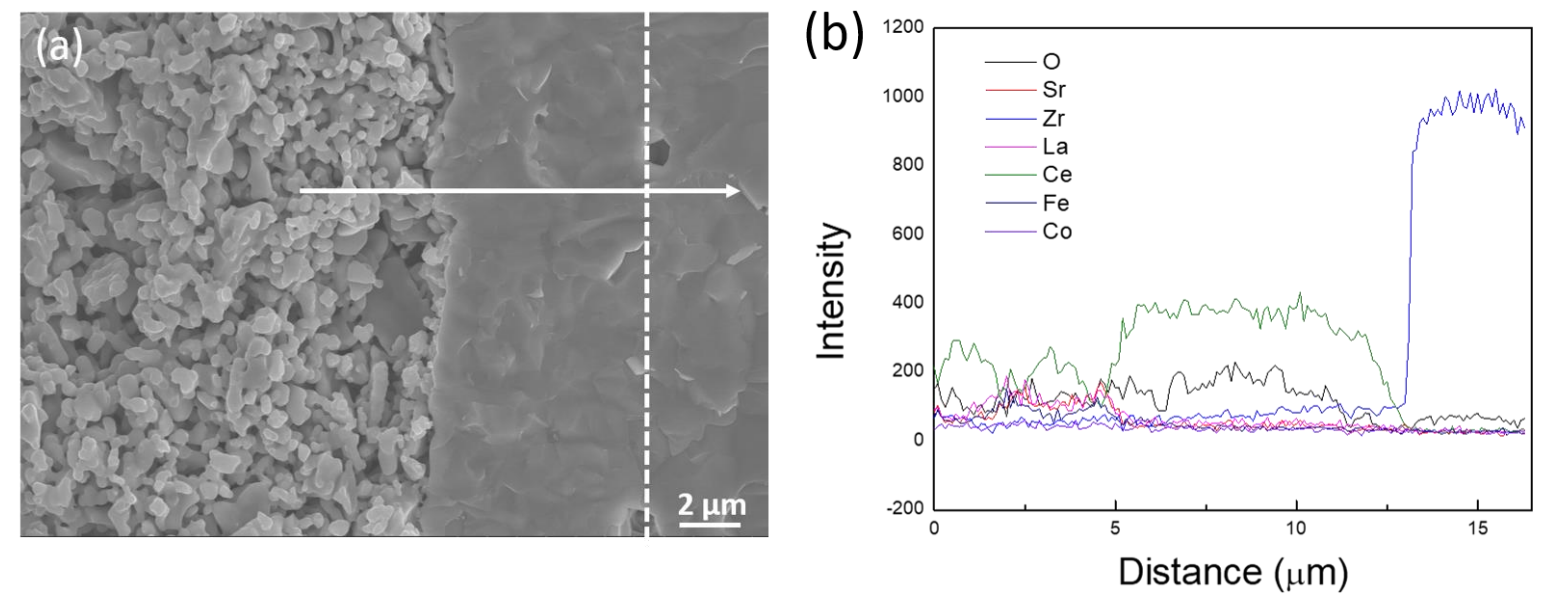

Fig 4-19 Cross-section morphology and EDS line scan of YSZ/GDC/LSCF+GDC after sintering at $800{ }^{\circ} \mathrm{C}$ for $500 \mathrm{~h}$

\subsection{Discussion}

\subsubsection{Rate-determining step}

In the suspension, $\mathrm{H}^{+}$ion is the dominant cation. Fig. 4-20 shows the schematic of EPD process on graphite at different time intervals. After applying a potential gradient, both charged particles and free ions move to cathode (Fig. 4-20a). At the same time, the vicinity of the cathode quickly run out of $\mathrm{H}^{+}$ions due to the charge transfer process. The $\mathrm{H}^{+}$ions must be supplied by the diffusion from the bulk of the suspension to the surface of the cathode [39, 133]. The reduction of $\mathrm{H}^{+}$ions at the cathode includes two steps shown in Eq. (1): 


$$
H_{\text {bulk }}^{+} \stackrel{\text { transport process }}{\longrightarrow} H_{\text {surface }}^{+} \stackrel{\text { charge transfer process }}{\longrightarrow} \frac{1}{2} H_{2}
$$

$H_{\text {bulk }}^{+}$is $\mathrm{H}^{+}$ion in the bulk of the suspension, and $H_{\text {surface }}^{+}$is $\mathrm{H}^{+}$ion in the vicinity of the cathode.

The current density is determined by the slower step. When the graphite plate is used as the cathode, the charge transfer process is faster than the transport process, resulting in the formation of an ion depletion zone and an increase of $\mathrm{pH}$ in the vicinity of the cathode (Fig. 4-20b) [142, 143]. Furthermore, the thickness of the depletion zone increases with time and it might be up to $400 \mu \mathrm{m}$ (Fig. 4-20c and d) [143]. Hence, the current decreases with time (Fig. 4-8b) as a consequence of the growing deposit [144] and the enlargement of the ion depletion zone near cathode [145]. A similar result was found by Koura et al. for the deposition of $\mathrm{BaTiO}_{3}$ on a platinum plate, in which the reduction of $\mathrm{H}^{+}$ions at the cathode was controlled by the diffusion of $\mathrm{H}^{+}$ions through the porous deposit. In particular, diffusion control is confirmed by the current density $\left(\mathrm{I}(\mathrm{t})\right.$ ) vs time fitting the Cottrell equation (I is proportional to $\mathrm{t}^{-1 / 2}$ ) [144].

In contrast, the $\mathrm{pH}$ value in the proximity of the cathode decreases from 2.94 to 2.01 after applying voltage for $10 \mathrm{~s}$ when the PPy coated YSZ is used instead of the graphite plate, suggesting that the charge transfer process is slower than the transport process. Due to the poor conductivity of PPy, the deposition of GDC on PPy coated YSZ is rate-determined by the charge transfer process, which is much slower than that on the graphite plate. 
(a)

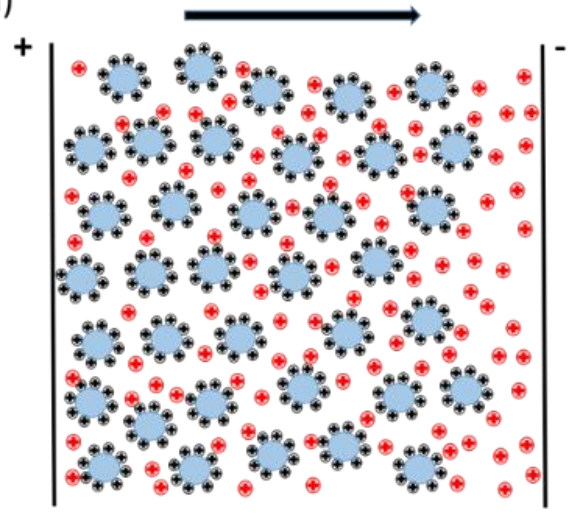

No ion

(C)

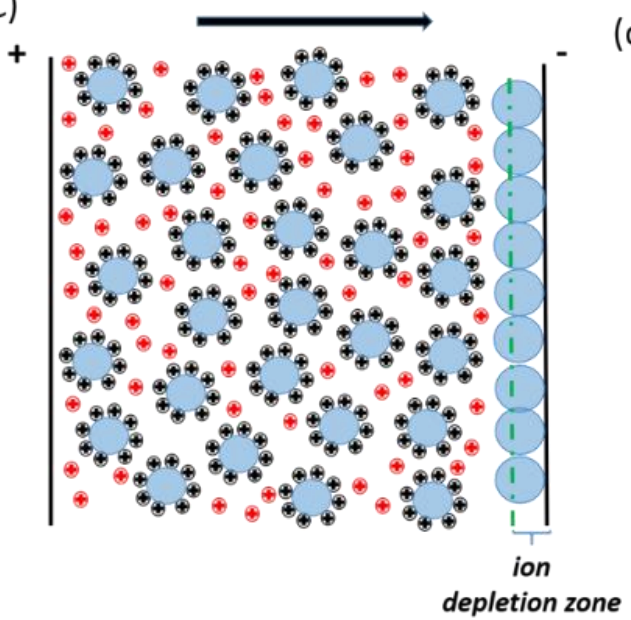

Absorbed $\mathrm{H}^{+}$ion (b)

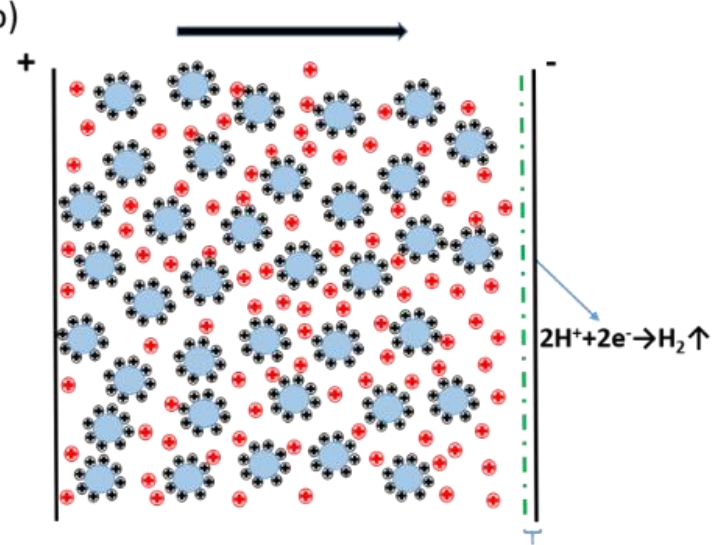

ion

depletion zone

(d)

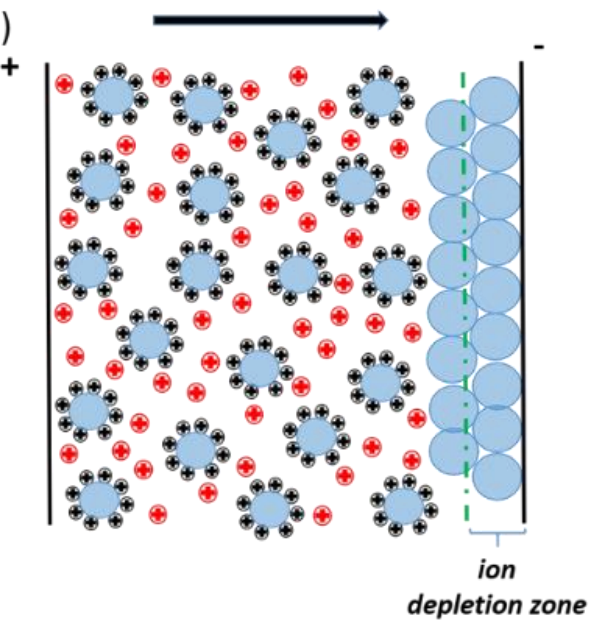

GDC particle

Fig 4-20 The schematic of the EPD process on graphite at different deposition times

\subsubsection{Deposition efficiency}

After particles deposit onto the cathode, the absorbed $\mathrm{H}^{+}$ions desorb from the particles and are then reduced to hydrogen gas. Assuming that the charge-transfer quantity from one particle to the deposit is constant [100], the deposition yield at a fixed voltage or current density is clearly proportional to the quantity of electric charge transferred during the whole deposition process as shown in Fig. 4-9a and b. The deposit weight can be determined by the following Eq. (4-3): 


$$
\frac{m}{m_{0}} Z e=Q_{a b}
$$

The parameter $\mathrm{m}$ is the deposit weight in $\mathrm{g}, \mathrm{m}_{0}$ is the average mass of one single particle in $\mathrm{g}, Z$ is the valence of one charged particle, $e$ is the electronic charge in C, and $Q_{a b}$ is the electric charge amount transferred resulted from the reduction of absorbed $\mathrm{H}^{+}$ions. The "absorbed $\mathrm{H}^{+}$ ions" refers to the part of total $\mathrm{H}^{+}$ions which desorb from the particles after deposition as distinguished from the existing free $\mathrm{H}^{+}$ions in the suspension.

Recognizing that the ethanol solution contains $5 \%$ water, the electrochemical reactions accompanying the deposition are shown in the following equations:

$$
\begin{gathered}
\text { Anode: } 2 \mathrm{H}_{2} \mathrm{O}-4 e^{-} \rightarrow 4 \mathrm{H}^{+}+\mathrm{O}_{2} \text { (4-5a) } \\
\text { Cathode: } 2 \mathrm{H}^{+}+2 e^{-} \rightarrow \mathrm{H}_{2} \text { (4-5a) and } 2 \mathrm{H}_{2} \mathrm{O}+2 e^{-} \rightarrow \mathrm{H}_{2}+2 \mathrm{OH}^{-}
\end{gathered}
$$

The $\mathrm{H}^{+}$ions in Eq. (4-5a) are composed of free $\mathrm{H}^{+}$ions and absorbed $\mathrm{H}^{+}$ions. Eq. (4-3) can also be revised to Eq. (4-6)

$$
\frac{m}{m_{0}} Z e=Q_{a b}=\boldsymbol{f} Q_{T}
$$

$Q_{T}$ is the total amount of electric charge passed during the whole process in $\mathrm{C}$, and $f$ is the percentage of the electric charge associated with the reduction of absorbed $\mathrm{H}^{+}$ions in the total charge.

It is important to note that only the reduction of the absorbed $\mathrm{H}^{+}$ions contribute to the growth of the deposit. In contrast, free $\mathrm{H}^{+}$ions reduction and water reduction are the unavoidable side reactions. Hence, $f$ could be defined as the deposition efficiency to reflect the competitive 
relationship between the deposition (the reduction of absorbed $\mathrm{H}^{+}$ions) and the inevitable side reactions (the reduction of free $\mathrm{H}^{+}$ions and water reduction). Considering two limiting conditions, if all the reduced $\mathrm{H}^{+}$ions are initially absorbed on particles, the electric charge solely comes from the reduction of absorbed $\mathrm{H}^{+}$ions and $f$ is 1 . In contrast, if there are no charged particles in the suspension, the electric charge is derived from the reduction of free $\mathrm{H}^{+}$ions and water reduction and $f$ is 0 .

As the rate-determining step for the deposition on PPy coated YSZ is the charge transfer step, $\boldsymbol{f}$ is equal to the ratio of the absorbed $\mathrm{H}^{+}$ions to the total $\mathrm{H}^{+}$reduced at the cathode (Eq. 4-7a). In contrast, $\boldsymbol{f}$ is less than that value when using graphite as the cathode since some charge is used to drive water reduction. This assumption accounts for the observation that the deposit weight at a given time is larger on PPy coated YSZ than the deposit weight on the graphite under constant current (Fig. 4-10).

The schematic of EPD process is shown in Fig. 4-21. Under the effect of electric field, both charged particles and free $\mathrm{H}^{+}$ions move to the cathode. At the suspension/ deposit interface, GDC particles deposit on the existing layer while the absorbed $\mathrm{H}^{+}$ions desorb from the particles and move forward to the cathode surface to be reduced. From the suspension/ deposit interface to the cathode surface, there is no difference between desorbed $\mathrm{H}^{+}$ions and free $\mathrm{H}^{+}$ions. The percentage of desorbed $\mathrm{H}^{+}$ions in the total $\mathrm{H}^{+}$ions reduced at cathode is equal to that value at the suspension/ deposit interface, which is determined by the amount ratio and the migration speed ratio of the absorbed $\mathrm{H}^{+}$ions to free $\mathrm{H}^{+}$ions in the suspension. As the main charge carriers in the suspension are the free ions other than the charged particles [146] and the migration speed of free $\mathrm{H}^{+}$ions is faster than that of absorbed $\mathrm{H}^{+}$ions moving along with particles, the amount ratio of absorbed $\mathrm{H}^{+}$ions to total $\mathrm{H}^{+}$ions reaching the suspension/ deposit interface decreases 
with increasing current density. That is the reason why the deposit yield for a specified electric charge amount decreases with the increase of current density (Fig. 4-10).

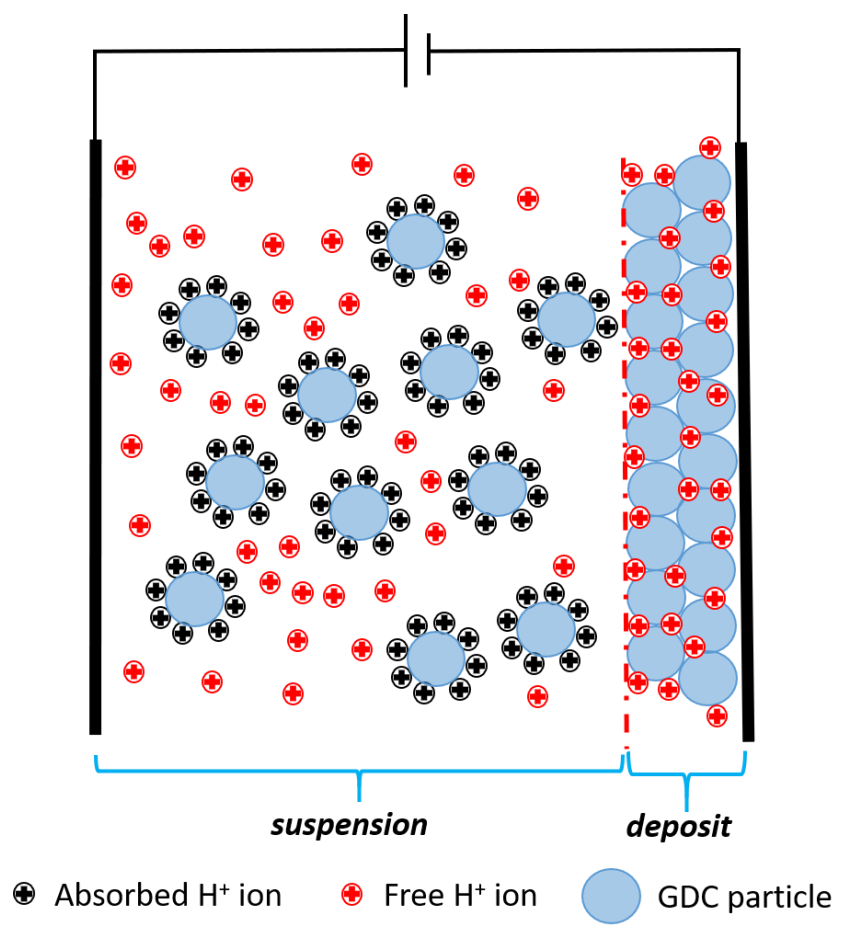

Fig 4-21 The schematic of an EPD cell with an existing deposit.

\subsubsection{Increasing resistance}

It is helpful in the discussion to define the equivalent circuit of the EPD cell (Fig. 4-22). $\mathrm{R}_{1}$ is the contact resistance due to the poorly conductive PPy $(2050 \Omega), \mathrm{R}_{2}$ is faradic (polarization) resistance at the cathode, $R_{3}$ is the ohmic resistance in the deposit layer, $R_{4}$ is the ohmic resistance of the $1 \mathrm{~cm}$ suspension $(450 \Omega), R_{5}$ is the faradic resistance at the anode, $C_{1}$ is the capacitance of the double layer at the cathode, and $\mathrm{C}_{2}$ is capacitance of the double layer at the anode. 


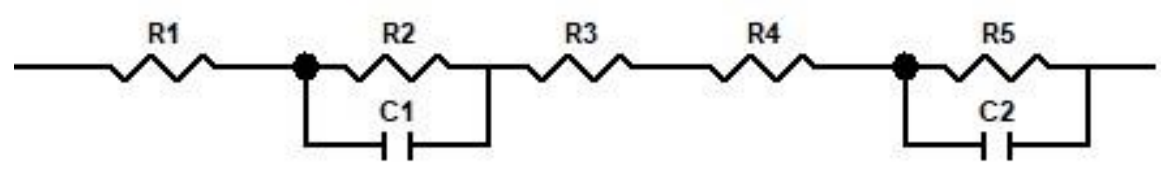

Fig 4-22 The equivalent circuit of the EPD bath

As the resistances associated with the bulk suspension $\left(R_{4}\right)$ and the anode side $\left(R_{5}\right)$ remain constant during the deposition process [100], the variation of resistance is determined by the cathode side $\left(R_{2}\right.$ and $\left.R_{3}\right)$. At constant current, it is reasonable to assume that the polarization resistance $\mathrm{R}_{2}$ is constant. Several explanations have been proposed to clarify the increasing resistance during deposition, e.g., the formation of an ion depletion zone in the proximity of the deposition electrode [147, 148] and the ion transportation through the growing deposit [144], both affecting the value of $\mathrm{R}_{3}$. However, there is no agreement on which process dominates during EPD.

Fig. 4-23 depicts the schematic of EPD of GDC on PPy coated YSZ at different time intervals based on the experimental results. After applying an electric field, the current flowing through the ohmic resistors, $R_{1}$ and $R_{4}$, results in a rapid rise of voltage from point $A$ to point $B$ in Fig. 411. At the same time, both charged GDC particles and free $\mathrm{H}^{+}$ions in the suspension move to the cathode. Wherein, free $\mathrm{H}^{+}$ions move faster than charged particles (Fig. 4-23a). Charge transfer process, i.e., proton reduction, (Eq (4-7a)) takes place once free $\mathrm{H}^{+}$ions reach the cathode surface. The voltage grows from point $\mathrm{B}$ to point $\mathrm{C}$ correspondingly since the potentials of both cathode and anode adjust to the rates of the faradic reactions at both electrodes. Because of the poor conductivity of PPy, the rate of charge transfer process is slower than that of transport process (Eq. (4-2)) resulting in the formation of an $\mathrm{H}^{+}$ions accumulation zone forms in the vicinity of the cathode (Fig. 4-23b), which lowers the local $\mathrm{pH}$ in the proximity of the cathode 
(Fig. 4-12) and ohmic resistance. Then the GDC particles deposit onto PPy coated YSZ and the thickness of the ion accumulation zone initially grows correspondingly (Fig. 4-23c). The slow decay of voltage from point $C$ to point $D$ in Fig. 4-9 is under the combined effect of the growing deposit and the thickening $\mathrm{H}^{+}$ion accumulation zone.

Under a constant current, charge transfer rate is fixed while the rate of the diffusion of $\mathrm{H}^{+}$ions decreases with time due to the growing deposit. Hence, there is a time point (i.e., point D in Fig. 4-9) when the rate of the diffusion of $\mathrm{H}^{+}$ions is equal to that of the charge transfer. Thereby, the thickness of this $\mathrm{H}^{+}$ions accumulation zone reaches the maximum value (Fig. 4-23c). After that, the charge transfer process is faster than the transport process, thinning the $\mathrm{H}^{+}$ions accumulation zone (Fig. 4-23d) and enlarging the voltage from point D to point E in Fig. 4-11. After a certain time, there is no $\mathrm{H}^{+}$ions accumulation zone (Fig. 4-23e). Finally, there is an ion depletion zone instead (Fig. 4-23f), indicated by the increase of pH (Fig. 4-12).

In summary, the resistance tracks the thickness of the $\mathrm{H}^{+}$ions accumulation or depletion zone instead of the deposit, implying that the main reason accounting for the increasing resistance is the formation of an ion depletion zone. 
(a)

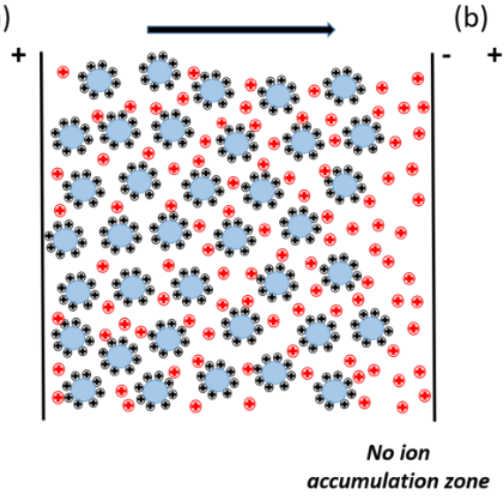

(b)

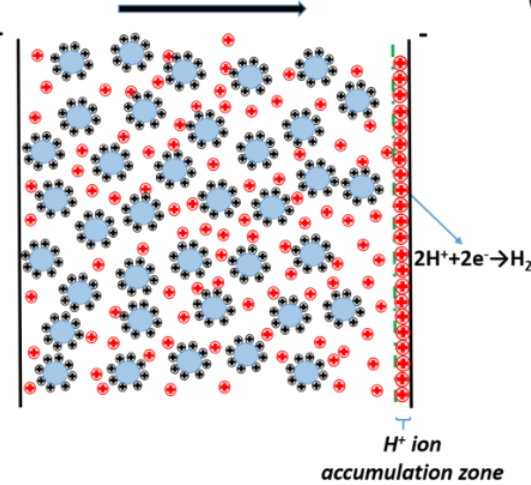

(C)

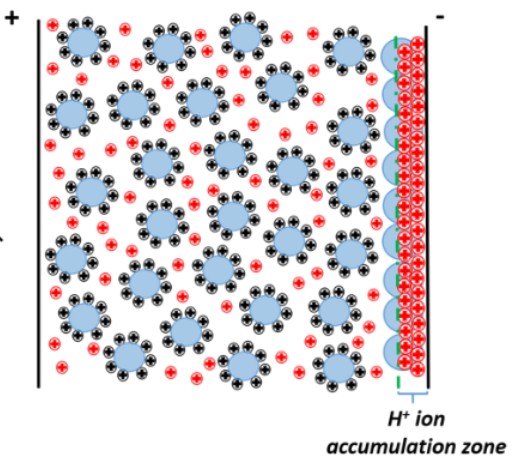

(f)

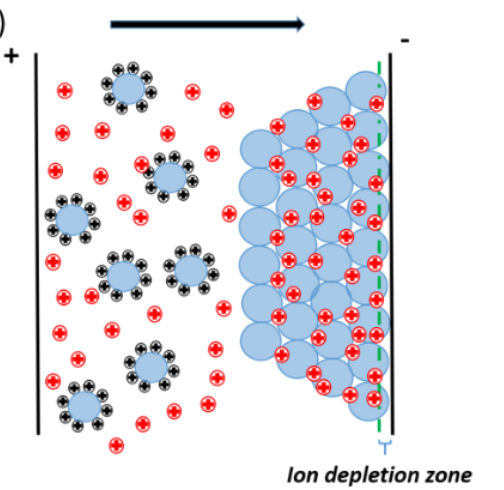

GDC particle

Fig 4-23 The schematic of the EPD process on a PPy coated YSZ at different deposition times.

\subsubsection{Mechanism}

To draw a full picture of EPD, several mechanisms have been proposed by co-workers to explain the deposition process. Grillions et al. suggested that the particles experienced charge neutralization when they came into contact with the oppositely charged electrode [149]. This mechanism is plausible for the initial deposition in a dilute suspension. However, this process is invalid for a long-time deposition, e.g., the deposition of GDC with a thickness of $10 \mu \mathrm{m}$. Sarkar et al. suggested that the electric field and fluid dynamics distorted the double layer around the particles during movement, the double layer becoming thinner ahead and wider behind. Under London Van der Waal attractive forces, the following particles reacted with the counterions in 
the extended tail, which thins the double layer and facilitates coagulation [39]. This process is plausible for the deposition in the suspension with a high concentration of charged particles. Unfortunately, it does not explain the formation of an ion depletion zone in the vicinity of the cathode. De et al suggested that the increase of $\mathrm{pH}$ to the isoelectric point facilitated the coagulation since the $\mathrm{H}^{+}$ions were depleted due to the charge transfer process [150], also experimentally verified by Besra et al [142]. However, in the results described above, the deposit grows with deposition time even when an $\mathrm{H}^{+}$accumulation zone is formed in the proximity of the cathode. To explain the deposition of GDC on PPy coated YSZ, a new model is proposed as shown in Fig. 4-24. After applying an electric field, GDC particles along with absorbed $\mathrm{H}^{+}$ions in the bulk suspension move to the oppositely charged electrode, i.e., cathode (Fig. 4-24a: transport process). When the charged particles come into contact with the existing deposit or cathode surface, GDC particles stick to it due to Van der Waals forces while absorbed $\mathrm{H}^{+}$ions desorb from the particles (Fig. 4-24b: $\mathrm{H}^{+}$desorption). Thereafter, there is no difference between absorbed $\mathrm{H}^{+}$ions and free $\mathrm{H}^{+}$ions from suspension/ deposition interface to the cathode surface. The driving force exerted on $\mathrm{H}^{+}$ions continues to drive $\mathrm{H}^{+}$ions moving forward by diffusing through the porous deposit to the cathode surface (Fig. 4-24c: diffusion process) where the charge transfer takes place (Fig. 4-24d: charge transfer process). The reduction of absorbed $\mathrm{H}^{+}$ ions at cathode consists of four steps as shown in Eq. (4-7):

$$
\begin{aligned}
& H_{a b, \text { bulk }}^{+} \stackrel{\text { transport process }}{\longrightarrow} H_{a b, \text { interface }}^{+} \stackrel{\text { desorption }}{\longrightarrow} H_{\text {free, interface }}^{+} \\
& \stackrel{\text { diffusion process }}{\longrightarrow} H_{\text {free, surface }}^{+} \stackrel{\text { charge transfer }}{\longrightarrow} H_{2}
\end{aligned}
$$

$H_{a b, \quad b u l k}^{+}$is the absorbed $\mathrm{H}^{+}$ion in the bulk suspension, $H_{a b \text {, interface }}^{+}$is the absorbed $\mathrm{H}^{+}$ion at the suspension/ deposit interface, $H_{\text {free, interface }}^{+}$is the free $\mathrm{H}^{+}$ion at the suspension/ deposit 
interface, and $\mathrm{H}_{\text {free, surface }}^{+}$is the free $\mathrm{H}^{+}$ion in the vicinity of cathode. The deposition of GDC particles on PPy coated YSZ is ascribed in part to the successful desorption of $\mathrm{H}^{+}$ions from particles.
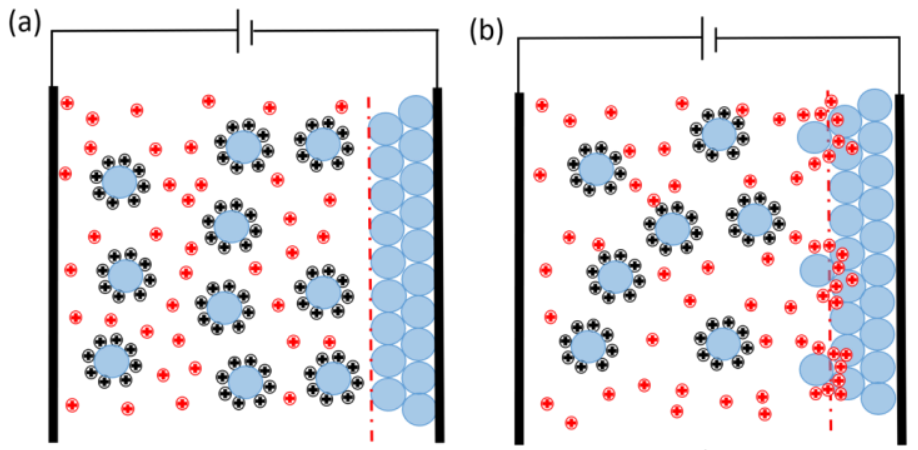

(†) Absorbed $\mathrm{H}^{+}$ion
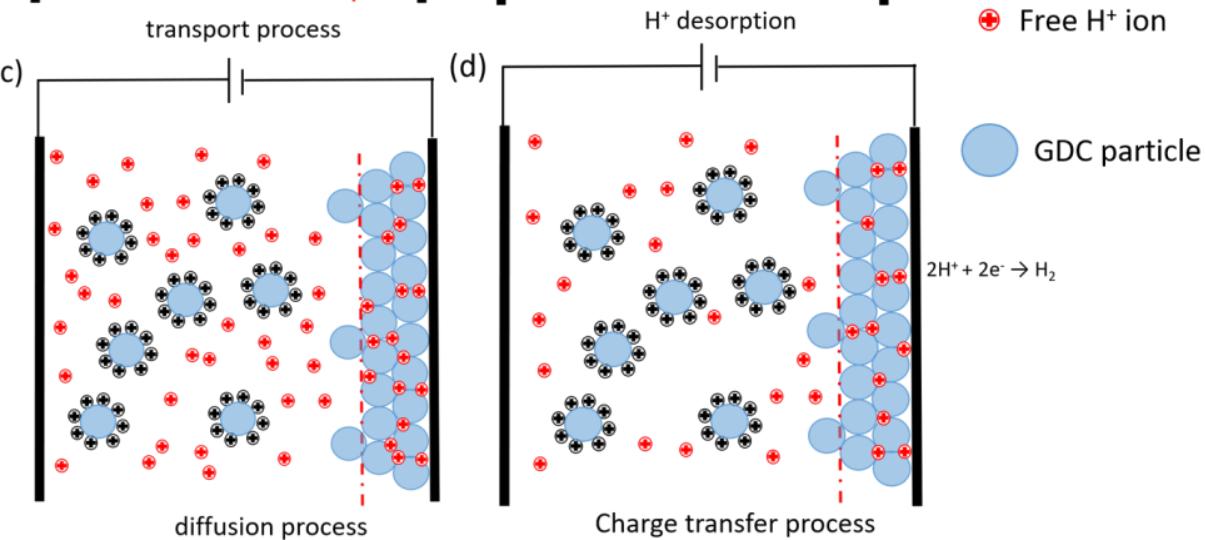

Fig 4-24 The schematic model of the EPD mechanism of GDC on PPy coated YSZ.

\subsection{Summary}

A dense GDC barrier layer is deposited on YSZ substrate to prevent chemical reaction between LSCF and YSZ by a cost-effective EPD method. A highly compact GDC green layer is obtained by the EPD process in an ethanol-based suspension. GDC thin layers in a thickness range of 5-8 $\mu \mathrm{m}$ are successfully densified at as low as $1300^{\circ} \mathrm{C}$ and the adhesion between GDC and YSZ is good. Compared to GDC barrier layer made by a conventional spin-coating method, the ohmic resistance of GDC made by EPD is reduced by $0.09 \Omega \mathrm{cm}^{2}$ at $750{ }^{\circ} \mathrm{C}$, which could account for a 
$30 \%$ improvement of the electrolyte ohmic resistance in an electrode-supported fuel cells, demonstrating the promising potential of EPD as a cost-effect and scalable method in SOFCs barrier layer fabrication.

The deposition rate of GDC on PPy coated YSZ is slower than that on graphite at the same voltage. However, at constant current, the mass of GDC deposited per coulomb of charge is larger on the PPy-coated YSZ cathode. An $\mathrm{H}^{+}$ion accumulation zone is formed near the PPy coated YSZ after applying the voltage. The thickness of this $\mathrm{H}^{+}$ion accumulation zone increases at the beginning and then decreases. Finally, the ion accumulation zone is replaced by an ion depletion zone; the main reason contributing to the increasing resistance is the formation of an ion depletion zone.

The absorbed $\mathrm{H}^{+}$ions desorb from particles after deposition and then move through the porous deposit to the cathode to be reduced. The reduction of free $\mathrm{H}^{+}$ions and absorbed $\mathrm{H}^{+}$ions corresponds to the unavoidable side reaction and the deposition, respectively. Deposition efficiency, $\boldsymbol{f}$, the percentage of electric charge associated with the reduction of $\mathrm{H}^{+}$ions in the total charge, is introduced to reflect the competitive relationship between deposition and the side reaction. $f$ decreases with the increase of current density and is larger for the PPy coated YSZ cathode. 


\section{Chapter 5 Alternating Current Electrophoretic Deposition (AC-}

\section{EPD) of Gadolinium Doped Ceria on Yttrium Stabilized Zirconia as}

\section{a Barrier Layer in Solid Oxide Fuel Cells (SOFCs)}

\subsection{Introduction}

In chapter 4, the technique feasibility of direct current electrophoretic deposition (AC-EPD) of GDC on non-conductive YSZ has been demonstrated. This GDC layer is densified after sintering at a relatively low temperature, i.e., $1300{ }^{\circ} \mathrm{C}$. Ethanol has been confirmed to be suitable to well disperse GDC powder with the addition of some iodine [151]. In the suspension, GDC particles are positively charged because of the absorbed $\mathrm{H}^{+}$ions. After applying a potential gradient, GDC particles move to the cathode and deposit onto it. At the same time, the $\mathrm{H}^{+}$ions are reduced to hydrogen evolving out in the form of gas bubbles which impairs the green density of the deposit and the adhesion between the deposit and the substrate $[53,116,130]$. To further lower the densification temperature of GDC to avoid the over-sintering of other components of SOFCs by eliminating the bubble evolution, alternating current electrophoretic deposition (AC-EPD) is applied to replace DC-EPD in this chapter. Moreover, the parameters associated with AC signal influencing the deposition rate are also thoroughly investigated. 


\subsection{Experimental details}

\subsubsection{EPD apparatus}

The EPD bath was prepared by adding $1.5 \mathrm{~g}$ gadolinium doped ceria (GDC) (Fuel cell materials Inc., surface area of $11.6 \mathrm{~cm}^{2} \mathrm{~g}^{-1}$ ) and $1.0 \mathrm{~g}$ iodine (Sigma-Aldrich) in $100 \mathrm{ml}$ ethanol (Carolina Co., $95 \%$ ) followed by ultrasonication for $30 \mathrm{~min}$.

YSZ pellets were made by coaxial pressing YSZ powder (TZ-8Y, Tosho) in a $31 \mathrm{~mm}$ mold followed by sintering at $1400{ }^{\circ} \mathrm{C}$ for $4 \mathrm{~h}$. Prior to use, the surface of YSZ pellets was coated by a thin layer of conductive polymer, polypyrrole (PPy), shown in our previous work, to make it electrically conductive [53]. Either a PPy coated YSZ plate or a graphite plate with a fixed area of $4 \mathrm{~cm}^{2}$ was used as the cathode which was parallelly placed $1 \mathrm{~cm}$ far away from a graphite plate with a dimension of $3 \times 4 \times 0.1 \mathrm{~cm}$, served as the counter electrode.

The AC signal shown in Fig. 5-1 was generated by an Agilent Technologies 33210A function generator. A Model 9100 amplifier with a fixed gain of 20 (Tabor Electronics Ltd) was used to amplify the signal. The resulting AC signal was monitored by a digital oscilloscope (Siglent SDS1102CML). Unless otherwise specified, the forward voltage step of -100 V and reverse voltage step of $+80 \mathrm{~V}$, with $50 \%$ forward width percentage $\left(\mathrm{T}_{\mathrm{f}} /\left(\mathrm{T}_{\mathrm{f}}+\mathrm{T}_{\mathrm{r}}\right)\right)$ were used. A DC power source (GENH750W) with a voltage range of $0-600 \mathrm{~V}$ and a current range of $0-3.6 \mathrm{~A}$ was used to provide DC current and voltage in selected experiments. 


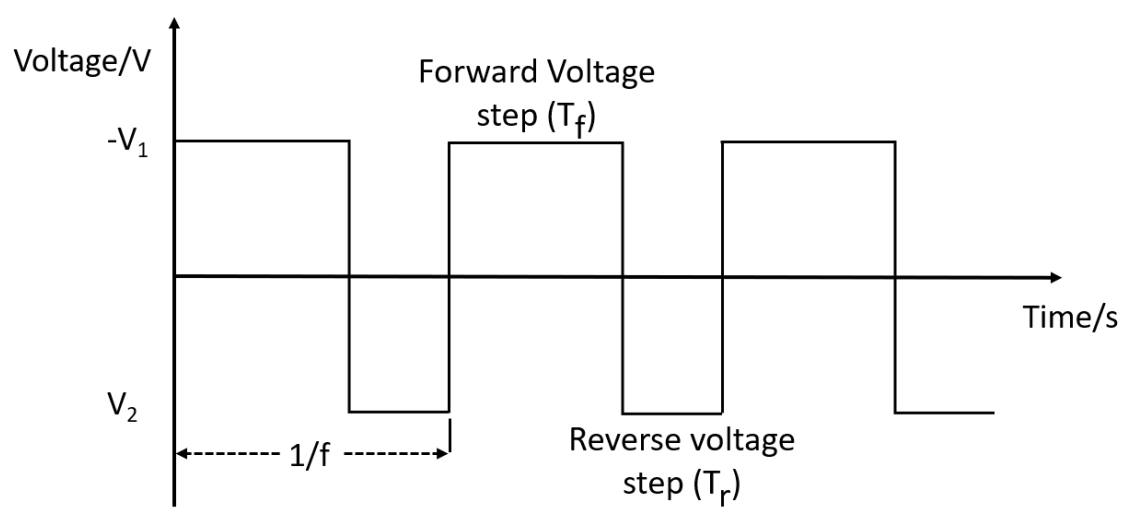

Fig 5-1 the figure of the applied AC signal

\subsubsection{Characterization}

The morphology and thickness of GDC layers formed on PPy coated YSZ was characterized by scanning electron microscope (SEM) before and after sintering by using a carefully adjusted heating process to non-destructively remove the polymer [53]. The deposit yield was determined by weighing the deposit along with the cathode after drying at $100{ }^{\circ} \mathrm{C}$ for $24 \mathrm{~h}$ in air. Every data in the present study is an average of three measurements.

As shown in our previous work [55], the current was measured by monitoring the voltage drop over a resistance with a fixed value of $10 \Omega$ connected in series with the EPD cell using a digital oscilloscope (Siglent SDS1102CML). Since the ohmic resistance of the suspension between these two electrodes is about $450 \Omega$ which is far higher than $10 \Omega$ [52], the effect of an extra 10 $\Omega$ in the EPD cell on the current density is negligible.

\subsubsection{Long-term stability}

A layer of $(\mathrm{LaSr})(\mathrm{CoFe}) \mathrm{O}_{3-\delta}(\mathrm{LSCF})+\mathrm{GDC}$ with a ratio of 1:1 and a thickness of $20 \mu \mathrm{m}$ was coated on the top of the obtained GDC layer sintered at $1250{ }^{\circ} \mathrm{C}$ by spin coating followed by 
sintering at $1100^{\circ} \mathrm{C}$ for $2 \mathrm{~h}$. Finally, this assemble was sintering at $800{ }^{\circ} \mathrm{C}$ for $500 \mathrm{~h}$. The crosssection and elemental distribution of this LSCF+GDC/GDC/YSZ specimen were examined by scanning electron spectroscopy (SEM) equipped with an energy disperse X-ray (EDS) analysis system.

\subsection{Results}

\subsubsection{Effect of frequency}

Fig. 5-2 shows the cross-sectional morphology of pure GDC layers formed by DC-EPD at -100 V (Fig. 5-2a) and AC-EPD with different frequencies (Fig. 5-2b-f) after sintering at $1350{ }^{\circ} \mathrm{C}$, respectively. As shown in Fig. 5-2a, the GDC layer formed by DC-EPD is porous which could undermine the effectiveness of the barrier layer. In contrast, the density of GDC layer obtained by using an asymmetric AC signal shown in Fig. 5-1 is improved with the increasing frequency from $10 \mathrm{~Hz}$ to $2 \mathrm{KHz}$. Dense GDC layer with good adhesion with YSZ substrate could be obtained when the frequency reaches $500 \mathrm{~Hz}$ or higher. The application of AC-EPD instead of DC-EPD successfully densifies the GDC layer, suggesting the pores in the GDC layers result from the bubble evolution associated with the accompanying electrochemical reaction (i.e., proton reduction and hydrogen evolution reaction (HER)) other than the inappropriate sintering temperature $[53,65]$. There are several possible mechanisms for the denser layer observed with the AC-EPD: the alternating electric field may shake the particles slightly, allowing them to pack more tightly $[65,152]$; the electrohydrodynamic flow (EHF) around the GDC particles near working electrode may drive them to pack closely [153-155] and the absence of microscopic hydrogen bubbles also may encourage better packing in the green layer $[55,65]$. 

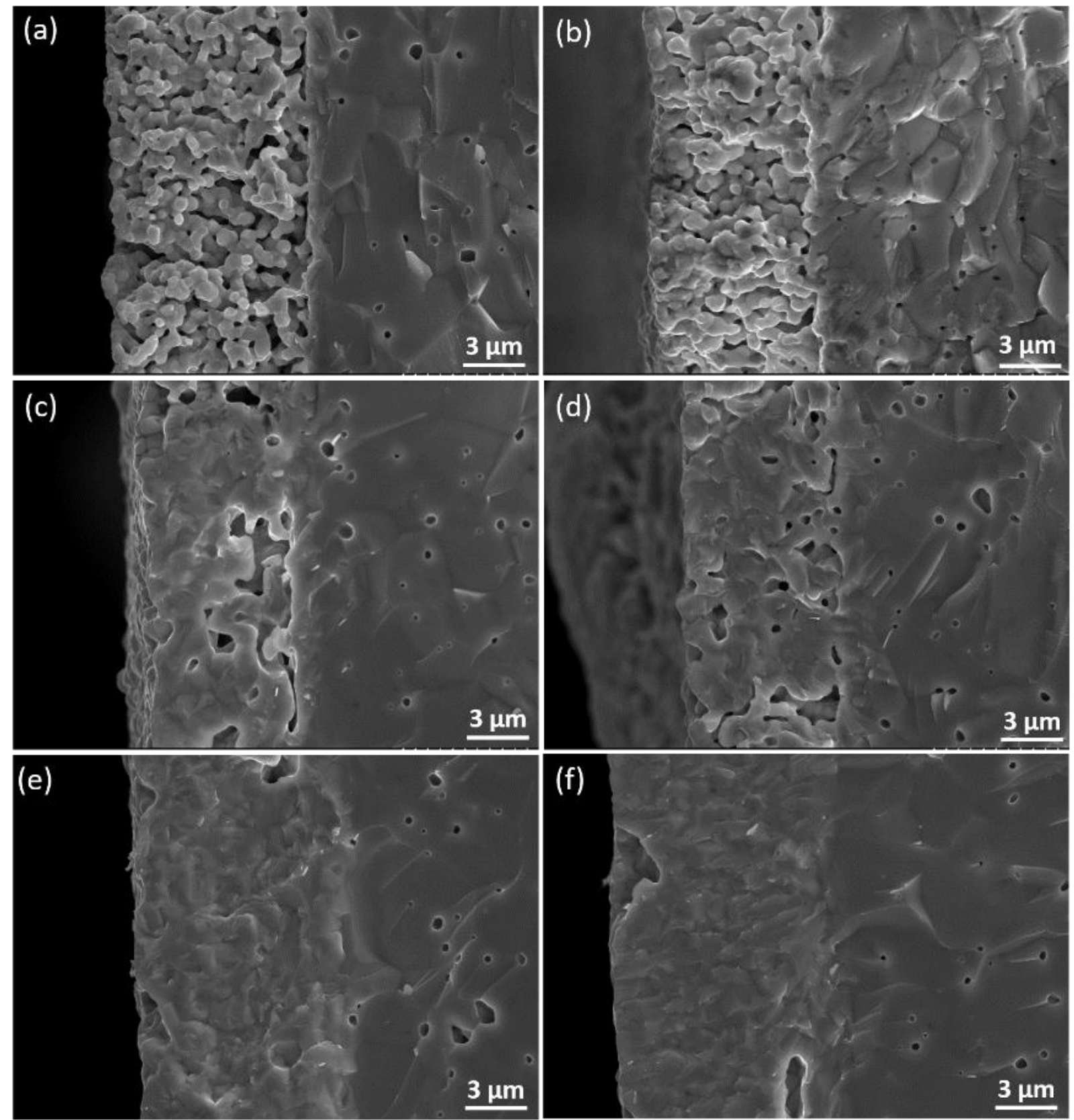

Fig 5-2 The cross-sectional morphologies of GDC layers formed on PPy coated YSZ by DC-EPD at-100 V (a) and AC-EPD with a frequency of $10 \mathrm{~Hz}(b), 100 \mathrm{~Hz}(c), 200 \mathrm{~Hz}(d), 500 \mathrm{~Hz}$ and $1 \mathrm{KHz}$ (voltage ratio: $-100 /+80, \mathrm{D}: 50 \%$ ) after sintering at $1350^{\circ} \mathrm{C}$ for $4 \mathrm{~h}$

To further declare the effect of frequency on the deposition behavior of GDC particles, the deposit yield for a fixed time of $10 \mathrm{~min}$ is plotted as a function of frequency with other 
parameters identical (Fig. 5-3). As depicted in Fig. 5-3, when the frequency increases from 10 $\mathrm{Hz}$ to $500 \mathrm{~Hz}$, the deposit mass grows corresponding. Further increase of frequency from $500 \mathrm{~Hz}$ to $5 \mathrm{KHz}$ lowers the deposit weight. An optimum frequency of $500 \mathrm{~Hz}$ leads to the maximum deposit yield in a specified time. Hence, the frequency was fixed at $500 \mathrm{~Hz}$ in the following study.

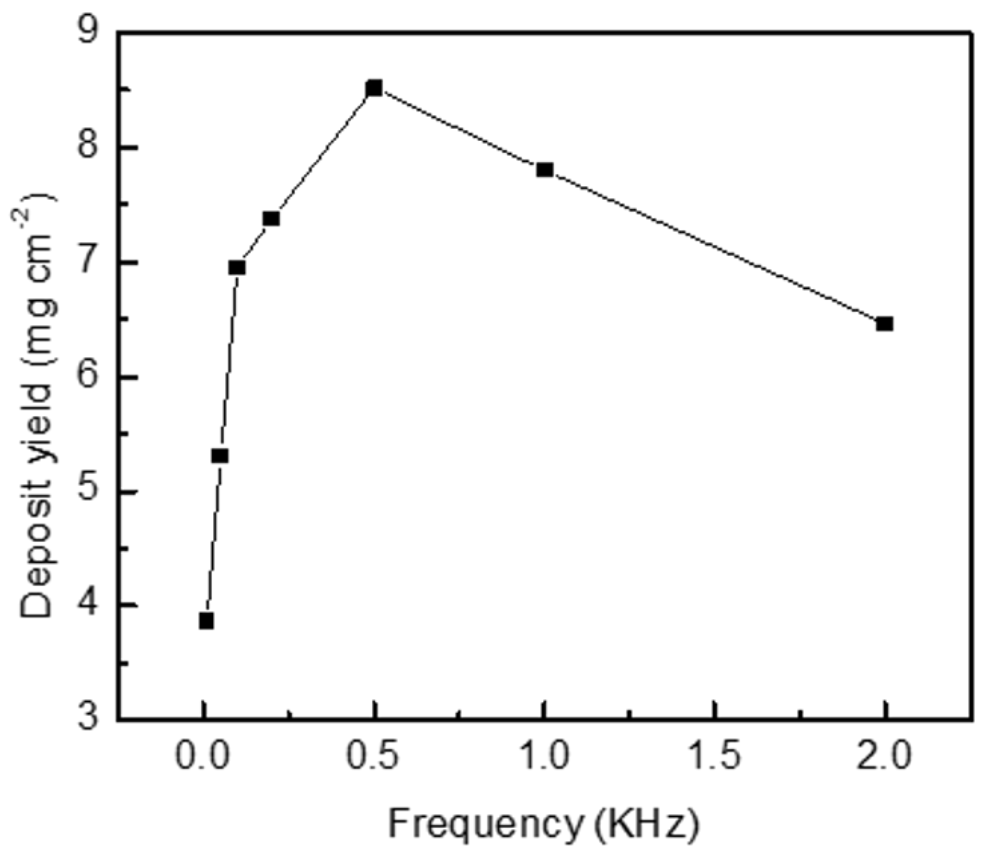

Fig 5-3 The deposit yield for 10 min as a function of frequency (voltage ratio: -100/+80; forward width percentage: $50 \%)$

\subsubsection{Effect of voltage ratio and forward width percentage}

Beside the frequency, another two parameters related to the AC electric field, voltage ratio and forward width percentage, are also expected to affect the deposition rate of GDC particles. Therefore, the effects of both factors on the deposit weight for a fixed time of $10 \mathrm{~min}$ are also characterized in Fig. 5-4. As illustrated in Fig. 5-4, the deposit mass increases with the growing 
voltage ratio or the forward width percentage as the net driving force rises correspondingly. The asymmetry of the voltage ratio ensures that there is a net flux of GDC particles to the working electrode; a symmetric voltage wave form $(-100 /+100 \mathrm{~V}, 50 \%$ duty cycle) results in no net deposit of GDC on the working electrode.
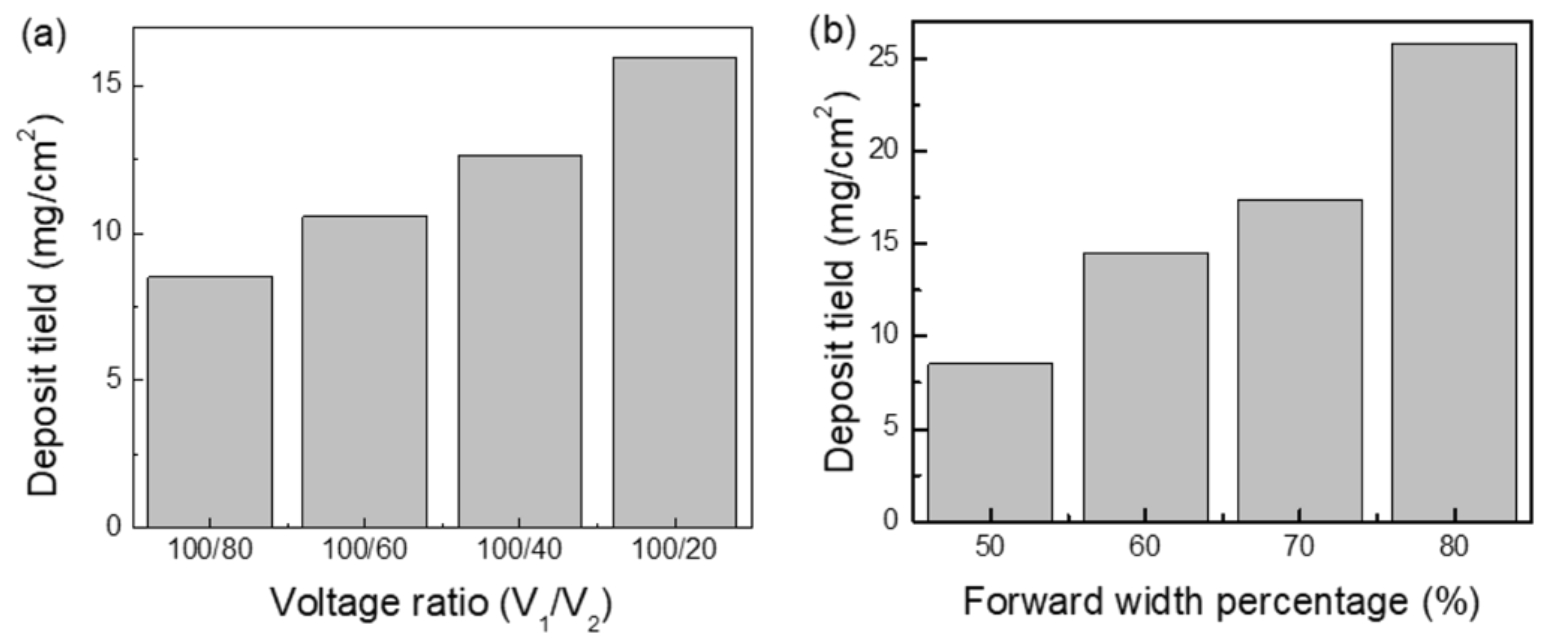

Fig 5-4 The deposit weight for 10 min as a function of (a) voltage ratio (frequency: $500 \mathrm{~Hz}$; forward width percentage: $50 \%$ ) and (b) forward width percentage (frequency: $500 \mathrm{~Hz}$; Voltage ratio: -100/+80)

\subsubsection{Morphology}

As shown in Fig. 5-2, the GDC layers obtained by AC-EPD with a frequency of $500 \mathrm{~Hz}$ or higher are almost dense with few discontinuous pinholes after sintering at $1350{ }^{\circ} \mathrm{C}$ which could effectively prevent the reaction between LSCF and YSZ. However, sintering at $1350{ }^{\circ} \mathrm{C}$ leads to the solid-state reaction between YSZ and GDC, yielding some insulating phase, which decreases the cell performance [156]. To lower the densification temperature, 2 at $\% \mathrm{FeO}_{1.5}$ is added in the GDC powder as sintering aid to improve its sintering ability. The process of the addition of $\mathrm{FeO}_{1.5}$ is described in our previous work (section 4.3.5) [53]. Fig. 5-5 shows the surface and 
cross-section morphology of GDC with 2 mol\% $\mathrm{FeO}_{1.5}$ obtained by AC-EPD at $500 \mathrm{~Hz}$, a voltage ratio of $-100 /+80$ and a forward width percentage of $50 \%$ followed by sintering at 1250 ${ }^{\circ} \mathrm{C}$ for 4 h. As shown in Fig. 5-5, the GDC layer is almost dense with few isolated pinholes, suggesting it is adequate to act as the barrier layer. The following GDC layer in the long-term stability test was electrophoretically deposited using the same experimental parameters.
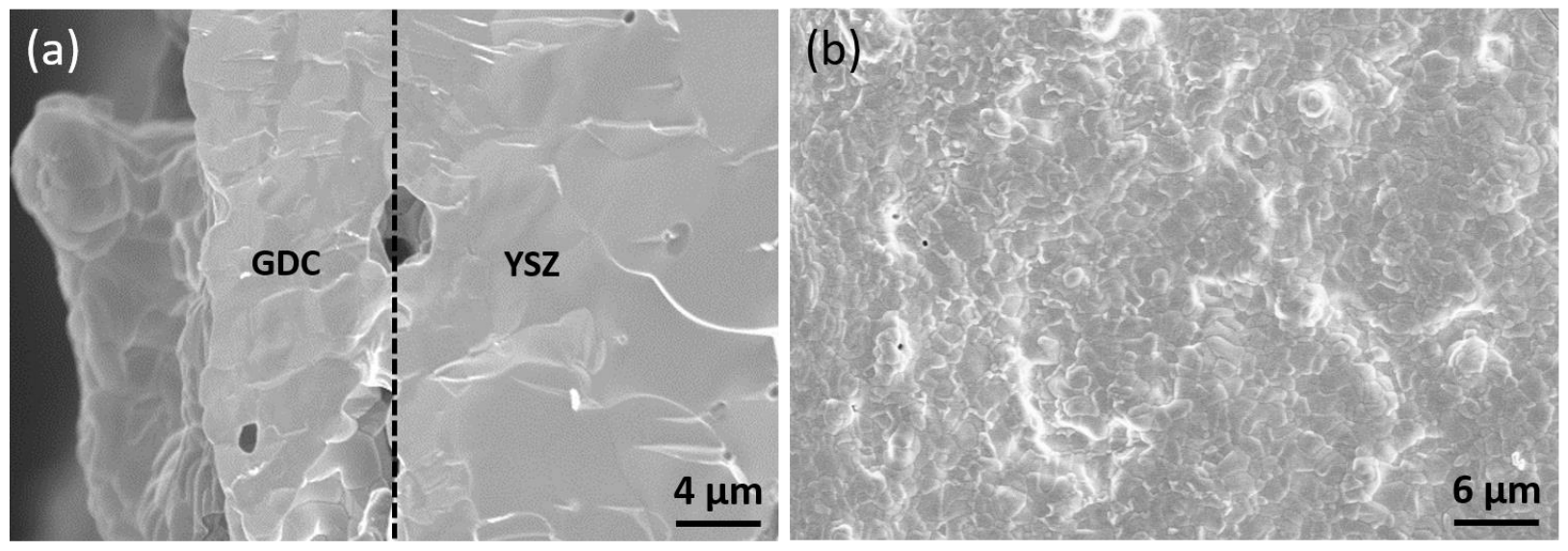

Fig 5-5 The surface and cross-sectional morphology of GDC with 2 at\% $\mathrm{FeO}_{1.5}$ after sintering at $1250^{\circ} \mathrm{C}$

\subsubsection{Long-term stability}

Fig. 5-6 shows the SEM image and EDX line scan image along the cross section of $\mathrm{LSCF}+\mathrm{GDC} / \mathrm{GDC} / \mathrm{YSZ}$ specimen. As shown in Fig. 5-6a, the obtained GDC is almost dense with few discontinued pinholes. Furthermore, no visible Sr diffusion was detected after $500 \mathrm{~h}$ (Fig. 5-6b), suggesting this GDC layer is adequate to act as the barrier layer to eliminate the reaction between LSCF and YSZ. 

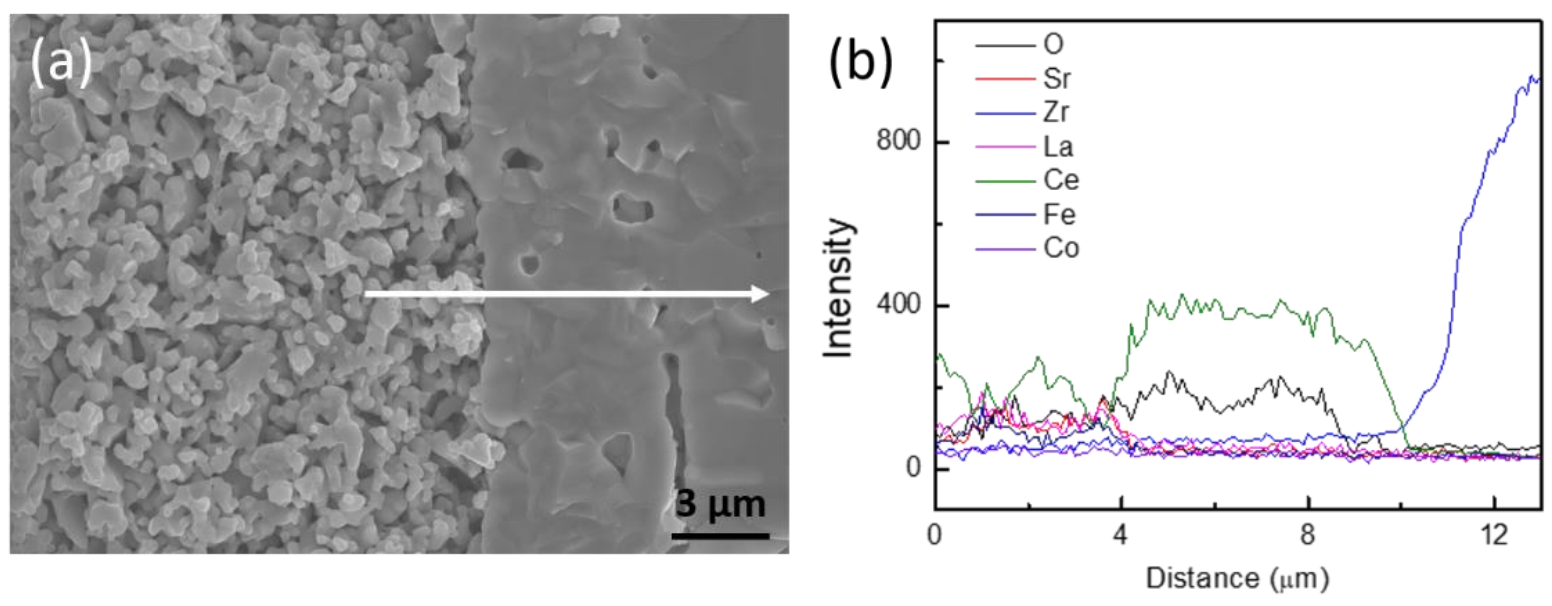

Fig 5-6 Cross-sectional morphology of the full cell and the EDX result after test

\subsection{Discussion}

\subsubsection{Effect of parameters of AC electric field}

The electrochemical reactions accompanying the deposition process are shown in the following equations $[52,157]$ :

$$
\text { Anode: } 2 \mathrm{H}_{2} \mathrm{O}-4 \mathrm{e}^{-} \rightarrow \mathrm{O}_{2}+4 \mathrm{H}^{+}
$$

$$
\text { Cathode: } 2 \mathrm{H}^{+}+2 \mathrm{e}^{-} \rightarrow \mathrm{H}_{2} \quad(5-2 \mathrm{a}) \quad \text { or } 2 \mathrm{H}_{2} \mathrm{O}+2 \mathrm{e}^{-} \rightarrow \mathrm{H}_{2}+2 \mathrm{OH}^{-}
$$

Due to the poor conductivity of PPy, the contact resistance of PPy coated YSZ cannot be neglected [52]. The equivalent circuit for the working electrode of this EPD cell is shown in Fig. $5-7$; the effect of the counter electrode is neglected in this discussion. $R_{1}$ is the ohmic resistance of the suspension between the two electrodes, $\mathrm{R}_{2}$ is the polarization resistance of the faradic current at the electrode surface, $\mathrm{C}_{1}$ is the capacitance of the double layer in the contacting electrolyte, and $\mathrm{R}_{3}$ is the contact resistance of the PPy coated YSZ. 


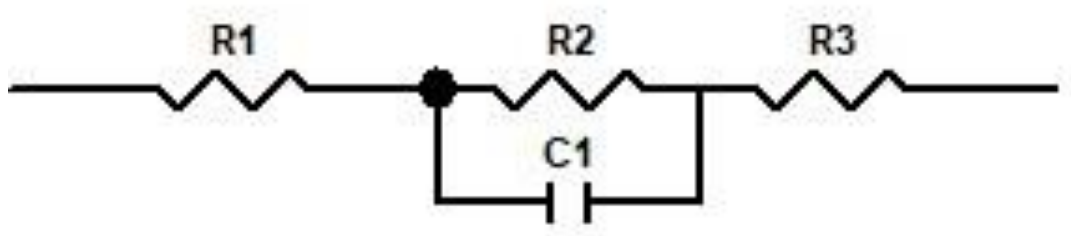

Fig 5-7 The equivalent circuit of the EPD cell

In DC-EPD, almost all the current flows through $\mathrm{R}_{2}$ resulting in hydrogen bubble evolution at the cathode due to the hydrogen evolution reaction (HER) (Eq. (5-2a and 5-2b)) which in turn affects the quality and green density of GDC layer (Fig. 5-2a). In contrast, the AC current from the voltage pulses also charges the double layer $\left(\mathrm{C}_{1}\right)$. Fig. 5-8 depicts the current density as a function of time in one period in AC-EPD with different frequencies. The total current is the sum of faradaic current $\left(\mathrm{R}_{2}\right)$ and charging current $\left(\mathrm{C}_{1}\right)$. The faradaic current grows from zero gradually to a plateau while charging current decays exponentially with time after each voltage step. At a very low frequency, i.e., $0.1 \mathrm{~Hz}$ (Fig. 5-8a), the current density decays to a plateau with a value of $0.44 \mathrm{~mA} \mathrm{~cm}^{-2}$, suggesting that the charging current decreases to zero when the faradaic current density rises to $0.44 \mathrm{~mA} \mathrm{~cm}^{-2}$. When the frequency is increased to higher frequencies, no plateau is observed. Moreover, the current density right before switching the from negative to positive voltage grows from $1.24 \mathrm{~mA} \mathrm{~cm}^{-2}$ to $2.08 \mathrm{~mA} \mathrm{~cm}^{-2}$ with the increase of frequency from $1 \mathrm{~Hz}$ to $1 \mathrm{KHz}$. These experimental results are consistent with decreasing faradic current flowing through $\mathrm{R}_{2}$ with increasing frequency, resulting in less hydrogen gas bubbles and a denser green GDC layer. The increase of density (Fig. 5-2 a-e) and deposit mass (Fig. 5-3) with the increase of frequency from $10 \mathrm{~Hz}$ to $500 \mathrm{~Hz}$ are caused by the weakened bubble evolution as the amount of faradaic current on the forward step decreases. However, a further increase in the frequency from $500 \mathrm{~Hz}$ to $5 \mathrm{KHz}$ lowers the deposit weight (Fig. 5-3) since the duration of the 
driving force acting on the particles decreases correspondingly. This effect is attributed to the minimum time to accelerate the GDC particles to their steady state velocity in the electric field. An optimum frequency is $500 \mathrm{~Hz}$ therefore effectively minimizes the bubble evolution and maximizes the deposition rate. A similar result has been observed for the deposition of doped ceria in the aqueous suspension [55].

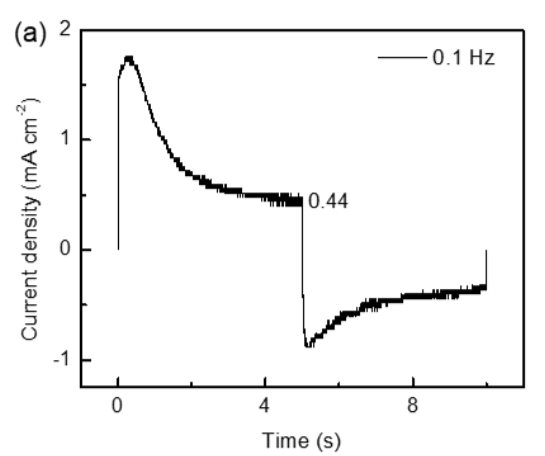

(d)
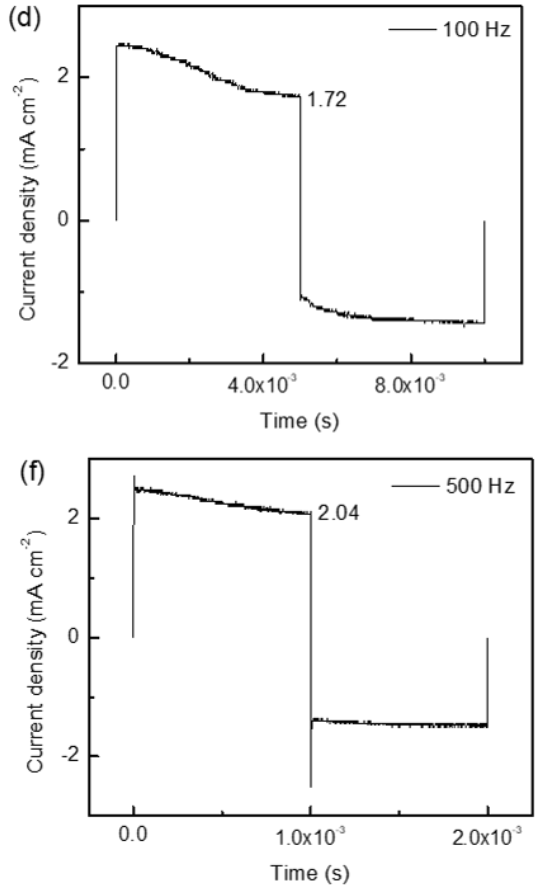
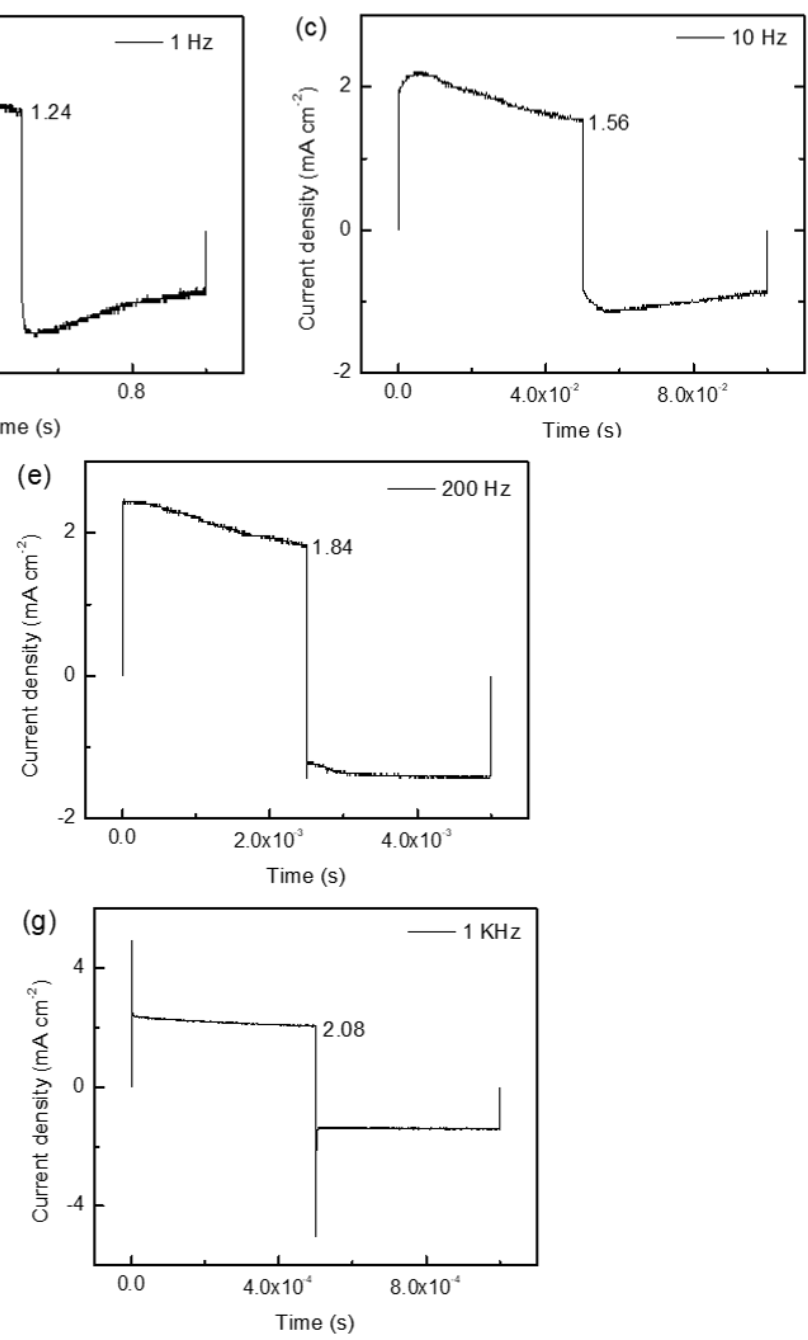

Fig 5-8 Time dependence of current density in one period in AC-EPD with different frequencies (a) $0.1 \mathrm{~Hz}$, (b) $1 \mathrm{~Hz}$, (c) $10 \mathrm{~Hz},(d) 100 \mathrm{~Hz},(e) 200 \mathrm{~Hz},(f) 500 \mathrm{~Hz}$ and (g) $1 \mathrm{KHz}$ 
Fig. 5-9 shows the time dependence of current density in one period in AC-EPD with different voltage ratios and forward width percentages. With the increase of voltage ratio from $-100 /+80$ to $-100 /+20$ and forward width percentage from $50 \%$ to $80 \%$, the net electric charge (the difference in the integrated current for the forward and reverse steps) in one period increases from $0.65 \mu \mathrm{C} \mathrm{cm}^{-2}$ to $1.48 \mu \mathrm{C} \mathrm{cm}^{-2}$ and $2.31 \mu \mathrm{C} \mathrm{cm}^{-2}$, respectively, leading to a faster deposition rate. As noted previously, no GDC deposit is obtained under an AC electric field symmetric in both voltage magnitude and pulse time since the net electrophoretic current is zero. Similar results have been also reported in other systems [55, 65].
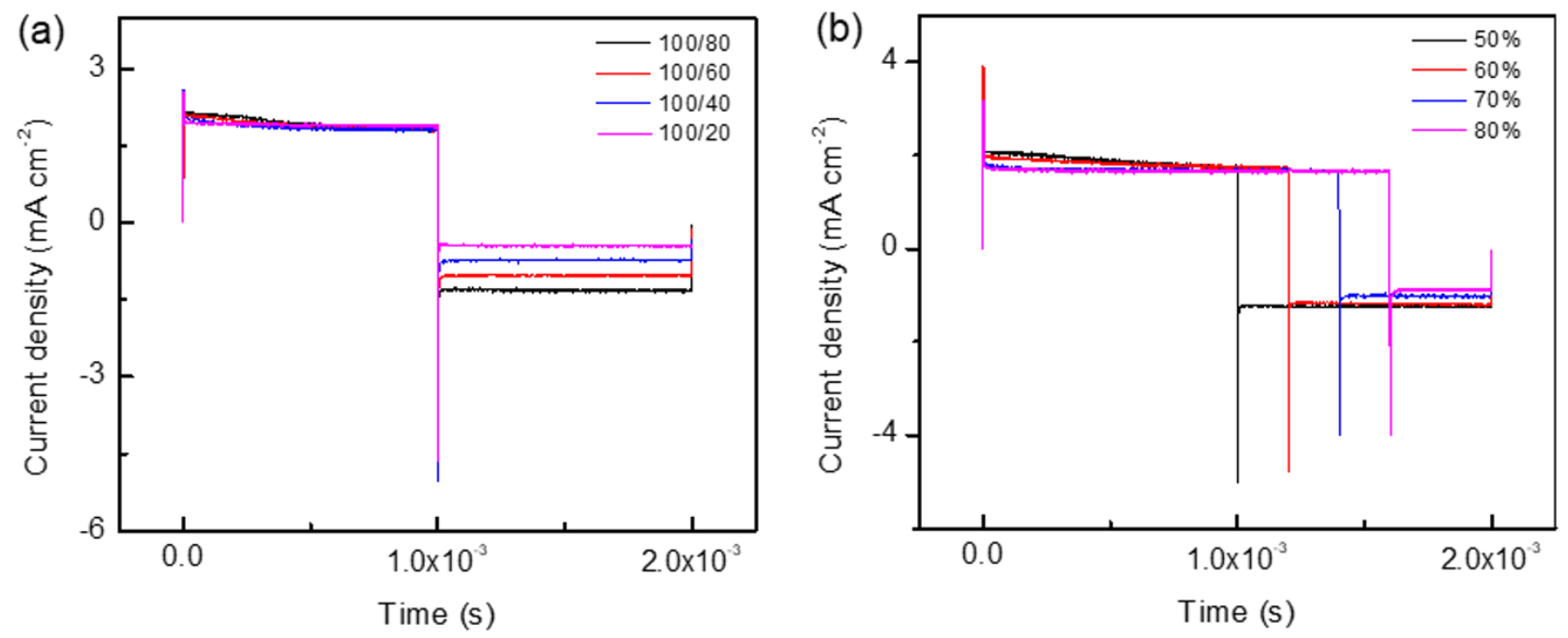

Fig 5-9 Current density as a function of time in one period in AC-EPD with different (a) voltage ratios and (b) forward width percentage

\subsubsection{AC-EPD mechanism}

According to the model discussed previously [52], the $\mathrm{H}^{+}$ions in the suspension are divided into two categories: free $\mathrm{H}^{+}$ions and absorbed $\mathrm{H}^{+}$ions. Fig. 5-10 depicts the schematic of EPD process. Free $\mathrm{H}^{+}$ions move independently while absorbed $\mathrm{H}^{+}$ions migrate along with particles 
to the cathode (transport process) when a potential gradient is applied. When the charged particles reach the deposit/ suspension interface, the particles deposit onto the existing deposit while the absorbed $\mathrm{H}^{+}$ions desorb from the particles (desorption process) and continue to diffuse through the deposit to the cathode (diffusion process) where the charge transfer takes place (charge transfer process). After desorption, there is no difference between free $\mathrm{H}^{+}$ions and absorbed $\mathrm{H}^{+}$ions. Four steps are involved in the reduction of absorbed $\mathrm{H}^{+}$ions shown in the following $\mathrm{Eq}(5-3)[52]$ :

$$
\begin{aligned}
& H_{a b, \text { bulk }}^{+} \stackrel{\text { transport process }}{\longrightarrow} H_{a b \text {, interface }}^{+} \stackrel{\text { desorption process }}{\longrightarrow} H_{\text {free, interface }}^{+} \\
& \stackrel{\text { diffusion process }}{\longrightarrow} H_{\text {free, surface }}^{+} \stackrel{\text { charge transfer process }}{\longrightarrow} H_{2}
\end{aligned}
$$

$H_{a b, b u l k}^{+}$is the absorbed $\mathrm{H}^{+}$ion in the bulk suspension, $H_{a b \text {, interface }}^{+}$is the absorbed $\mathrm{H}^{+}$ion at the suspension/ deposit interface, $H_{\text {free, interface }}^{+}$is the free $\mathrm{H}^{+}$ion at the suspension/ deposit interface, and $\mathrm{H}_{\text {free, surface }}^{+}$is the free $\mathrm{H}^{+}$ion in the vicinity of cathode.

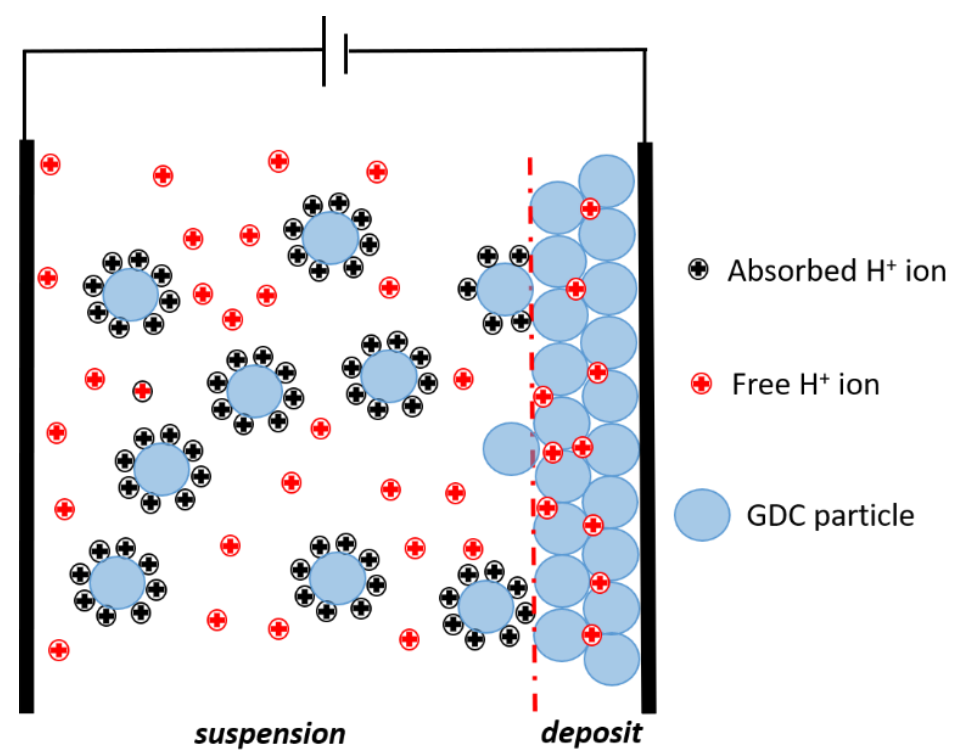

Fig 5-10. The schematic of EPD process 
When the voltage is too low to drive the charge transfer step, free $\mathrm{H}^{+}$ions and positively charged GDC particles accumulate in the vicinity of cathode while the anions gather in the proximity of anode. As a result, the effective electric strength drops to zero and no deposition occurs. Under a direct current (DC) voltage of $2 \mathrm{~V}$ without visible bubble evolution, no GDC deposit is found regardless of the deposition time. A similar result was found by Böhmer. et al in which some small clusters instead of an intact film were obtained under a voltage of $2 \mathrm{~V}$ after $30 \mathrm{~min}$; the clusters broke up when a reversed voltage was reapplied [155]. Furthermore, no GDC deposit is found on the anode in the aqueous suspension with a $\mathrm{pH}$ of 9.0 in which the GDC particles are negatively charged while applying a constant current of $4 \mathrm{~mA} \mathrm{~cm}^{-2}$ and suppressing the oxygen evolution reaction (OER) with $0.1 \mathrm{M} \mathrm{K}_{4} \mathrm{Fe}(\mathrm{CN})_{6}$ [55]. In this system, the oxidation of $\mathrm{K}_{4} \mathrm{Fe}(\mathrm{CN})_{6}$ to $\mathrm{K}_{3} \mathrm{Fe}(\mathrm{CN})_{6}$ preferentially occurs instead of $\mathrm{OER}$ at the anode and bubble formation is avoided [158]. These experimental results demonstrate that GDC particles could deposit onto the electrode only after fully losing their charge (charge transfer step in Eq. (5-3)) in contact with the existing deposit or the deposition electrode in DC-EPD.

Because the polarity of both electrodes changes periodically in the applied AC electric field, it is necessary to probe the reversibility of the desorption of absorbed $\mathrm{H}^{+}$ions. To achieve this goal, the deposit yield was measured in the following way. First, the weight of a fully dry graphite plate was measured as a blank. Subsequently, a DC voltage of $-100 \mathrm{~V}$ was applied to deposit the GDC layer. Then the mass of the blank sample coated with GDC layer was determined after fully drying at $100{ }^{\circ} \mathrm{C}$ in air for $24 \mathrm{~h}$. Next, a positive DC voltage was reapplied to the coated graphite plate to simulate the deposition behavior during the reverse step of the AC signal. Finally, the weight of this blank sample and GDC layer was measured again after fully drying. The distance between the working and counter electrodes was fixed as $1 \mathrm{~cm}$. The corresponding 
masses were shown in Table. 5-1. After applying the reverse (positive) voltage, the deposit yield decreases by less than $4 \%$. The decrement almost remains the same regardless of the time and applied voltage. Moreover, the surfaces of all samples are similar: the layers are rough with many visible craters and pits caused by the bubble evolution. The experimental result in Table 51 suggests that the small mass loss of the deposit yield is due to the bubble evolution associated with the oxygen evolution reaction (OER) rather than the deagglomeration of the formed GDC layer, implying that the desorption process of absorbed $\mathrm{H}^{+}$ions is irreversible and that reversing the electric field does not deagglomerate the formed GDC deposit.

Table 5-1 the deposit mass before and after the reversed EPD under different conditions

\begin{tabular}{ccccc}
\hline $\begin{array}{c}\text { Reversed EPD } \\
\text { parameters }\end{array}$ & $\begin{array}{c}\text { Deposit mass before } \\
\text { reversed EPD/mg cm }{ }^{-2}\end{array}$ & $\begin{array}{c}\text { Deposit mass after } \\
\text { reversed EPD } / \mathrm{mg} \mathrm{cm}^{-2}\end{array}$ & $\begin{array}{c}\text { Decrement of deposit } \\
\text { mass } / \mathrm{mg} \mathrm{cm}^{-2}\end{array}$ & $\begin{array}{c}\text { Decrement } \\
\text { percentage/\% }\end{array}$ \\
\hline $80 \mathrm{~V}, 5 \mathrm{~min}$ & 34.875 & 33.6 & 1.275 & 3.655914 \\
$80 \mathrm{~V}, 8 \mathrm{~min}$ & 34.625 & 33.4 & 1.225 & 3.537906 \\
$80 \mathrm{~V}, 10 \mathrm{~min}$ & 37.225 & 35.925 & 1.3 & 3.492277 \\
$80 \mathrm{~V}, 12.5 \mathrm{~min}$ & 37.025 & 35.775 & 1.25 & 3.376097 \\
$50 \mathrm{~V}, 8 \mathrm{~min}$ & 40.525 & 39.025 & 1.5 & 3.701419 \\
$100 \mathrm{~V}, 8 \mathrm{~min}$ & 38.875 & 37.625 & 1.25 & 3.215434 \\
\hline
\end{tabular}

In Eq. (5-3), the transport process is reversible since the direction of driving force exerted on charged GDC particles changes periodically in consonance with the applied AC electric field. Hence, no GDC deposit is obtained in a symmetric AC electric field. In contrast, a GDC deposit is obtained by using an asymmetric AC electric field at $500 \mathrm{~Hz}$ with negligible faradic current, suggesting that the $\mathrm{H}^{+}$ions are permanently removed from the adsorbed GDC particles. The deposit mass is proportional to the net electric charge if the deposition rate of GDC particles is solely determined by the transport process. To determine the rate-determining step in AC-EPD, 
the current density and deposit mass as a function of time under AC-EPD at $500 \mathrm{~Hz}$ were characterized (Fig. 5-11). The net electric charge (the integral of current density by time) in one period for graphite $\left(4.25 \mu \mathrm{C} \mathrm{cm}^{-2}\right.$; charge for the forward voltage step: $18.67 \mu \mathrm{C} \mathrm{cm}^{-2}$; charge for reverse voltage step: $\left.14.42 \mu \mathrm{C} \mathrm{cm}^{-2}\right)$ is 5.13 times as much as that for PPy coated YSZ $(0.83 \mu \mathrm{C}$ $\mathrm{cm}^{-2}$; charge for the forward voltage step: $2.27 \mu \mathrm{C} \mathrm{cm}^{-2}$; charge for the reverse voltage step: 1.44 $\mu \mathrm{C} \mathrm{cm}^{-2}$ ) while the deposition rate on graphite is just 1.65 time as fast as that on PPy coated YSZ. This observation suggests that the deposition of GDC particles in AC-EPD with negligible charge transfer process is jointly controlled by the transport process (reversible) and the desorption process (irreversible) in Eq. (5-3) and confirms the previous observation that more GPD is deposited per coulomb on the PPy-coated YSZ electrode than on the graphite electrode (Fig. 4-10). Moreover, the deposition yield is proportional to the deposition time (Fig. 5-11b), indicating the possibility of fabricating tunable thicknesses of GDC layers by AC-EPD.
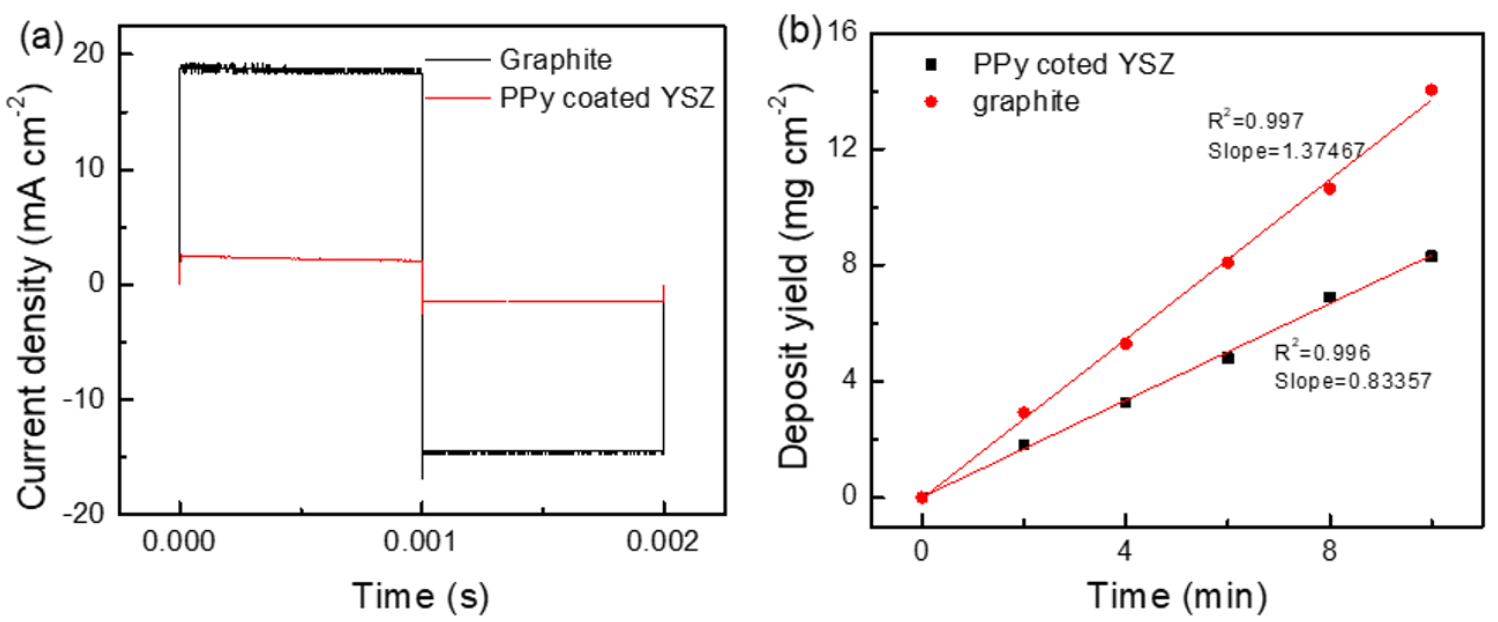

Fig 5-11 (a) current density in one period and (b) deposit mass as a function of time under AC-EPD at $500 \mathrm{~Hz}$

Based on these experimental results, the schematic model of the deposition of GDC on PPy coated YSZ in AC-EPD with negligible faradic current is depicted in Fig. 5-12. Under the effect 
of a potential graident, both free $\mathrm{H}^{+}$ions and positively charged GDC particles migrate to the deposition electrode, i.e., PPy coated YSZ (Fig. 5-12a: forward - transport process). As a part of the charged GDC particles reach the working electrode or the existing deposit, they stick to it while absorbed $\mathrm{H}^{+}$ions desorb from particles to be free $\mathrm{H}^{+}$ions (Fig. 5-12b: forward desorption process). When reversing the direction of applied electric field, free $\mathrm{H}^{+}$ions and charged GDC particles in the suspension move towards the counter electrode. Hence, the migration distance of charged particles is almost zero in one period under a symmetric electric field, thus no deposit is obtained. In contrast, the deposited GDC particles still remain on the existing deposit or working electrode surface as they do not carry any charge after desorption (Fig. 5-12c: backward - transport process). After the direction was switched back, processes in Fig. 5-12 $\mathrm{a}$ and $\mathrm{b}$ are repeated, resulting in a growing GDC deposit (Fig. 5-12d). 
(a)

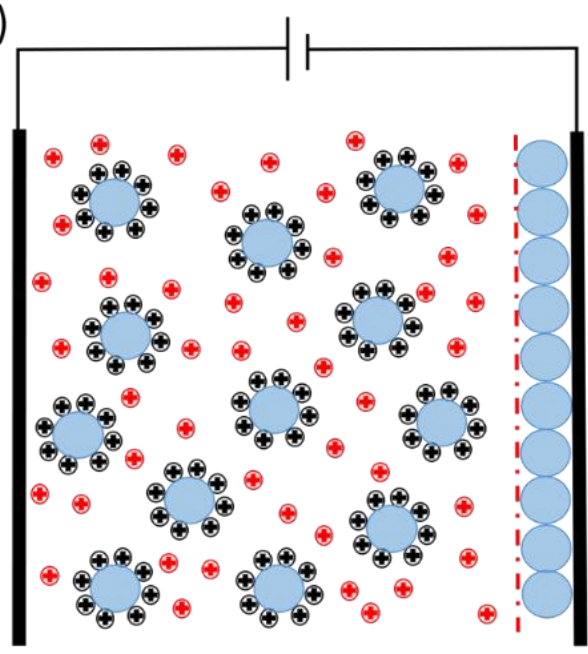

(c)

Forward - transport process

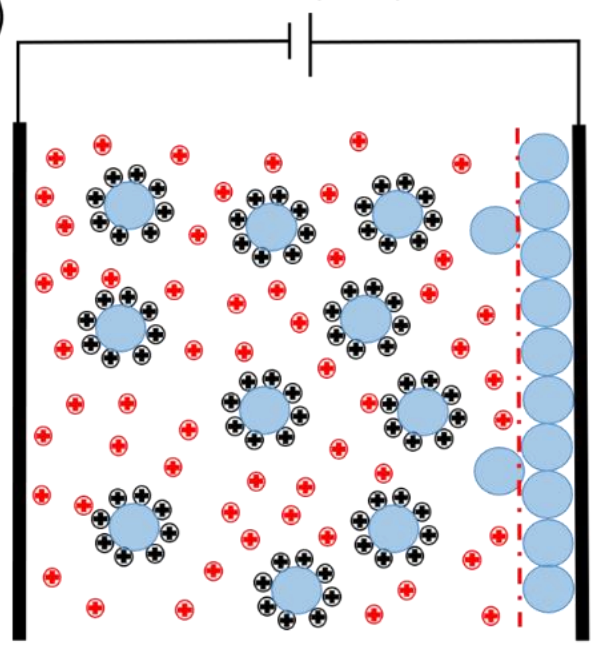

Backward - transport process (b)

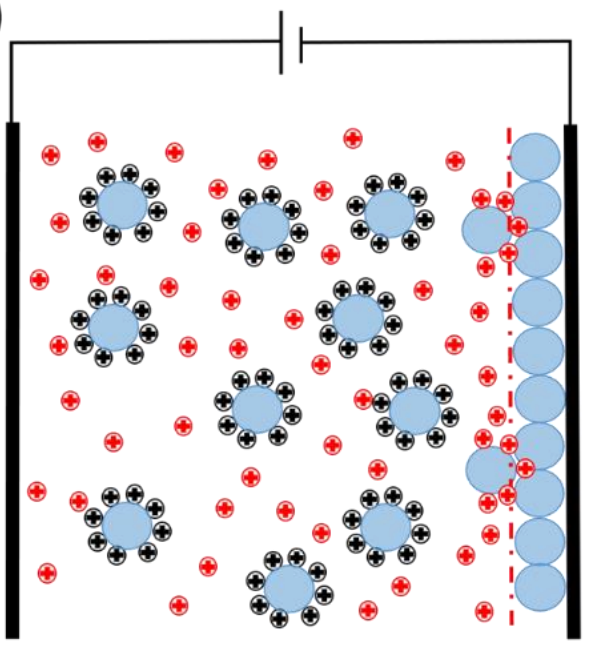

(d)

Forward - desorption process

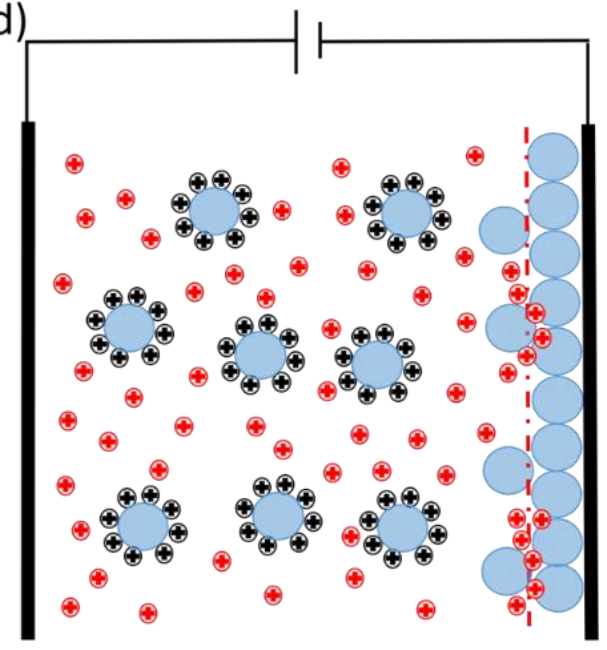

Forward - desorption process

Fig 5-12 The schematic model of the mechanism of AC-EPD of GDC particles

\subsection{Summary}

A dense GDC layer is successfully obtained by AC-EPD with a frequency of $500 \mathrm{~Hz}$ after sintering at a relatively low temperature, e.g., $1250{ }^{\circ} \mathrm{C}$ which could effectively eliminate the reaction between LSCF and YSZ. An optimum frequency of $500 \mathrm{~Hz}$ leads to the maximum deposition rate by balancing the suppression of bubble evolution and boost of the particle migration. The deposit yield in a given time grows with the increase of voltage ratio and forward 
width percentage. In AC-EPD with negligible faradic current, the deposition rate of GDC particles is determined both by the transport process and the desorption process, wherein the latter one is an irreversible process. The deposit yield is monotonically controlled by the deposition time, suggesting the possibility of fabrication of GDC layer with tunable thickness. 


\section{Chapter 6 Alternating Current Electrophoretic Deposition of}

\section{Gadolinium Doped Ceria in the Aqueous Suspension}

\subsection{Introduction}

In chapter 4 and 5, ethanol has been confirmed to be suitable to well disperse GDC powder with the addition of some iodine. However, compared with organic suspensions, e.g., ethanol, aqueous suspensions are more favorable due to the environmental benignity, low cost and low toxicity of water [159]. In this chapter, distilled water is utilized instead of ethanol to prepare a stable suspension to realize the deposition of GDC particles in aqueous suspensions. To investigate some crucial factors governing the deposition behavior of GDC films, we use conductive Ti substrate to optimize coating processes.

\subsection{Experimental details}

The suspension was prepared by dispersing $2.0 \mathrm{~g}$ commercial gadolinium doped ceria $\left(\mathrm{Gd}_{0.1} \mathrm{Ce}_{0.9} \mathrm{O}_{1.95}\right.$, Full Cell Materials Co., surface area of $\left.11.6 \mathrm{~cm}^{2} \mathrm{~g}^{-1}\right)$ in $50 \mathrm{~mL}$ distilled water followed by ultrasonication for $30 \mathrm{~min}$. The $\mathrm{pH}$ of the suspension was adjusted by adding commercial sodium carbonate/ sodium bicarbonate (OMEGA, $\mathrm{pH}=10.01$ ) and potassium hydrogen phthalate (OMEGA, $\mathrm{pH}=4.01)$ buffer solutions. Zeta potential and agglomeration particle distribution were measured by Zetasizer Nano ZS.

Two titanium plates $(2 \mathrm{~cm} \times 10 \mathrm{~cm} \times 0.2 \mathrm{~cm})$ were used as a working electrode for deposition and a counter electrode, respectively, which were placed in the suspension with a distance of 1 
$\mathrm{cm}$. The exposed area of the Ti plate for deposition was $2 \mathrm{~cm} \times 2 \mathrm{~cm}$ by masking other areas with silicone rubber.

The AC signal shown in Fig. 6-1a was generated by Agilent Technologies 33210A function generator. A Model 9100 amplifier with a fixed gain of 20 (Tabor Electronics Ltd) was used to amplify the signal. The resulting AC signal, with a $10 \mathrm{~V}$ positive voltage $\left(\mathrm{V}_{1}\right)$, a reverse voltage range $\left(\mathrm{V}_{2}\right)$ of -2 to $-8 \mathrm{~V}$, a frequency range (f) of $10-10000 \mathrm{~Hz}$ and a forward width percentage range $\left(\mathrm{D}=\mathrm{T}_{+} /\left(\mathrm{T}_{+}+\mathrm{T}_{-}\right)\right.$of $40-65 \%$ was monitored by a digital oscilloscope (Siglent SDS1102CML). For comparison, a DC power source (GENH750W) was used to supply a DC signal with a voltage of $10 \mathrm{~V}$.

The current was recorded by monitoring the voltage drop of a standard $10 \Omega$ resistor connected in series with the EPD cell using a digital oscilloscope (Siglent SDS1102CML) as shown in Fig. $1 b$.

(a)

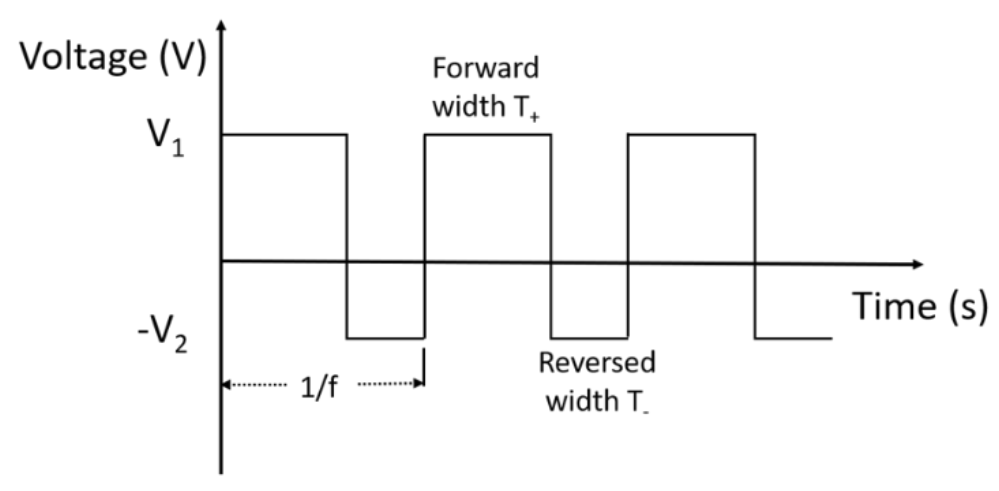

(b) Power

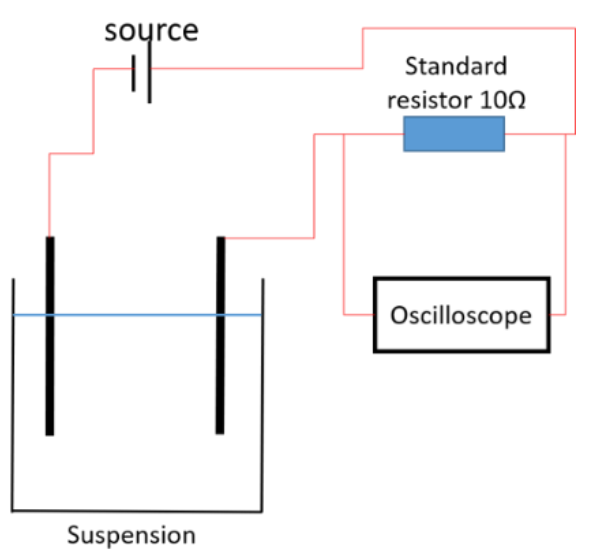

Fig 6-1 (a) The schematic of the applied AC signal and (b) setup for measuring the current 
The obtained deposits were dried in air at $100{ }^{\circ} \mathrm{C}$ for $24 \mathrm{~h}$. Then the deposit mass was calculated by the total weight increment of the dried deposition electrode before and after the EPD treatment. Every data is the average of three measurements. The surfaces of the deposits were examined by a digital microscope (ADSM302) and the scanning electron microscope (SEM), respectively. Then the deposit along with Ti plate was sealed by epoxy resin followed by grinding sequentially by silicon paper and cleaning by ethanol. The thickness of the deposit was examined by SEM.

\subsection{Results}

\subsubsection{Variation of zeta potential with $\mathrm{pH}$}

The zeta potential as a function of $\mathrm{pH}$ is shown in Fig. 6-2. As shown in Fig. 6-2, zeta potential decreases with increasing $\mathrm{pH}$. The isoelectric point (IEP) of GDC powder is $\mathrm{pH} 6.5$, which is similar to the value reported elsewhere [160]. Furthermore, the deposition rate grows with increasing $\mathrm{pH}$ (absolute value) since the mobility of GDC particles is proportional to the zeta potential $[161,162]$.

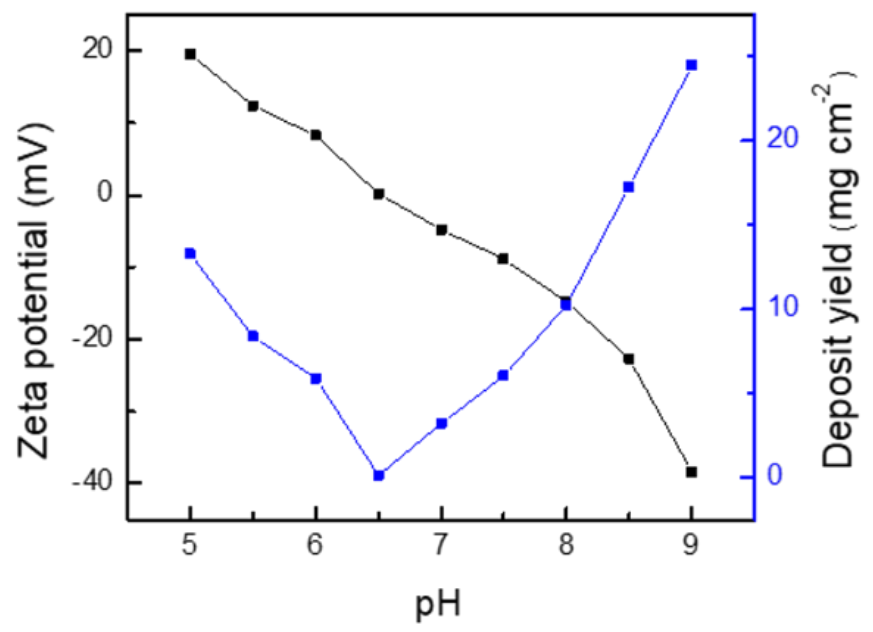


Fig 6-2 Zeta potential of GDC particles and deposit mass in 5 min at $10 \mathrm{~V}$ as a function of pH in the aqueous suspension

The electrochemical reactions accompanying by the deposition process in the aqueous suspension are shown in the following equations [163]:

Anode: $4 \mathrm{OH}^{-} \rightarrow \mathrm{O}_{2}+2 \mathrm{H}_{2} \mathrm{O}+4 \mathrm{e}^{-} \quad(6-1 \mathrm{a}) \quad$ or $2 \mathrm{H}_{2} \mathrm{O} \rightarrow \mathrm{O}_{2}+4 \mathrm{H}^{+}+4 \mathrm{e}^{-} \quad(6-1 \mathrm{~b})$

Cathode: $2 \mathrm{H}_{2} \mathrm{O}+2 \mathrm{e}^{-} \rightarrow \mathrm{H}_{2}+2 \mathrm{OH}^{-} \quad(6-2)$

Since the solubility of oxygen in water $\left(0.043 \mathrm{~g} \mathrm{~L}^{-1}\right)$ is larger than that of hydrogen $\left(0.0016 \mathrm{~g} \mathrm{~L}^{-1}\right)$ at room temperature, the $\mathrm{pH}$ value is fixed at 9.0 in the following experiments to achieve a relatively fast deposition rate and to enable anode rather than cathodic electrophoretic deposition to undermine the impairment associated with bubble evolution.

Fig. 6-3 depicts the particle size distribution of GDC powder in the aqueous suspension with a $\mathrm{pH}$ of 9.0 at different times determined by dynamic light scattering. It clearly reveals that no visible agglomeration was observed after keeping it still without stirring for $2 \mathrm{~h}$, suggesting the suspension with a pH of 9.0 was stable enough for EPD. 


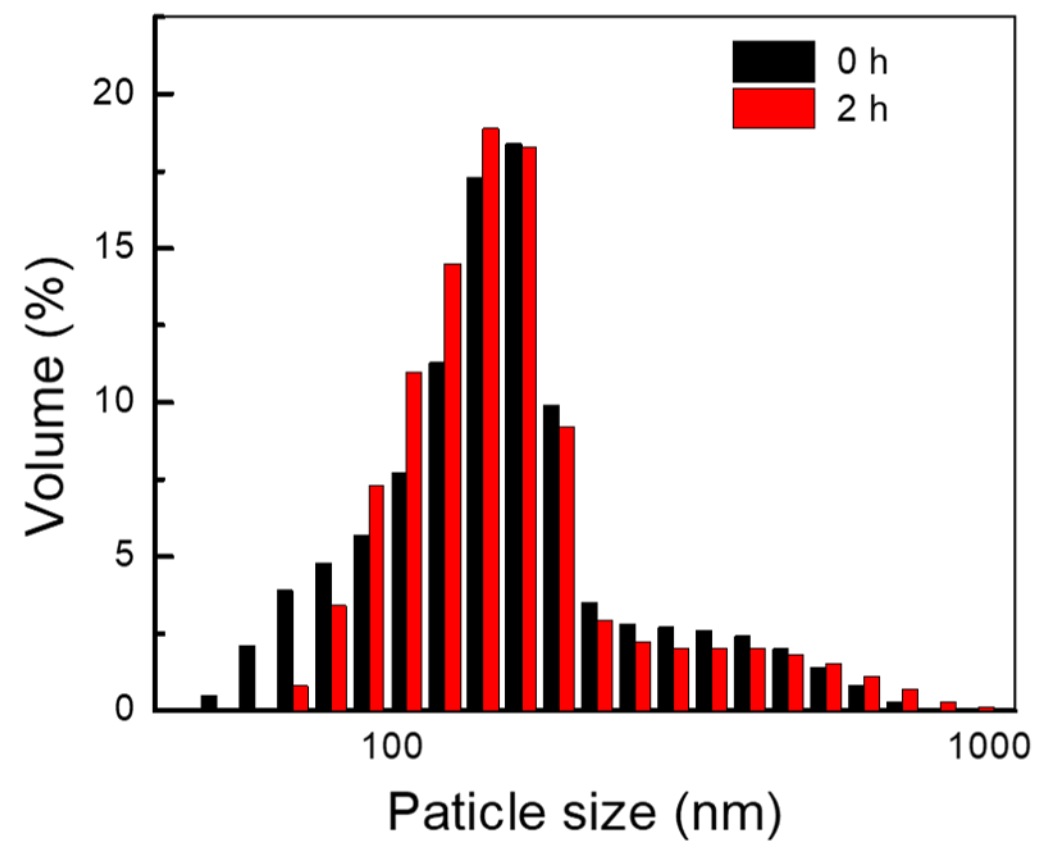

Fig 6-3 Size distribution histogram by volume for GDC particles

\subsubsection{DC-EPD vs AC-EPD}

\subsubsection{Morphology}

Fig. 6-4a shows the surface morphology of GDC deposits formed by DC-EPD at $10 \mathrm{~V}$. The surface is rough with many craters and pits, caused by oxygen bubble evolution of water electrolysis. The deposits formed by using the AC signal depicted in Fig. 6-1a with varied frequencies are displayed in Fig. 6-4b-f. The surfaces of the deposits under asymmetrical AC electric fields have smaller and fewer pits, as the frequency grows from $10 \mathrm{~Hz}$ to $2 \mathrm{kHz}$. A smooth surface without any visible defects could be obtained when the frequency reaches $1 \mathrm{kHz}$ or higher in sharp contrast with the uneven surface of the counterpart fabricated by DC-EPD. 

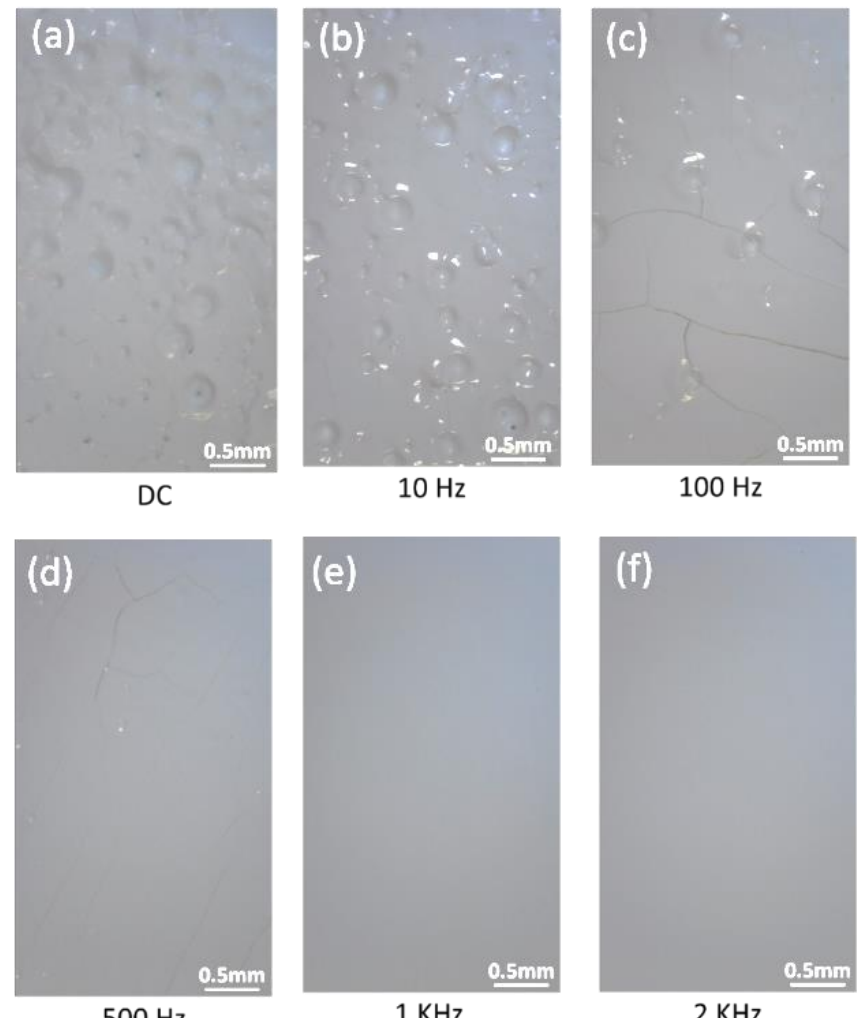

Fig 6-4 Surface morphology of deposits obtained by (a) DC-EPD at $10 \mathrm{~V}$ and (b-f) AC-EPD with varied frequencies [D: $\left.50 \%, V_{1} / V_{2}: 10 / 4\right]$.

Fig. 6-5 displays the corresponding SEM images of green films obtained by DC-EPD at $10 \mathrm{~V}$ and AC-EPD at $1 \mathrm{KHz}$, correspondingly. As shown in Fig. 6-5a and e, the particles are nonuniformly distributed on the substrate with many pits after deposition using a DC voltage. In some areas, particles are separated from each other with loose agglomeration as shown in the image at a higher magnification (Fig. 6-5b). This loose morphology is ascribed to the bubble evolution associated with oxygen evolution reaction (OER) at the anode. In contrast, the distribution of GDC particles on the electrode is homogeneous under AC-EPD at $1 \mathrm{KHz}$ (Fig. 65c) and particles are closely and compactly packed without any large voids (Fig. 6-5d and f). 

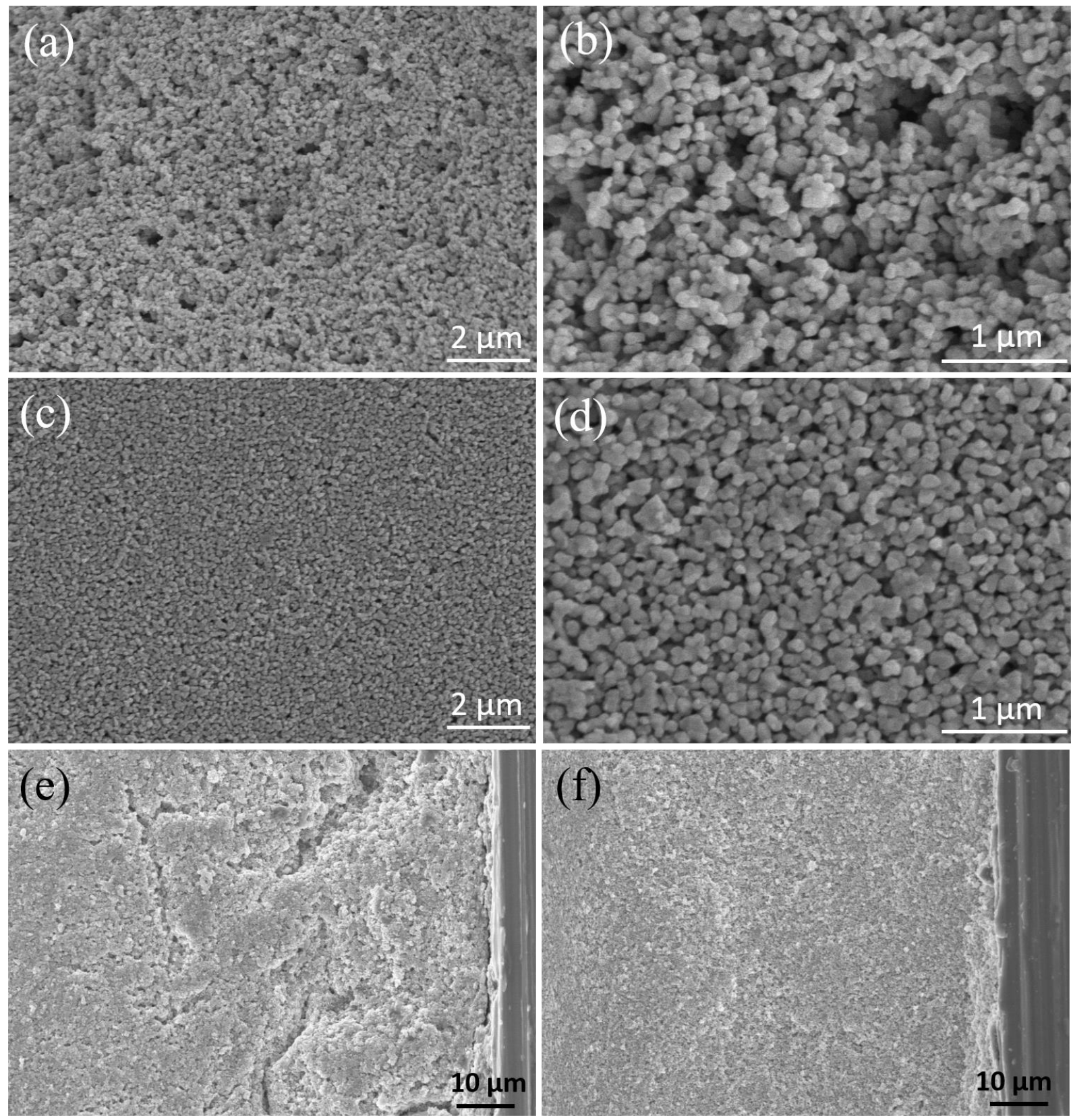

Fig 6-5 Surface (a-d) and cross-section (e and f) morphology of green films obtained by DC-EPD $(a, b$ and $e$ ) and $A C$-EPD with a frequency of $1 \mathrm{KHz}(c, d$ and $f)$

\subsubsection{Deposition rate}

To further reveal the effect of the frequency on the deposition process, the deposit mass is plotted as a function of the frequency (Fig. 6-6a) in a fixed time of $10 \mathrm{~min}$ with other parameters 
identical. As shown in Fig. 6-6a, the deposit weight grows with the increase of frequency from $10 \mathrm{~Hz}$ to $1 \mathrm{KHz}$. Further increase of frequency will lower the deposit yield. An optimal frequency is $1 \mathrm{kHz}$, leading to the maximum deposit mass in a given time. Therefore, the frequency is fixed as $1 \mathrm{kHz}$ in the following study.

The deposition rates are also investigated under the DC and asymmetric AC electric fields. Fig. $6 \mathrm{~b}$ illustrates the changes of GDC deposit mass over deposition time under DC and AC EPD conditions. The deposit mass initially increases and is quickly stabilized over time in DC-EPD. In contrast, the deposition mass increases monotonically with increasing time under the AC-EPD conditions, resulting in an average deposition rate of $2.35 \mathrm{mg} \mathrm{cm}^{-2} \min ^{-1}\left(5.4 \mu \mathrm{m} \mathrm{min}^{-1}\right)$. Moreover, the green density of GDC layer obtained by AC-EPD is $59.4 \%$ which is higher than that formed by DC-EPD (i.e., $52.6 \%$ ).
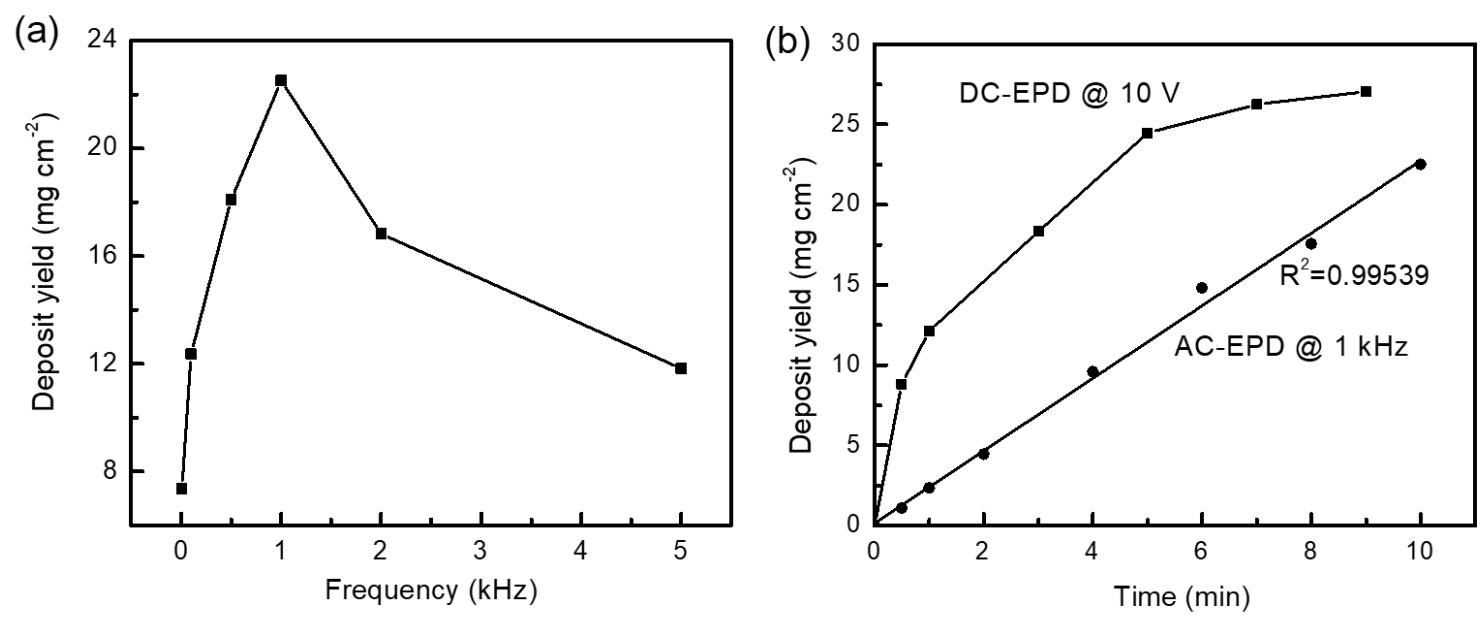

Fig 6-6 (a) Deposit weight for 10 min as a function of frequency [D:50\%, V1/V2: 10/4] and (b) time dependence of deposit yield under AC-EPD [f: $\left.1 \mathrm{kHz}, D: 50 \%, V_{1} / V_{2}: 10 / 4\right]$ and $D C-E P D$ at $10 \mathrm{~V}$. 


\subsubsection{Effect of voltage ratio and forward width percentage}

Besides the frequency, the $\mathrm{AC}$ electric field signals have another two parameters: the forward width percentage and voltage ratio, which are also expected to influence the movement and deposition rate of GDC particles. Therefore, the effects of both factors on the morphology of deposit surface are studied by fixing other parameters. As shown in Fig. 6-7, the amount of bubbles on the deposit increases with the increase of forward width percentage (Fig. 6-7a) or increase of voltage ratio (Fig. 6-7b) with other parameters identical.
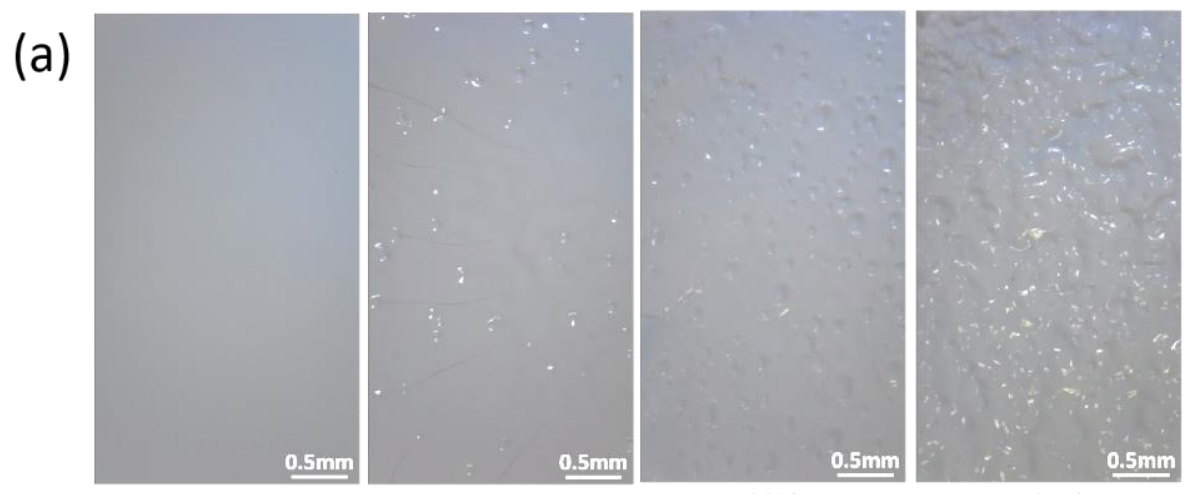

(b)
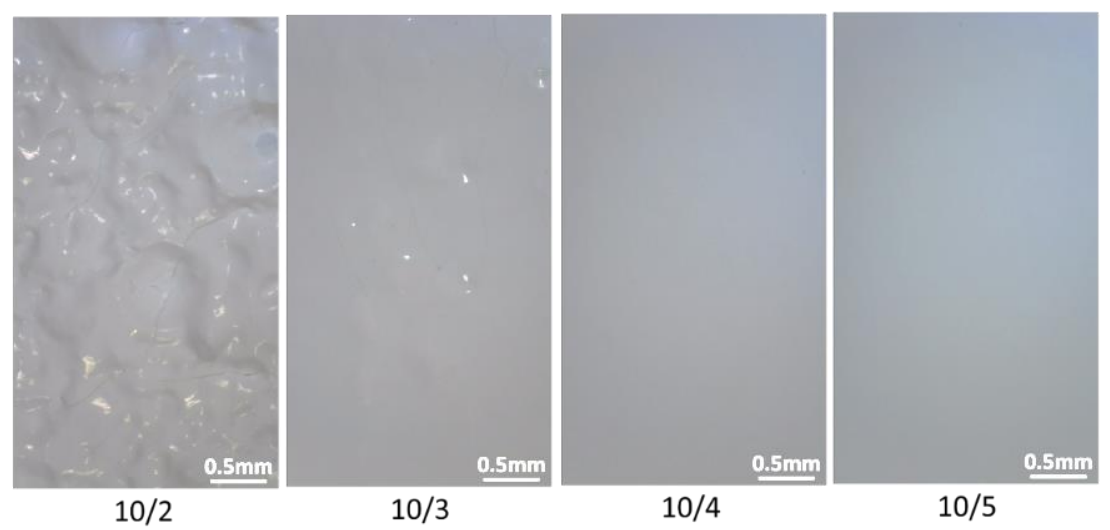

Fig 6-7 Surface morphology of deposits obtained by AC-EPD at (a) various forward width percentage [f: $1 \mathrm{kHz}$, $\left.V_{1} / V_{2}: 10 / 4\right]$ and $(b)$ different voltage ratios $[f: 1 \mathrm{kHz}, \mathrm{D}: 50 \%]$. 


\subsection{Discussion}

\subsubsection{DC-EPD vs AC-EPD}

The equivalent circuit of the EPD cell can be denoted by $R_{s}\left(R_{p} C_{d l}\right)$, wherein $R_{s}$ is the ohmic resistance of the suspension between these two electrodes, $R_{p}$ is the polarization resistance of faradic current at the electrode surfaces, and $\mathrm{C}_{\mathrm{dl}}$ is the capacitance of the double layers in the vicinity of the electrodes. Under a DC electric field, almost all of the current flows through $\mathrm{R}_{\mathrm{p}}$ corresponding to the electrochemical reaction (Eq. 6-1a and b) which results in oxygen bubble evolution at the deposition electrode, impairing the quality of GDC layer (Fig. 6-4a and Fig. 65a). By contrast, the electric field that drives electrochemical reaction $\left(R_{p}\right)$ also charges the double layer $\left(\mathrm{C}_{\mathrm{dl}}\right)$ in $\mathrm{AC}$-EPD. The current as a function of time in one period of AC signal with different frequencies is shown in Fig. 6-8. The observed current is the sum of faradic current and charging current, wherein the charging current exhibits an exponential decay while the faradic current increases gradually to a plateau when a potential step is applied. The total current is mainly due to the charging current at short times. In contrast, the total current is equal to the faradic current when the charge current decays to zero. As shown in Fig. 6-8a and b, at low frequencies $(10 \mathrm{~Hz}$ and $100 \mathrm{~Hz}$ ), the current initially decreases by time, then quickly attains a plateau with a value of $12 \mathrm{~mA} \mathrm{~cm}^{-2}$, suggesting the charging current decreases to zero when the current decays to $12 \mathrm{~mA} \mathrm{~cm}^{-2}$. Moreover, the length of this plateau at $100 \mathrm{~Hz}$ is shorter than that at $10 \mathrm{~Hz}$. As the frequency grows to $500 \mathrm{~Hz}$ (Fig. 6-8c), the current at the point before switching the direction of the power source is $14.2 \mathrm{~mA} \mathrm{~cm}^{-2}$ and no plateau is observed. With the increase of frequency from $500 \mathrm{~Hz}$ (Fig. 6-8c) to $10 \mathrm{KHz}$ (Fig. 6-8f), the current right before reversing the electric field grows from $14.2 \mathrm{~mA} \mathrm{~cm}^{-2}$ to $16.8 \mathrm{~mA} \mathrm{~cm}^{-2}$. These experimental results suggest that with the increase of frequency, more current flows through the double layer capacitance with 
less bubble evolution, resulting in fewer pits on the surface in Fig. 6-4. Hence, there is a frequency threshold value (i.e., $1 \mathrm{KHz}$ ) above which almost all the current flows through the capacitance of double layer with negligible gas bubbles [65]. Moreover, the alternation of a reversed current field might suppress the bubble incorporation and partly reduce the pre-formed oxygen gas $[56,84,85,164]$. This enables the obtainment of homogeneous and dense GDC films (Fig. 6-4e and f, Fig. 6-5c and f) in AC-EPD.

Similar to the reduction process of hydrogen ion at cathode in other systems [39, 133], after applying a potential gradient, the hydroxide ions in the proximity of anode would soon run out due to the charge transfer process. The hydroxide ions must be supplied by the diffusion from the bulk suspension to the vicinity of anode. Hence, the oxidation of hydroxide ions includes two steps shown in the following equation:

$$
\mathrm{OH}_{\infty}^{-} \stackrel{\text { transport process }}{\longrightarrow} \mathrm{OH}_{0}^{-} \stackrel{\text { charge transfer process }}{\longrightarrow} \mathrm{O}_{2}
$$

Wherein $\mathrm{OH}_{\infty}^{-}$is the hydroxide ion in the bulk suspension and $\mathrm{OH}_{0}^{-}$is the hydroxide ions near anode.

When the $\mathrm{Ti}$ is used as the deposition electrode, the rate of transport process is slower than that of charge transfer, resulting in the formation of an ion depletion zone [63]. The resistance increases by time because of the growing deposit and the existence of an ion depletion zone in the proximity of anode, wherein the latter process is the main reason. Hence, the deposition rate decreases by time under DC-EPD shown in Fig. 6-6b. Similar results can also be found in other systems [144, 165, 166]. 
In AC-EPD, with the increase of frequency from $10 \mathrm{~Hz}$ to $1 \mathrm{kHz}$, the impairment of bubble evolution on the deposition process is weakened as less faradaic current associated with oxygen evolution reaction (OER) flows through the electrode (Fig. 6-8), resulting to fewer pits in the surface (Fig. 6-4b-e) and larger deposit yield in a given time (Fig. 6a). However, the deposition yield declines when the frequency further increases from $1 \mathrm{kHz}$ to $5 \mathrm{kHz}$ (Fig. 6-6a), since the duration of the driving force exerted on the particles is too short to accelerate them and overcome their inertia. It is proposed that the optimum of $1 \mathrm{kHz}$ shows the best balance between the suppression of bubble evolution and boost of the particle migration, thereby effectively minimizing the bubble evolution and maximizing the deposition yield. Moreover, unlike the scenario of DC-EPD, negligible ion depletion zone is formed in the proximity of the deposition electrode, since the OER is imperceptible when the frequency is $1 \mathrm{KHz}$. That's the reason why the deposit mass is proportional to the deposition time. This suggests the great potential of ACEPD for fabricating tunable thickness of deposition layers in aqueous suspensions.
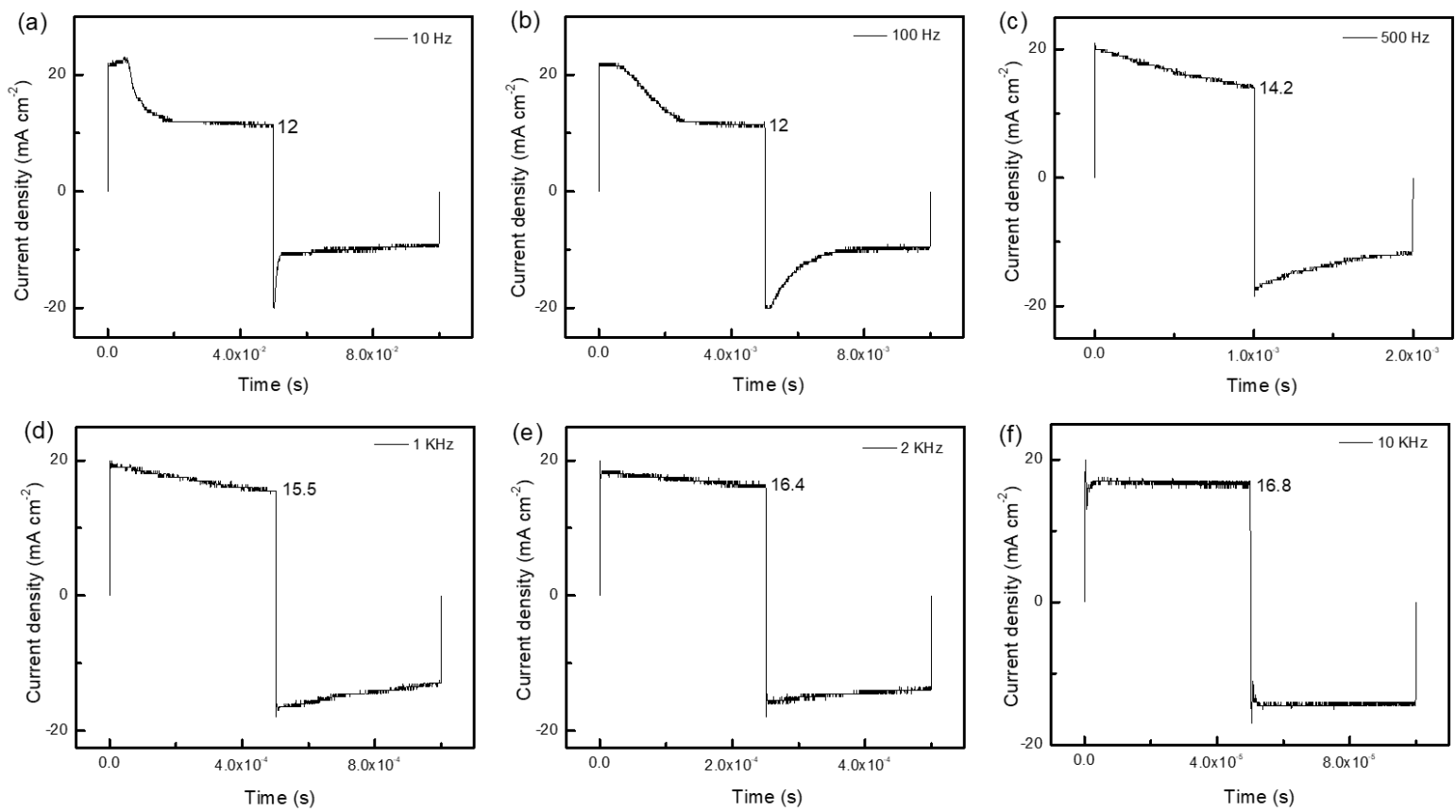
Fig 6-8 The current as a function of time in one period under AC-EPD with different frequencies

\subsubsection{Effect of parameters related to AC electric field}

To probe the effect of the loss of particles' charges upon migration (charge transfer step in Eq. (6-3)) to the deposition electrode, the DC-EPD experiment was carried out under a constant current of $4 \mathrm{~mA}$ with the addition of $0.1 \mathrm{M} \mathrm{K}_{4} \mathrm{Fe}(\mathrm{CN})_{6}$. As the redox potential of $\mathrm{Fe}(\mathrm{CN})_{6}{ }^{4-}$ $/ \mathrm{Fe}(\mathrm{CN}) 6^{3-}$ is less positive than that of the OER, the oxidation of $\mathrm{Fe}(\mathrm{CN}) 6^{4-}$ to $\mathrm{Fe}(\mathrm{CN}) 6^{3-}$ preferentially takes place on the deposition electrode (i.e., anode) instead of the OER under the DC conditions $[158,167]$. Therefore, the adsorbed hydroxide ions over the GDC particles cannot be fully desorbed. No deposit is found in this experiment regardless of the deposition time, suggesting that the particles could only be deposited when they completely lose their charge in the contact with the deposition electrode. In AC-EPD with negligible OER, the rate determining step of deposition is the desorption of absorbed $\mathrm{OH}^{-}$ions which depends on the applied electric field. Hence all the parameters related to the AC electric field influence the movement and the deposition of GDC particles.

The current density as a function of time in one period with different voltage ratios and percentage width percentage is shown in Fig. 6-9. It was clearly shown that with the increasing voltage ratio and forward width percentage, the net electric charge amount rises correspondingly, leading to more pits and craters in the surface shown in Fig. 6-7. Moreover, the increase of forward width percentage and voltage ratio might weaken the reduction of per-formed oxygen gas. It is important to note that there is a threshold value of forward width percentage (40\%) or voltage ratio (10/8) below which no deposition was observed as the net electrophoretic current is zero. Similar results have been found by Neirinck et al. for AC-EPD of alumina [65]. 

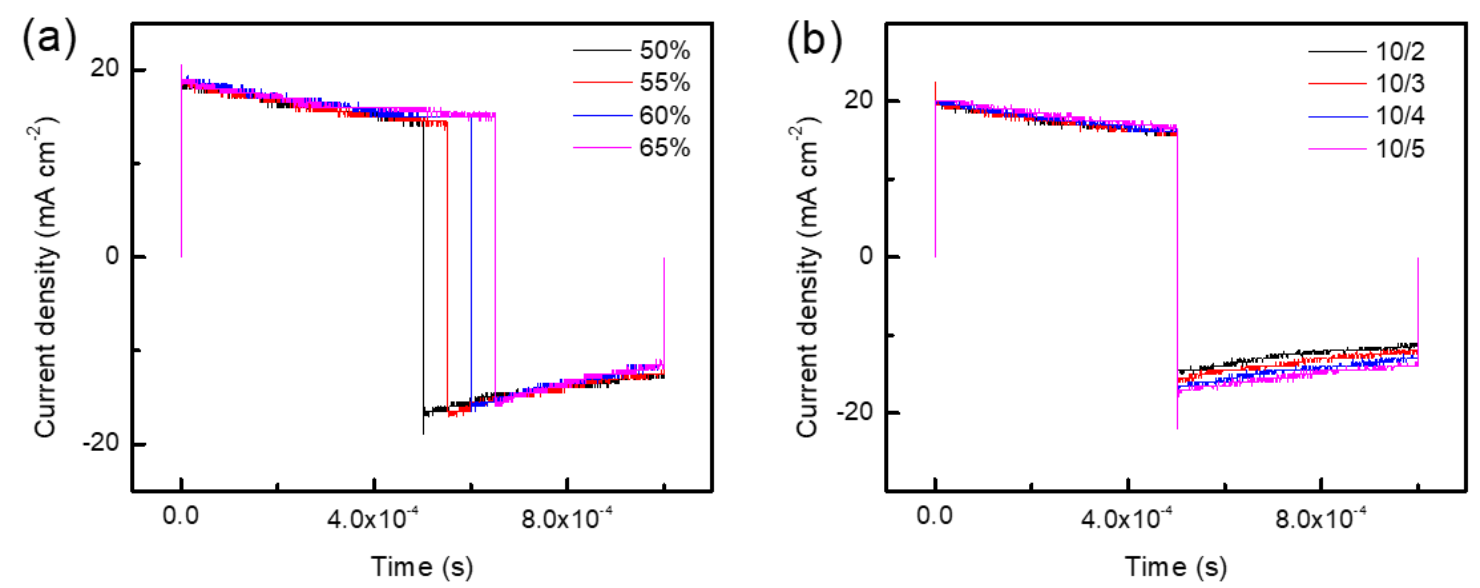

Fig 6-9 The current as a function of time in one period under AC-EPD with (a) varied forward width percentage (f: $\left.1 \mathrm{kHz}, V_{1} / V_{2}: 10 / 4\right)$ and (b) different voltage ratios [f: $\left.1 \mathrm{kHz}, \mathrm{D}: 50 \%\right]$

\subsection{Summary}

Dense and even GDC films are successfully prepared by AC-EPD in an aqueous suspension. The parameters influencing the quality of deposition films have been thoroughly investigated and the optimal deposition conditions include the frequency of $1 \mathrm{kHz}$, forward width percentage of $50 \%$ and voltage ratio of 10/4. This work provides a facile approach to fabricating smooth GDC barrier layers with tunable thickness in an environmentally benign, rapid, versatile and low-cost manner, indicating its promise for SOFC and other applications. 


\section{Chapter 7 Conclusions}

The direct deposition of GDC on non-conductive YSZ has been achieved by EPD. The fundamental characteristics of EPD including the deposition rate, increasing resistance, deposition efficiency and mechanism are also investigated experimentally and analytically.

In prior to EPD, a thin conductive polypyrrole (PPy) is in-situ synthesized on non-conductive YSZ substrate. The highly GDC green layer is successfully obtained on PPy coated YSZ by the scalable and cost-effective EPD process in an ethanol-based suspension. This GDC layer has been almost densified by sintering at a relatively low temperature, i.e., $1300{ }^{\circ} \mathrm{C}$ and the adhesion between GDC and YSZ was good. Moreover, the ohmic resistance of GDC made by EPD is reduced, compared to GDC barrier layer made by a conventional spin-coating method. The deposition rate of GDC on PPy coated YSZ is slower than that on graphite at the same voltage. However, at constant current, the mass of GDC deposited per coulomb of charge is larger on the PPy-coated YSZ cathode. Due to the low charge transfer rate, an $\mathrm{H}^{+}$ion accumulation zone is formed near the PPy coated YSZ after applying the voltage. The thickness of this $\mathrm{H}^{+}$ion accumulation zone increases at the beginning and then decreases. Finally, the ion accumulation zone is replaced by an ion depletion zone. The absorbed $\mathrm{H}^{+}$ions desorb from particles after deposition and then move through the porous deposit to the cathode to be reduced. The reduction of free $\mathrm{H}^{+}$ions and absorbed $\mathrm{H}^{+}$ions corresponds to the unavoidable side reaction and the deposition, respectively. Deposition efficiency, $\boldsymbol{f}$, the percentage of electric charge associated with the reduction of $\mathrm{H}^{+}$ions in the total charge, is introduced to reflect the competitive relationship between deposition and the side reaction. $f$ decreases with the increase of current density and is larger for the PPy coated YSZ cathode. 
In order to improve the green density of GDC layer, AC-EPD has been applied instead of DCEPD to eliminate the bubble evolution. A dense GDC layer is successfully obtained by AC-EPD in ethanol with a frequency of $500 \mathrm{~Hz}$ after sintering at a relatively low temperature, e.g., 1250 ${ }^{\circ} \mathrm{C}$. This GDC layer is adequate to eliminate the reaction between LSCF and YSZ. An optimum frequency of $500 \mathrm{~Hz}$ leads to the maximum deposition rate by balancing the suppression of bubble evolution and boost of the particle migration. The deposit yield in a given time grows with the increase of voltage ratio and forward width percentage. In AC-EPD with negligible electrochemical reaction, the deposition rate of GDC particles is determined by the transport process and the desorption process, wherein the latter one is an irreversible process. The deposit yield is monotonically controlled by the deposition time, suggesting the possibility of fabrication of GDC layer with tunable thickness.

A facile approach to fabricating smooth GDC barrier layers with tunable thickness in an environmentally benign, rapid, versatile and low-cost manner is demonstrated by using aqueous suspensions. Dense and even GDC films on titanium electrodes are successfully prepared by ACEPD in an aqueous suspension. The parameters influencing the quality of deposition films have been thoroughly investigated and the optimal deposition conditions include the frequency of 1 $\mathrm{kHz}$, forward width percentage of $50 \%$ and voltage ratio of 10/4. 


\section{References}

[1] B. Guan, W. Li, H. Zhang, X. Liu, Oxygen Reduction Reaction Kinetics in Sr-Doped La2NiO4+ס

Ruddlesden-Popper Phase as Cathode for Solid Oxide Fuel Cells, Journal of the Electrochemical Society, 162 (2015) F707-F712.

[2] W. Li, B. Guan, X. Zhang, J. Yan, Y. Zhou, X. Liu, New mechanistic insight into the oxygen reduction reaction on Ruddlesden-Popper cathodes for intermediate-temperature solid oxide fuel cells, Physical Chemistry Chemical Physics, 18 (2016) 8502-8511.

[3] W. Li, B. Guan, J. Yan, N. Zhang, X. Zhang, X. Liu, Enhanced surface exchange activity and electrode performance of ( $\mathrm{La} 2-2 \mathrm{x} \operatorname{Sr} 2 \mathrm{x})(\mathrm{Ni} 1-\mathrm{x} \mathrm{Mnx}) \mathrm{O} 4+\delta$ cathode for intermediate temperature solid oxide fuel cells, Journal of Power Sources, 318 (2016) 178-183.

[4] W. Li, B. Guan, L. Ma, S. Hu, N. Zhang, X. Liu, High performing triple-conductive $\operatorname{Pr} 2 \mathrm{NiO} 4+\delta$ anode for proton-conducting steam solid oxide electrolysis cell, J Mater Chem A Mater, 6 (2018) 18057-18066. [5] H. Qi, T. Yang, W. Li, L. Ma, S. Hu, W. Shi, E.M. Sabolsky, J.W. Zondlo, R. Hart, G.A. Hackett, Reversible In-Situ Exsolution of Fe Catalyst in La0. 5Sr1. 5Fe1. 5Mo0. 506- $\delta$ Anode for SOFCs, ECS Trans, 91 (2019) 1701-1710.

[6] S.P. Simner, J.P. Shelton, M.D. Anderson, J.W. Stevenson, Interaction between La (Sr) FeO 3 SOFC cathode and YSZ electrolyte, Solid State lonics, 161 (2003) 11-18.

[7] T. Hosomi, M. Matsuda, M. Miyake, Electrophoretic deposition for fabrication of YSZ electrolyte film on non-conducting porous NiO-YSZ composite substrate for intermediate temperature SOFC, Journal of the European Ceramic Society, 27 (2007) 173-178.

[8] Z. Lu, X.-D. Zhou, J. Templeton, J.W. Stevenson, Electrochemical Performance and Stability of the Cathode for Solid Oxide Fuel Cells IV. On the Ohmic Loss in Anode-Supported Button Cells with LSM or LSCF Cathodes, Journal of The Electrochemical Society, 157 (2010) B964-B969. 
[9] F. Tietz, D. Sebold, A. Brisse, J. Schefold, Degradation phenomena in a solid oxide electrolysis cell after 9000 h of operation, Journal of Power Sources, 223 (2013) 129-135.

[10] A. Mai, V.A. Haanappel, F. Tietz, D. Stöver, Ferrite-based perovskites as cathode materials for anode-supported solid oxide fuel cells: Part II. Influence of the CGO interlayer, Solid state ionics, 177 (2006) 2103-2107.

[11] N. Jordan, W. Assenmacher, S. Uhlenbruck, V. Haanappel, H. Buchkremer, D. Stöver, W. Mader, Ce $0.8 \mathrm{Gd} 0.202-\delta$ protecting layers manufactured by physical vapor deposition for IT-SOFC, Solid State Ionics, 179 (2008) 919-923.

[12] M. Matsuda, T. Hosomi, K. Murata, T. Fukui, M. Miyake, Fabrication of bilayered YSZ/SDC electrolyte film by electrophoretic deposition for reduced-temperature operating anode-supported SOFC, Journal of Power Sources, 165 (2007) 102-107.

[13] I. Corni, M.P. Ryan, A.R. Boccaccini, Electrophoretic deposition: From traditional ceramics to nanotechnology, J Eur Ceram Soc, 28 (2008) 1353-1367.

[14] A.B. Stambouli, E. Traversa, Solid oxide fuel cells (SOFCs): a review of an environmentally clean and efficient source of energy, Renew sust energ rev, 6 (2002) 433-455.

[15] D. Mogensen, J.-D. Grunwaldt, P.V. Hendriksen, K. Dam-Johansen, J. Nielsen, Internal steam reforming in solid oxide fuel cells: Status and opportunities of kinetic studies and their impact on modelling, J Power Sources, 196 (2011) 25-38.

[16] K. Huang, H.Y. Lee, J.B. Goodenough, $\mathrm{Sr}$ - and Ni - doped LaCoO3 and LaFeO3 perovskites new cathode materials for solid - oxide fuel cells, J Electrochem Soc, 145 (1998) 3220-3227.

[17] G. Amow, I. Davidson, S. Skinner, A comparative study of the Ruddlesden-Popper series, Lan+ 1NinO3n+ 1 ( $n=1,2$ and 3), for solid-oxide fuel-cell cathode applications, Solid State Ion, 177 (2006) 1205-1210. 
[18] J.-H. Kim, A. Manthiram, Layered LnBaCo2O5+ $\delta$ perovskite cathodes for solid oxide fuel cells: an overview and perspective, J Mater Chem A Mater, 3 (2015) 24195-24210.

[19] Y. Teraoka, H. Zhang, K. Okamoto, N. Yamazoe, Mixed ionic-electronic conductivity of La1-xSrxCo1yFeyO3- $\delta$ perovskite-type oxides, Materials Research Bulletin, 23 (1988) 51-58.

[20] E. Armstrong, K. Duncan, D. Oh, J. Weaver, E. Wachsman, Determination of surface exchange coefficients of LSM, LSCF, YSZ, GDC constituent materials in composite SOFC cathodes, J Electrochem Soc, 158 (2011) B492-B499.

[21] Y. Li, K. Gerdes, T. Horita, X. Liu, Surface exchange and bulk diffusivity of LSCF as SOFC cathode: electrical conductivity relaxation and isotope exchange characterizations, Journal of The Electrochemical Society, 160 (2013) F343-F350.

[22] Y.-L. Liu, A. Hagen, R. Barfod, M. Chen, H.-J. Wang, F.W. Poulsen, P.V. Hendriksen, Microstructural studies on degradation of interface between LSM-YSZ cathode and YSZ electrolyte in SOFCs, Solid State Ion, 180 (2009) 1298-1304.

[23] A. Mitterdorfer, L. Gauckler, La2Zr2O7 formation and oxygen reduction kinetics of the La0. 85SrO. 15MnyO3, O2 (g)| YSZ system, Solid State Ion, 111 (1998) 185-218.

[24] A.-K. Huber, M. Falk, M. Rohnke, B. Luerßen, L. Gregoratti, M. Amati, J. Janek, In situ study of electrochemical activation and surface segregation of the SOFC electrode material La $0.75 \mathrm{Sr} 0.25 \mathrm{Cr} 0.5$ Mn 0.50 3 \pm , Phys Chem Chem Phys, 14 (2012) 751-758.

[25] R. Kiebach, W.-W. Zhang, W. Zhang, M. Chen, K. Norrman, H.-J. Wang, J.R. Bowen, R. Barfod, P.V. Hendriksen, Stability of La0. $6 \mathrm{Sr} 0.4 \mathrm{Co} .2 \mathrm{Fe} 0.8 \mathrm{O} / \mathrm{Ce} 0.9 \mathrm{Gd} 0.102$ cathodes during sintering and solid oxide fuel cell operation, Journal of Power Sources, 283 (2015) 151-161.

[26] D. Oh, D. Gostovic, E.D. Wachsman, Mechanism of La 0.6 Sr 0.4 Co 0.2 Fe 0.803 cathode degradation, J Mater Res, 27 (2012) 1992-1999. 
[27] Y. Chen, W. Jung, Z. Cai, J.J. Kim, H.L. Tuller, B. Yildiz, Impact of Sr segregation on the electronic structure and oxygen reduction activity of SrTi 1- x Fe x O 3 surfaces, Energy Environ Sci, 5 (2012) 79797988.

[28] Z. Zhao, L. Liu, X. Zhang, W. Wu, B. Tu, D. Cui, D. Ou, M. Cheng, High-and low-temperature behaviors of La0. $6 \mathrm{SrO} .4 \mathrm{Co} 0.2 \mathrm{Fe} 0.803-\delta$ cathode operating under $\mathrm{CO} 2 / \mathrm{H} 2 \mathrm{O}$-containing atmosphere, Int J Hydrogen Energy, 38 (2013) 15361-15370.

[29] M. Arnold, H. Wang, A. Feldhoff, Influence of $\mathrm{CO} 2$ on the oxygen permeation performance and the microstructure of perovskite-type (Ba0. 5Sr0. 5)(Co0. 8Fe0. 2) O3- $\delta$ membranes, J Memb Sci, 293 (2007) 44-52.

[30] G.C. Kostogloudis, C. Ftikos, Chemical compatibility of RE 1- $x \operatorname{Sr} \times \mathrm{MnO} 3 \pm \delta(R E=\mathrm{La}, \mathrm{Pr}, \mathrm{Nd}, \mathrm{Gd}, 0 \leqslant$ $x \leqslant 0.5)$ with yttria stabilized zirconia solid electrolyte, Journal of the European Ceramic Society, 18 (1998) 1707-1710.

[31] J. Labrincha, F. Marques, J. Frade, Protonic and oxygen-ion conduction in SrZrO3-based materials, Journal of materials science, 30 (1995) 2785-2792.

[32] F.P. Van Berkel, Y. Zhang-Steenwinkel, G. Schoemakers, M. Van Tuel, B. Rietveld, Enhanced ASC Performance at 600 \{degree sign\} C by Ceria Barrier Layer Optimisation, ECS Transactions, 25 (2009) 2717-2726.

[33] T. Tsai, S.A. Barnett, Increased solid-oxide fuel cell power density using interfacial ceria layers, Solid State lonics, 98 (1997) 191-196.

[34] A.R. Boccaccini, J. Cho, J.A. Roether, B.J. Thomas, E.J. Minay, M.S. Shaffer, Electrophoretic deposition of carbon nanotubes, Carbon, 44 (2006) 3149-3160.

[35] A. Boccaccini, S. Keim, R. Ma, Y. Li, I. Zhitomirsky, Electrophoretic deposition of biomaterials, J R Soc Interface, 7 (2010) S581-S613. 
[36] M. Yao, Z. Zeng, H. Zhang, J. Yan, X. Liu, Electrophoretic deposition of carbon nanofibers/silicon film with honeycomb structure as integrated anode electrode for lithium-ion batteries, Electrochim Acta, 281 (2018) 312-322.

[37] I. Zhitomirsky, Electrophoretic deposition of organic-inorganic nanocomposites, J Mater Sci, 41 (2006) 8186-8195.

[38] D. Craig Jr John, Process for electrophoretic deposition of polymer, Google Patents, 1975.

[39] P. Sarkar, P.S. Nicholson, Electrophoretic deposition (EPD): mechanisms, kinetics, and application to ceramics, J Am Ceram Soc, 79 (1996) 1987-2002.

[40] A. Hajalilou, E. Abouzari-Lotf, R. Etemadifar, V. Abbasi-Chianeh, A. Kianvash, Fabrication by Electrophoretic Deposition of Nano-Fe 304 and Fe 30 4@ SiO 2 3D Structure on Carbon Fibers as Supercapacitor Materials, JOM, (2018) 1-7.

[41] T. Teranishi, M. Hosoe, T. Tanaka, M. Miyake, Size control of monodispersed Pt nanoparticles and their 2D organization by electrophoretic deposition, J Phys Chem B, 103 (1999) 3818-3827.

[42] F. Bouyer, A. Foissy, Electrophoretic deposition of silicon carbide, J Am Ceram Soc, 82 (1999) 20012010.

[43] P. Sarkar, X. Huang, P.S. Nicholson, Zirconia/alumina functionally gradiented composites by electrophoretic deposition techniques, J Am Ceram Soc, 76 (1993) 1055-1056.

[44] F. Bouyer, A. Foissy, Electrophoretic deposition of silicon carbide, Journal of the American Ceramic Society, 82 (1999) 2001-2010.

[45] O.O. Van der Biest, L.J. Vandeperre, Electrophoretic deposition of materials, Annual Review of Materials Science, 29 (1999) 327-352.

[46] H. Hamaker, Formation of a deposit by electrophoresis, Trans Faraday Soc, 35 (1940) 279-287.

[47] Y. Hirata, A. Nishimoto, Y. Ishihara, Forming of alumina powder by electrophoretic deposition, J Ceram Soc Jpn, 99 (1991) 108-113. 
[48] T. Ishihara, K. Sato, Y. Takita, Electrophoretic deposition of Y2O3 - stabilized ZrO2 electrolyte films in solid oxide fuel cells, J Am Ceram Soc, 79 (1996) 913-919.

[49] F. Chen, M. Liu, Preparation of yttria-stabilized zirconia (YSZ) films on La 0.85 Sr 0.15 MnO 3 (LSM) and LSM-YSZ substrates using an electrophoretic deposition (EPD) process, Journal of the European Ceramic Society, 21 (2001) 127-134.

[50] F. Tang, T. Uchikoshi, K. Ozawa, Y. Sakka, Effect of polyethylenimine on the dispersion and electrophoretic deposition of nano-sized titania aqueous suspensions, J Eur Ceram Soc, 26 (2006) 15551560.

[51] F. Guo, I.P. Shapiro, P. Xiao, Effect of $\mathrm{HCl}$ on electrophoretic deposition of yttria stabilized zirconia particles in organic solvents, J Eur Ceram Soc, 31 (2011) 2505-2511.

[52] S. Hu, W. Li, W. Li, N. Zhang, H. Qi, H. Finklea, X. Liu, A study on the electrophoretic deposition of gadolinium doped ceria on polypyrrole coated yttrium stabilized zirconia, J Colloid Interface Sci, 555 (2019) 115-123.

[53] S. Hu, W. Li, M. Yao, T. Li, X. Liu, Electrophoretic Deposition of Gadolinium - doped Ceria as a Barrier Layer on Yttrium - stabilized Zirconia Electrolyte for Solid Oxide Fuel Cells, Fuel Cells, 17 (2017) 869-874.

[54] J.H. Kennedy, A. FOISSY, Measurement of Mobility and Zeta Potential of Beta - Alumina Suspensions in Various Solvents, J Am Ceram Soc, 60 (1977) 33-36.

[55] S. Hu, W. Li, W. Li, N. Zhang, H. Qi, H. Finklea, X. Liu, Aqueous electrophoretic deposition of gadolinium doped ceria, Colloids Surf A Physicochem Eng Asp, 579 (2019) 123717.

[56] L. Besra, T. Uchikoshi, T.S. Suzuki, Y. Sakka, Bubble - Free Aqueous Electrophoretic Deposition (EPD) by Pulse - Potential Application, J Am Ceram Soc, 91 (2008) 3154-3159.

[57] A. Chmielewska, M. Żurada, K. Klimaszewski, A. Bald, Dielectric properties of methanol mixtures with ethanol, isomers of propanol, and butanol, J Chem Eng Data, 54 (2008) 801-806. 
[58] J. Canosa, A. Rodriguez, J. Tojo, Dynamic viscosities of (methyl acetate or methanol) with (ethanol, 1-propanol, 2-propanol, 1-butanol, and 2-butanol) at 298.15 K, J Chem Eng Data, 43 (1998) 417-421.

[59] M. Farrokhi-Rad, T. Shahrabi, Effect of suspension medium on the electrophoretic deposition of hydroxyapatite nanoparticles and properties of obtained coatings, Ceram Int, 40 (2014) 3031-3039. [60] M. Farrokhi-Rad, Electrophoretic deposition of hydroxyapatite nanoparticles in different alcohols: effect of Tris (tris (hydroxymethyl) aminomethane) as a dispersant, Ceram Int, 42 (2016) 3361-3371. [61] L. Vandeperre, O. Van der Biest, W. Clegg, Silicon carbide laminates with carbon interlayers by electrophoretic deposition, Key Engineering Materials, Trans Tech Publ, 1997, pp. 567-574.

[62] R. Moreno, B. Ferrari, Effect of the slurry properties on the homogeneity of alumina deposits obtained by aqueous electrophoretic deposition, Mater Res Bull, 35 (2000) 887-897.

[63] L. Stappers, L. Zhang, O. Van der Biest, J. Fransaer, The effect of electrolyte conductivity on electrophoretic deposition, J Colloid Interface Sci, 328 (2008) 436-446.

[64] P. Collini, S. Kota, A.D. Dillon, M.W. Barsoum, A.T. Fafarman, Electrophoretic Deposition of TwoDimensional Titanium Carbide (MXene) Thick Films, J Electrochem Soc, 164 (2017) D573-D580.

[65] B. Neirinck, J. Fransaer, O. Van der Biest, J. Vleugels, Aqueous electrophoretic deposition in asymmetric AC electric fields (AC-EPD), Electrochem commun, 11 (2009) 57-60.

[66] N. Koura, T. Tsukamoto, H. Shoji, T. Hotta, Preparation of various oxide films by an electrophoretic deposition method: a study of the mechanism, Japanese journal of applied physics, 34 (1995) 1643.

[67] R.N. Basu, C.A. Randall, M.J. Mayo, Fabrication of dense zirconia electrolyte films for tubular solid oxide fuel cells by electrophoretic deposition, J Am Ceram Soc, 84 (2001) 33-40.

[68] Y.-C. Wang, C. Leu, M.-H. Hon, Size control of ZnO nanofibril within template by electrophoretic deposition, Electrochemical and solid-state letters, 7 (2004) D15-D18. 
[69] M. Mehrali, A.R. Akhiani, S. Talebian, M. Mehrali, S.T. Latibari, A. Dolatshahi-Pirouz, H.S.C. Metselaar, Electrophoretic deposition of calcium silicate-reduced graphene oxide composites on titanium substrate, Journal of the European Ceramic Society, 36 (2016) 319-332.

[70] P. Sarkar, D. De, H. Rho, Synthesis and microstructural manipulation of ceramics by electrophoretic deposition, J Mater Sci, 39 (2004) 819-823.

[71] L. Besra, C. Compson, M. Liu, Electrophoretic deposition on non-conducting substrates: the case of YSZ film on NiO-YSZ composite substrates for solid oxide fuel cell application, J Power Sources, 173 (2007) 130-136.

[72] M. Santillán, A. Caneiro, N. Quaranta, A. Boccaccini, Electrophoretic deposition of La0. 6Sr0. 4Co0. 8Fe0. 203- $\delta$ cathodes on $\mathrm{Ce} 0.9 \mathrm{Gd} 0.101 .95$ substrates for intermediate temperature solid oxide fuel cell (IT-SOFC), Journal of the European Ceramic Society, 29 (2009) 1125-1132.

[73] S. Wang, T. Kato, S. Nagata, T. Honda, T. Kaneko, N. Iwashita, M. Dokiya, Performance of a La0. 6Sr0. 4Co0. 8Fe0. 203-Ce0. 8Gd0. 201. 9-Ag cathode for ceria electrolyte SOFCs, Solid State lonics, 146 (2002) 203-210.

[74] S.P. Simner, M.D. Anderson, J.W. Templeton, J.W. Stevenson, Silver-perovskite composite SOFC cathodes processed via mechanofusion, Journal of power sources, 168 (2007) 236-239.

[75] M.D. Lima, M.J. de Andrade, C.P. Bergmann, S. Roth, Thin, conductive, carbon nanotube networks over transparent substrates by electrophoretic deposition, Journal of Materials Chemistry, 18 (2008) 776-779.

[76] J. Wang, M. Kuwabara, Electrophoretic deposition of BaTiO3 films on a Si substrate coated with conducting polyaniline layers, J Eur Ceram Soc, 28 (2008) 101-108.

[77] H.T. Suzuki, T. Uchikoshi, K. Kobayashi, T.S. Suzuki, T. Sugiyama, K. Furuya, M. Matsuda, Y. Sakka, F. Munakata, Electrophretic Deposition of LDC/LSGM/LDC Tri-layers on NiO-YSZ for Anode-supported SOFC, Transactions of the Materials Research Society of Japan, 35 (2010) 723-725. 
[78] J. Will, M.K. Hruschka, L. Gubler, L.J. Gauckler, Electrophoretic deposition of zirconia on porous anodic substrates, Journal of the American Ceramic Society, 84 (2001) 328-332.

[79] K. Yamaji, H. Kishimoto, Y. Xiong, T. Horita, N. Sakai, H. Yokokawa, Performance of anode-supported SOFCs fabricated with EPD techniques, Solid State Ion, 175 (2004) 165-169.

[80] M. Matsuda, T. Hosomi, K. Murata, T. Fukui, M. Miyake, Direct EPD of YSZ electrolyte film onto porous NiO-YSZ composite substrate for reduced-temperature operating anode-supported SOFC, Electrochemical and solid-state letters, 8 (2005) A8-A11.

[81] J. Tabellion, R. Clasen, Electrophoretic deposition from aqueous suspensions for near-shape manufacturing of advanced ceramics and glasses -applications, Journal of Materials Science, 39 (2004) 803-811.

[82] L. Besra, C. Compson, M. Liu, Electrophoretic Deposition of YSZ Particles on Non - Conducting Porous NiO - YSZ Substrates for Solid Oxide Fuel Cell Applications, Journal of the American Ceramic Society, 89 (2006) 3003-3009.

[83] O. Sakurada, K. Suzuki, M. Hashiba, Electrophoretic bubble-free deposition on anodes from aqueous alumina and zirconia suspensions with hydroquinone: fabrication of alumina/zirconia gradiented composites, Journal of the Ceramic Society of Japan, Supplement Journal of the Ceramic Society of Japan, Supplement 112-1, PacRim5 Special Issue, J Ceram Soc Jpn, 2004, pp. S153-S155.

[84] L. Besra, T. Uchikoshi, T. Suzuki, Y. Sakka, Application of constant current pulse to suppress bubble incorporation and control deposit morphology during aqueous electrophoretic deposition (EPD), J Eur Ceram Soc, 29 (2009) 1837-1845.

[85] K. Arlt, K. Eckert, M. Stockbrink, R. Schulte, H. Berlin, G. Nienhaus, Pulse-modulated DC electrochemical coating process and apparatus, Google Patents, 2001.

[86] T. Uchikoshi, K. Ozawa, B.D. Hatton, Y. Sakka, Dense, bubble-free ceramic deposits from aqueous suspensions by electrophoretic deposition, Journal of Materials Research, 16 (2001) 321-324. 
[87] F. Bozza, R. Polini, E. Traversa, High performance anode-supported intermediate temperature solid oxide fuel cells (IT-SOFCs) with La0. 8Sr0. 2Ga0. 8Mg0. 203- $\delta$ electrolyte films prepared by electrophoretic deposition, Electrochemistry Communications, 11 (2009) 1680-1683.

[88] M. Matsuda, O. Ohara, K. Murata, S. Ohara, T. Fukui, M. Miyake, Electrophoretic fabrication and cell performance of dense Sr-and Mg-doped LaGaO3-based electrolyte films, Electrochem solid st, 6 (2003) A140-A143.

[89] I. Zhitomirsky, A. Petric, Electrophoretic deposition of ceramic materials for fuel cell applications, Journal of the European Ceramic Society, 20 (2000) 2055-2061.

[90] M. Asamoto, S. Miyake, Y. Itagaki, Y. Sadaoka, H. Yahiro, Electrocatalytic performances of Ni/SDC anodes fabricated with EPD techniques for direct oxidation of $\mathrm{CH} 4$ in solid oxide fuel cells, Catalysis Today, 139 (2008) 77-81.

[91] M.J. Santillán, A. Caneiro, F.C. Lovey, N. Quaranta, A.R. Boccaccini, Electrophoretic codeposition of La0. 6Sr0. 4Co0. 8Fe0. 203- $\delta$ and carbon nanotubes for developing composite cathodes for intermediate temperature solid oxide fuel cells, International Journal of Applied Ceramic Technology, 7 (2010) 30-40.

[92] Y. Itagaki, S. Watanabe, T. Yamaji, M. Asamoto, H. Yahiro, Y. Sadaoka, Electrophoretic deposition of bi-layered LSM/LSM-YSZ cathodes for solid oxide fuel cell, Journal of Power Sources, 214 (2012) 153-158. [93] Z. Wang, N. Zhang, J. Qiao, K. Sun, P. Xu, Improved SOFC performance with continuously graded anode functional layer, Electrochemistry Communications, 11 (2009) 1120-1123.

[94] M. Zarabian, A.Y. Yar, S. Vafaeenezhad, M.F. Sani, A. Simchi, Electrophoretic deposition of functionally-graded NiO-YSZ composite films, Journal of the European Ceramic Society, 33 (2013) 18151823.

[95] E. Ivers-Tiffée, A. Weber, D. Herbstritt, Materials and technologies for SOFC-components, Journal of the European Ceramic Society, 21 (2001) 1805-1811. 
[96] S.C. Singhal, K. Kendall, High-temperature solid oxide fuel cells: fundamentals, design and applications, Elsevier2003.

[97] A. Mc Evoy, Laboratoire de Photonique et des Interfaces. Ecole Polytechnique Féderale de Lausanne, Fuel cell technology status and prospects, (1998).

[98] Z. Xu, G. Rajaram, J. Sankar, D. Pai, Electrophoretic deposition of YSZ electrolyte coatings for solid oxide fuel cells, Surface and Coatings Technology, 201 (2006) 4484-4488.

[99] J. Cherng, J. Sau, C. Chung, Aqueous electrophoretic deposition of YSZ electrolyte layers for solid oxide fuel cells, Journal of Solid State Electrochemistry, 12 (2008) 925-933.

[100] H. Negishi, K. Yamaji, T. Imura, D. Kitamoto, T. Ikegami, H. Yanagishita, Electrophoretic deposition mechanism of YSZ/n-propanol suspension, Journal of The Electrochemical Society, 152 (2005) J16-J22.

[101] T. Ishihara, M. Honda, T. Shibayama, H. Minami, H. Nishiguchi, Y. Takita, Intermediate Temperature Solid Oxide Fuel Cells Using a New LaGaO3 Based Oxide Ion Conductor I. Doped as a New Cathode Material, Journal of the Electrochemical Society, 145 (1998) 3177-3183.

[102] S. Zha, W. Rauch, M. Liu, Ni-Ce0. 9Gd0. 101. 95 anode for GDC electrolyte-based low-temperature SOFCs, Solid State lonics, 166 (2004) 241-250.

[103] F. Bozza, R. Polini, E. Traversa, Electrophoretic Deposition of Dense Sr - and Mg - Doped LaGaO3 Electrolyte Films on Porous La - Doped Ceria for Intermediate Temperature Solid Oxide Fuel Cells, Fuel Cells, 8 (2008) 344-350.

[104] S.P. Simner, J.P. Shelton, M.D. Anderson, J.W. Stevenson, Interaction between La (Sr) FeO3 SOFC cathode and YSZ electrolyte, Solid State Ion, 161 (2003) 11-18.

[105] H.T. Suzuki, T. Uchikoshi, K. Kobayashi, T.S. Suzuki, T. Sugiyama, K. Furuya, M. Matsuda, Y. Sakka, F. Munakata, Fabrication of GDC/LSGM/GDC tri-layers on polypyrrole-coated NiO-YSZ by electrophoretic deposition for anode-supported SOFC, J Ceram Soc Jpn, 117 (2009) 1246-1248. 
[106] J. Wu, X. Liu, Recent development of SOFC metallic interconnect, Journal of materials science \& technology, 26 (2010) 293-305.

[107] J.C. Mah, A. Muchtar, M.R. Somalu, M.J. Ghazali, Metallic interconnects for solid oxide fuel cell: a review on protective coating and deposition techniques, International Journal of Hydrogen Energy, 42 (2017) 9219-9229.

[108] J.W. Fergus, Metallic interconnects for solid oxide fuel cells, Materials Science and Engineering: A, 397 (2005) 271-283.

[109] F. Smeacetto, A. De Miranda, S.C. Polo, S. Molin, D. Boccaccini, M. Salvo, A.R. Boccaccini, Electrophoretic deposition of Mn1. 5Co1. 504 on metallic interconnect and interaction with glassceramic sealant for solid oxide fuel cells application, Journal of Power Sources, 280 (2015) 379-386. [110] H. Zhang, Z. Zhan, X. Liu, Electrophoretic deposition of (Mn, Co) 304 spinel coating for solid oxide fuel cell interconnects, J Power Sources, 196 (2011) 8041-8047.

[111] W. Huang, S. Gopalan, U.B. Pal, S.N. Basu, Evaluation of electrophoretically deposited CuMn1. 804 spinel coatings on Crofer 22 APU for solid oxide fuel cell interconnects, Journal of The Electrochemical Society, 155 (2008) B1161-B1167.

[112] Z. Sun, S. Gopalan, U.B. Pal, S.N. Basu, Cu1. 3Mn1. 704 spinel coatings deposited by electrophoretic deposition on Crofer 22 APU substrates for solid oxide fuel cell applications, Surface and Coatings Technology, 323 (2017) 49-57.

[113] Y. Zhang, A. Javed, M. Zhou, S. Liang, P. Xiao, Fabrication of M n-C o Spinel Coatings on C rofer 22 APU Stainless Steel by Electrophoretic Deposition for Interconnect Applications in Solid Oxide Fuel Cells, International Journal of Applied Ceramic Technology, 11 (2014) 332-341.

[114] L. Besra, S. Zha, M. Liu, Preparation of NiO-YSZ/YSZ bi-layers for solid oxide fuel cells by electrophoretic deposition, Journal of power sources, 160 (2006) 207-214. 
[115] H. Negishi, N. Sakai, K. Yamaji, T. Horita, H. Yokokawa, Application of electrophoretic deposition technique to solid oxide fuel cells, Journal of the Electrochemical Society, 147 (2000) 1682-1687.

[116] Z. Peng, M. Liu, Preparation of Dense Platinum - Yttria Stabilized Zirconia and Yttria Stabilized Zirconia Films on Porous La0. 9Sr0. $1 \mathrm{MnO3}$ (LSM) Substrates, J Am Ceram Soc, 84 (2001) 283-288.

[117] K. Kobayashi, I. Takahashi, M. Shiono, M. Dokiya, Supported Zr (Sc) O2 SOFCs for reduced temperature prepared by electrophoretic deposition, Solid State lonics, 152 (2002) 591-596.

[118] T. Mathews, N. Rabu, J.R. Sellar, B.C. Muddle, Fabrication of La1-xSrxGa1-yMgyO3-(x+y)/2 thin films by electrophoretic deposition and its conductivity measurement, Solid State Ion, 128 (2000) 111115.

[119] M. Zunic, L. Chevallier, E. Di Bartolomeo, A. D'Epifanio, S. Licoccia, E. Traversa, Anode supported protonic solid oxide fuel cells fabricated using electrophoretic deposition, Fuel Cells, 11 (2011) 165-171. [120] L.V. Kovalev, M.V. Yarmolich, M.L. Petrova, J. Ustarroz, H.A. Terryn, N.A. Kalanda, M.L. Zheludkevich, Double perovskite Sr2FeMoO6 films prepared by electrophoretic deposition, ACS applied materials \& interfaces, 6 (2014) 19201-19206.

[121] J. Yoo, S.-K. Woo, J.H. Yu, S. Lee, G.W. Park, La0. 8SrO. 2MnO3 and (Mn1. 5Co1. 5) O4 double layer coated by electrophoretic deposition on Crofer22 APU for SOEC interconnect applications, international journal of hydrogen energy, 34 (2009) 1542-1547.

[122] P. Garcia, B. Ferrari, R. Moreno, A.J. Sánchez-Herencia, M.T. Colomer, YSZ/Ni-YSZ semi-cells shaped by electrophoretic deposition, Journal of the European Ceramic Society, 27 (2007) 4241-4244. [123] L. Jia, Z. Lü, X. Huang, Z. Liu, K. Chen, X. Sha, G. Li, W. Su, Preparation of YSZ film by EPD and its application in SOFCs, Journal of alloys and compounds, 424 (2006) 299-303.

[124] L. Besra, C. Compson, M. Liu, Electrophoretic deposition on non-conducting substrates: the case of YSZ film on NiO-YSZ composite substrates for solid oxide fuel cell application, Journal of Power Sources, 173 (2007) 130-136. 
[125] K. Yamaji, H. Kishimoto, Y. Xiong, T. Horita, N. Sakai, H. Yokokawa, Performance of anodesupported SOFCs fabricated with EPD techniques, Solid State lonics, 175 (2004) 165-169.

[126] D. Das, R.N. Basu, Electrophoretic deposition of zirconia thin film on nonconducting substrate for solid oxide fuel cell application, Journal of the American Ceramic Society, 97 (2014) 3452-3457.

[127] T. Uchikoshi, S. Furumi, T. Suzuki, Y. Sakka, Direct Shaping of Alumina Ceramics by Electrophoretic Deposition Using Conductive Polymer-Coated Ceramic Substrates, Adv Mat Res, Trans Tech Publ, 2007, pp. 227-230.

[128] Y. Bao, P.S. Nicholson, Conductive, polypyrrole coating on mullite/alumina fibers for electrophoretic deposition of oxide matrices, J Am Ceram Soc, 87 (2004) 1767-1770.

[129] T. Uchikoshi, S. Furumi, N. Shirahata, T.S. Suzuki, Y. Sakka, Conductive polymer coating on nonconductive ceramic substrates for use in the electrophoretic deposition process, J Am Ceram Soc, 91 (2008) 1674-1677.

[130] F. Chen, M. Liu, Preparation of yttria-stabilized zirconia (YSZ) films on La0. 85Sr0. 15MnO3 (LSM) and LSM-YSZ substrates using an electrophoretic deposition (EPD) process, J Eur Ceram Soc, 21 (2001) 127-134.

[131] Y. Bao, P.S. Nicholson, Conductive, polypyrrole coating on mullite/alumina fibers for electrophoretic deposition of oxide matrices, Journal of the American Ceramic Society, 87 (2004) 17671770.

[132] S. Panigrahi, S. Bhattacharjee, L. Besra, B.P. Singh, S. Sinha, Electrophoretic deposition of doped ceria: Effect of solvents on deposition microstructure, Journal of the European Ceramic Society, 30 (2010) 1097-1103.

[133] M. Mishra, S. Bhattacharjee, L. Besra, H. Sharma, T. Uchikoshi, Y. Sakka, Effect of pH localization on microstructure evolution of deposits during aqueous electrophoretic deposition (EPD), J Eur Ceram Soc, 30 (2010) 2467-2473. 
[134] C. MA, P. SG, S. Shashwati, Synthesis and characterization of polypyrrole (PPy) thin films, Soft Nanoscience Letters, 2011 (2011).

[135] H. Eisazadeh, Studying the characteristics of polypyrrole and its composites, World journal of Chemistry, 2 (2007) 67-74.

[136] J.D. Nicholas, L.C. De Jonghe, Prediction and evaluation of sintering aids for cerium gadolinium oxide, Solid State Ionics, 178 (2007) 1187-1194.

[137] T. Zhu, Y. Lin, Z. Yang, D. Su, S. Ma, M. Han, F. Chen, Evaluation of Li $2 \mathrm{O}$ as an efficient sintering aid for gadolinia-doped ceria electrolyte for solid oxide fuel cells, Journal of Power Sources, 261 (2014) 255263.

[138] T. Zhang, J. Ma, L. Kong, S. Chan, P. Hing, J. Kilner, Iron oxide as an effective sintering aid and a grain boundary scavenger for ceria-based electrolytes, Solid State lonics, 167 (2004) 203-207.

[139] E.P. Murray, M. Sever, S. Barnett, Electrochemical performance of (La, Sr)(Co, Fe) O 3-(Ce, Gd) O 3 composite cathodes, Solid State lonics, 148 (2002) 27-34.

[140] H. Fan, M. Keane, P. Singh, M. Han, Electrochemical performance and stability of lanthanum strontium cobalt ferrite oxygen electrode with gadolinia doped ceria barrier layer for reversible solid oxide fuel cell, Journal of Power Sources, 268 (2014) 634-639.

[141] Y.M. Park, H. Kim, Porous Gd-doped ceria barrier layer on solid oxide fuel cell with Sm 0.5 Sr 0.5 CoO 3- $\delta$ Cathodes, Ceramics International, 39 (2013) 2037-2043.

[142] L. Besra, T. Uchikoshi, T.S. Suzuki, Y. Sakka, Experimental verification of pH localization mechanism of particle consolidation at the electrode/solution interface and its application to pulsed DC electrophoretic deposition (EPD), Journal of the European Ceramic Society, 30 (2010) 1187-1193. [143] L. Stappers, L. Zhang, O. Van der Biest, J. Fransaer, The effect of electrolyte conductivity on electrophoretic deposition, J Colloid Interface Sci, 328 (2008) 436-446. 
[144] N. Koura, T. Tsukamoto, H. Shoji, T. Hotta, Preparation of various oxide films by an electrophoretic deposition method: a study of the mechanism, Jpn J Appl Phys, 34 (1995) 1643.

[145] B. Ferrari, R. Moreno, EPD kinetics: a review, J Eur Ceram Soc, 30 (2010) 1069-1078.

[146] Y. Fukada, N. Nagarajan, W. Mekky, Y. Bao, H.-S. Kim, P. Nicholson, Electrophoretic depositionmechanisms, myths and materials, Journal of Materials Science, 39 (2004) 787-801.

[147] J.J. Van Tassel, C.A. Randall, Role of ion depletion in the electrophoretic deposition of alumina powder from ethanol with increasing quantities of $\mathrm{HCl}$, Journal of materials science, 41 (2006) 80318046.

[148] J.J. Van Tassel, C.A. Randall, lonic gradients at an electrode above the equilibrium limit current. 1. Concentration and charge gradients in an immobile electrolyte, The Journal of Physical Chemistry C, 111 (2007) 3341-3348.

[149] F. Grillon, D. Fayeulle, M. Jeandin, Quantitative image analysis of electrophoretic coatings, J Mater Sci Lett, 11 (1992) 272-275.

[150] D. De, P.S. Nicholson, Role of ionic depletion in deposition during electrophoretic deposition, J Am Ceram Soc, 82 (1999) 3031-3036.

[151] I. Zhitomirsky, A. Petric, Electrophoretic deposition of electrolyte materials for solid oxide fuel cells, J Mater Sci, 39 (2004) 825-831.

[152] Y. Solomentsev, M. Böhmer, J.L. Anderson, Particle clustering and pattern formation during electrophoretic deposition: a hydrodynamic model, Langmuir, 13 (1997) 6058-6068.

[153] J.A. Fagan, P.J. Sides, D.C. Prieve, Evidence of multiple electrohydrodynamic forces acting on a colloidal particle near an electrode due to an alternating current electric field, Langmuir, 21 (2005) 17841794.

[154] W. Ristenpart, I.A. Aksay, D. Saville, Electrohydrodynamic flow around a colloidal particle near an electrode with an oscillating potential, J Fluid Mech, 575 (2007) 83-109. 
[155] M. Böhmer, In situ observation of 2-dimensional clustering during electrophoretic deposition, Langmuir, 12 (1996) 5747-5750.

[156] A. Tsoga, A. Gupta, A. Naoumidis, P. Nikolopoulos, Gadolinia-doped ceria and yttria stabilized zirconia interfaces: regarding their application for SOFC technology, Acta Mater, 48 (2000) 4709-4714. [157] L. Besra, T. Uchikoshi, T.S. Suzuki, Y. Sakka, Experimental verification of pH localization mechanism of particle consolidation at the electrode/solution interface and its application to pulsed DC electrophoretic deposition (EPD), J Eur Ceram Soc, 30 (2010) 1187-1193.

[158] W. Li, N. Jiang, B. Hu, X. Liu, F. Song, G. Han, T.J. Jordan, T.B. Hanson, T.L. Liu, Y. Sun, Electrolyzer Design for Flexible Decoupled Water Splitting and Organic Upgrading with Electron Reservoirs, Chem, 4 (2018) 637-649.

[159] M. Santillán, N. Quaranta, A. Boccaccini, Titania and titania-silver nanocomposite coatings grown by electrophoretic deposition from aqueous suspensions, Surf Coat Technol, 205 (2010) 2562-2571. [160] J.M. Berg, A. Romoser, N. Banerjee, R. Zebda, C.M. Sayes, The relationship between pH and zeta potential of $\sim 30 \mathrm{~nm}$ metal oxide nanoparticle suspensions relevant to in vitro toxicological evaluations, Nanotoxicology, 3 (2009) 276-283.

[161] L. Besra, M. Liu, A review on fundamentals and applications of electrophoretic deposition (EPD), Prog Mater Sci, 52 (2007) 1-61.

[162] O.O. Van der Biest, L.J. Vandeperre, Electrophoretic deposition of materials, Annu Rev Mater Sci, 29 (1999) 327-352.

[163] M. Ammam, Electrophoretic deposition under modulated electric fields: a review, RSC Adv, 2 (2012) 7633-7646.

[164] S. Put, J. Vleugels, G. Anné, O. Van der Biest, Functionally graded ceramic and ceramic-metal composites shaped by electrophoretic deposition, Colloids Surf A Physicochem Eng Asp, 222 (2003) 223232. 
[165] Y.-C. Wang, C. Leu, M.-H. Hon, Size control of ZnO nanofibril within template by electrophoretic deposition, Electrochem solid st, 7 (2004) D15-D18.

[166] M. Mehrali, A.R. Akhiani, S. Talebian, M. Mehrali, S.T. Latibari, A. Dolatshahi-Pirouz, H.S.C. Metselaar, Electrophoretic deposition of calcium silicate-reduced graphene oxide composites on titanium substrate, J Eur Ceram Soc, 36 (2016) 319-332.

[167] W. Li, D. Xiong, X. Gao, L. Liu, The oxygen evolution reaction enabled by transition metal phosphide and chalcogenide pre-catalysts with dynamic changes, Chem Commun 55 (2019) 8744-8763. 